\title{
AN INTERFEROMETRIC STUDY OF FREE CONVECTIVE HEAT TRANSFER AT AN INDOOR GLAZING WITH AN INSECT SCREEN ATTACHMENT
}

\author{
by \\ Daniel Zalcman \\ B. Eng., Ryerson University, Toronto, 2011
}

\author{
A thesis \\ Presented to Ryerson University \\ in partial fulfilment of the \\ requirements for the degree of \\ Master of Applied Science \\ in the Program of
}

Mechanical and Industrial Engineering

Toronto, Ontario, Canada, 2014

(C) Daniel Zalcman 2014 


\section{AUTHOR'S DECLARATION FOR ELECTRONIC SUBMISSION OF A THESIS}

I hereby declare that I am the sole author of this thesis. This is a true copy of the thesis, including any required final revisions, as accepted by my examiners.

I authorize Ryerson University to lend this thesis to other institutions or individuals for the purpose of scholarly research

I further authorize Ryerson University to reproduce this thesis by photocopying or by other means, in total or in part, at the request of other institutions or individuals for the purpose of scholarly research. I understand that my thesis may be made electronically available to the public. 


\title{
AN INTERFEROMETRIC STUDY OF FREE CONVECTIVE HEAT TRANSFER AT AN INDOOR GLAZING WITH AN INSECT SCREEN ATTACHMENT
}

\author{
Daniel Zalcman \\ Master of Applied Science \\ Department of Mechanical \& Industrial Engineering \\ Ryerson University, Toronto, Ontario, Canada, 2013
}

\begin{abstract}
Free convective heat transfer from an idealized window with an insect screen attachment was studied using a Mach-Zehnder interferometer. An experimental model was set up with an isothermal plate, two commercially available screens $\left(K_{H P}=8.74 \times 10^{-9} \mathrm{~m}^{2}, t_{H P}=0.29 \mathrm{~mm}\right.$ and $\left.K_{L P}=3.40 \times 10^{-9} \mathrm{~m}^{2}, t_{L P}=0.65 \mathrm{~mm}\right)$ and window to screen spacings of $b=2 \mathrm{~cm}$ and $b=1 \mathrm{~cm}$. Heat transfer measurements using finite fringe interferograms were taken at a Rayleigh number of $\mathrm{Ra}=5.30 \times 10^{7}$ based on window height. Infinite fringe interferograms were taken for temperature field visualization. Screen temperature was also measured. Experimental results were compared to a preliminary CFD model developed with SolidWorks Flow Simulation and show good agreement. The results show that an insect screen produces a reduction in the convective heat transfer from the indoor glazing. The current measurements show that the effect of window to screen spacing is small. Results from this study are expected to be used for the validation of CFD models and for the development of correlations.
\end{abstract}




\section{Acknowledgements}

The author would like to thank Dr. David Naylor for his invaluable advice and guidance throughout this project. Without his guidance, this project would not have been possible.

The author would also like to acknowledge the support of the Natural Sciences and Engineering Research Council of Canada, the Smart Net-zero Energy Buildings Strategic Research Network and the Centre for Urban Energy in conjunction with Toronto Hydro Electric System Ltd. for the funding of this research.

The author would also like to thank Alan Machin, Joseph Amankra and Chao Ma for their time and assistance in building the experimental model, Dr. Michael Collins for making screen transmittance and reflectance measurements, and Derek Roeleveld for his assistance in setting up the interferometer as well as his continued advice in setting up the experimental model.

Lastly, the author would like to thank his friends and family for their continued support and encouragement. 


\section{Table of Contents}

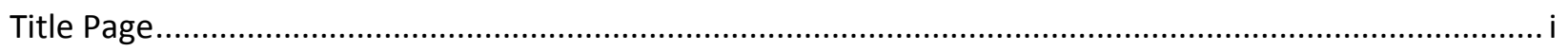

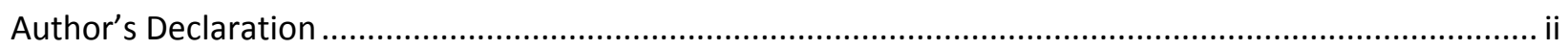

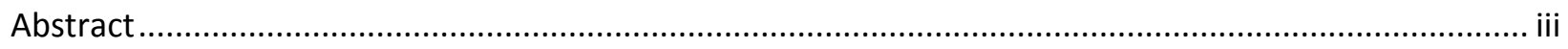

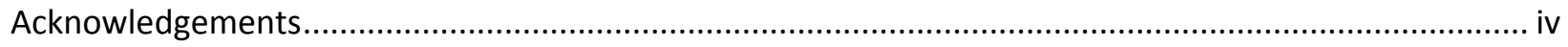

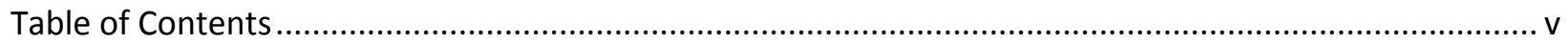

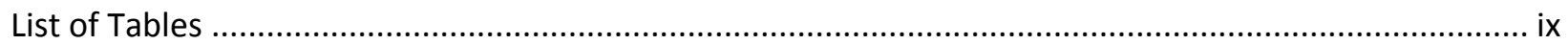

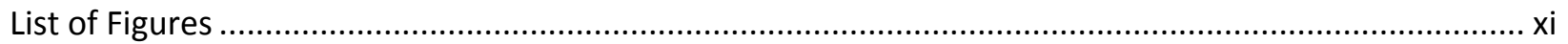

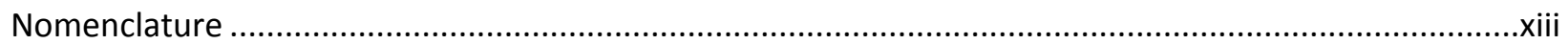

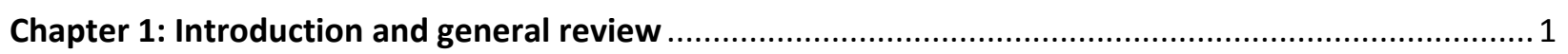

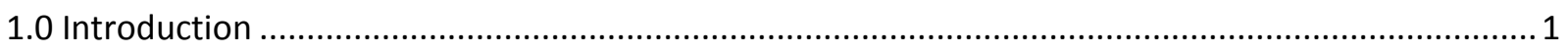

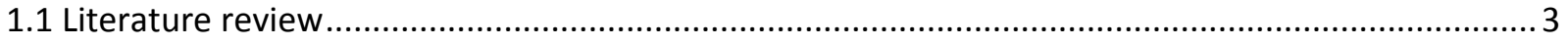

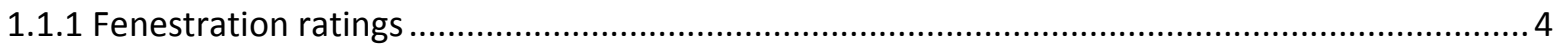

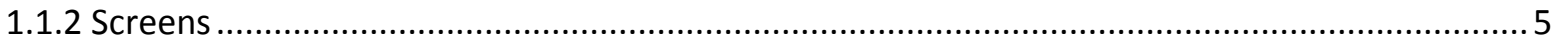

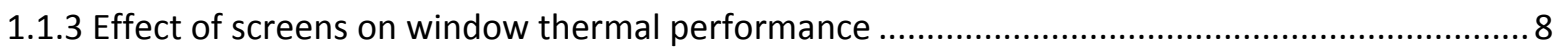

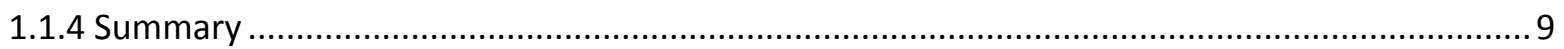

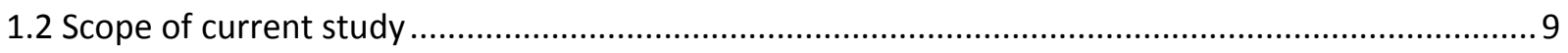

Chapter 2: Experimental equipment and apparatus.................................................................... 11

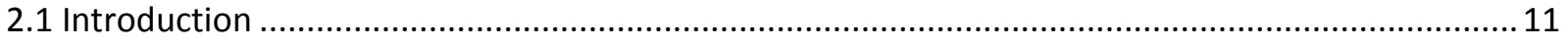

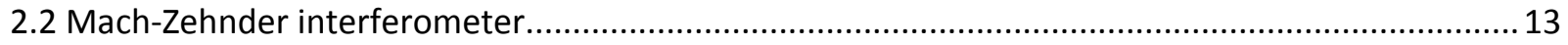

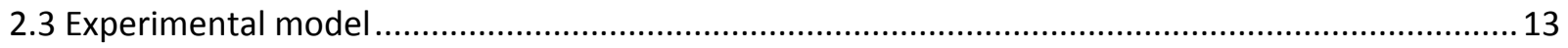

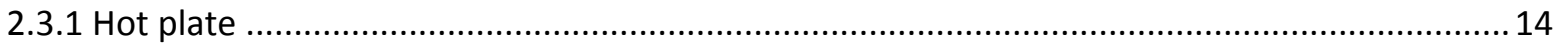

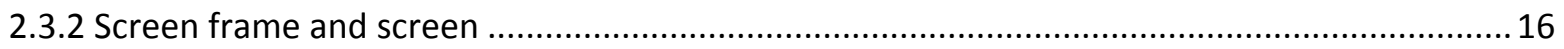

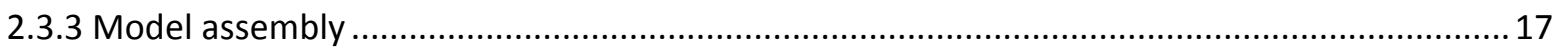

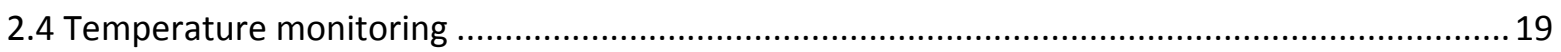

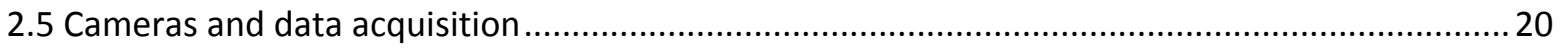

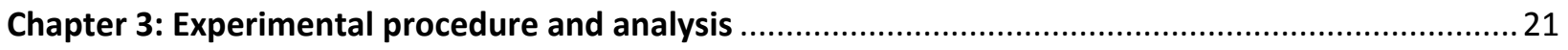

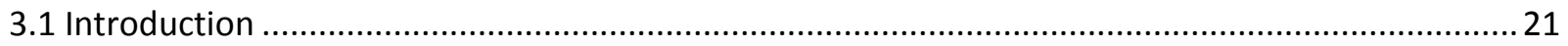




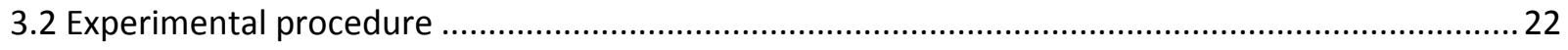

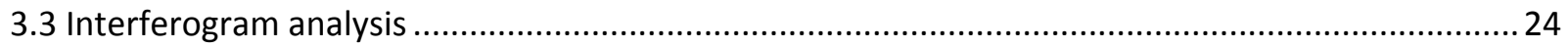

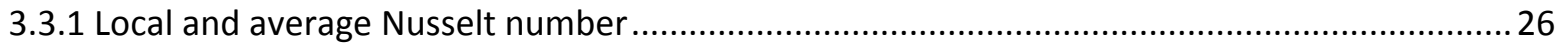

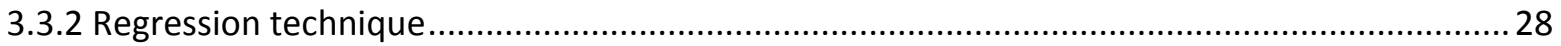

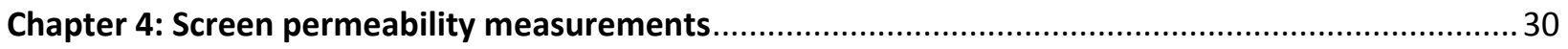

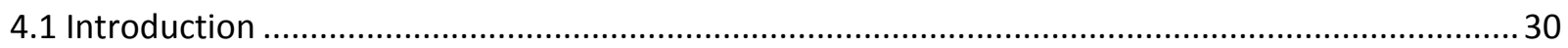

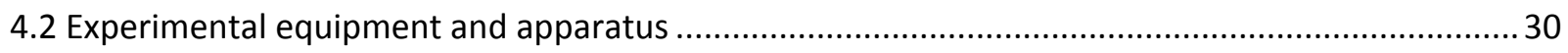

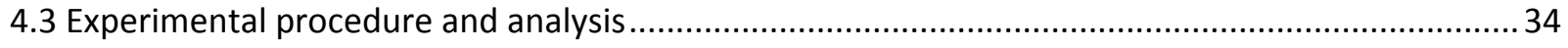

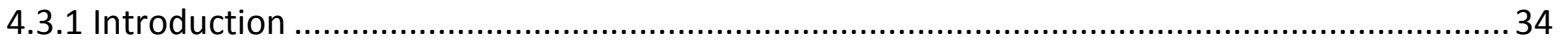

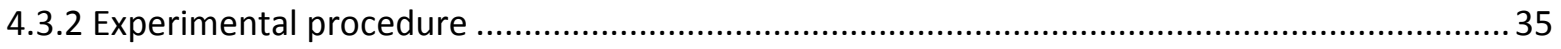

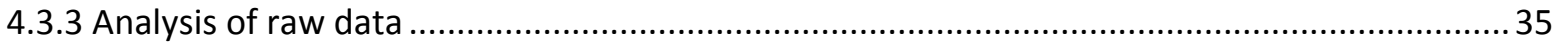

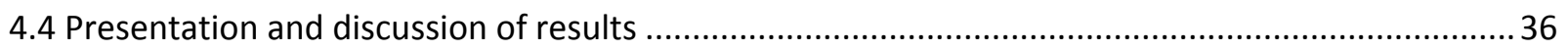

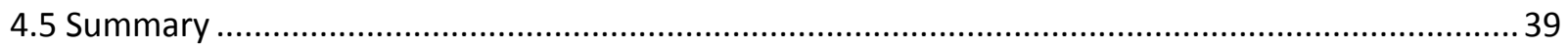

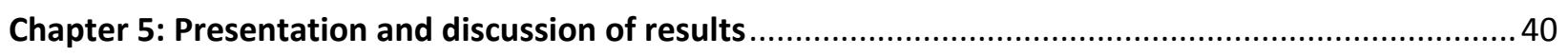

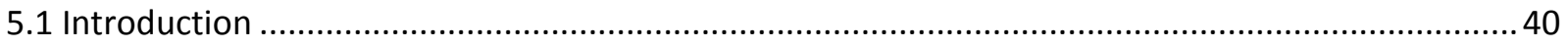

5.2 Temperature field results: Infinite fringe interferograms .......................................................... 41

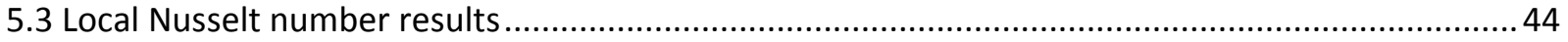

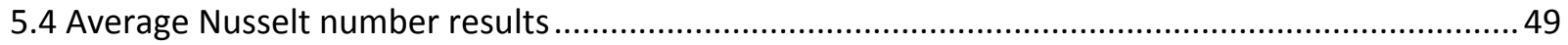

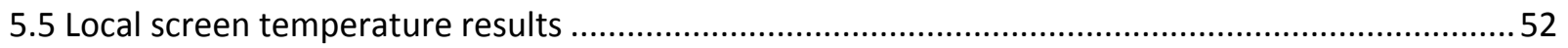

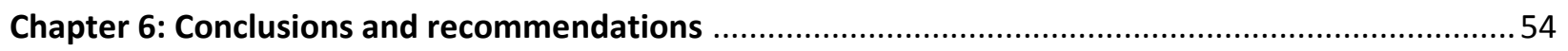

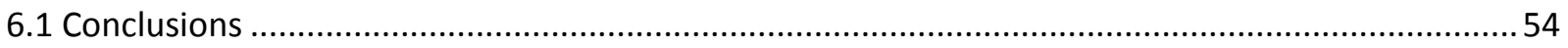

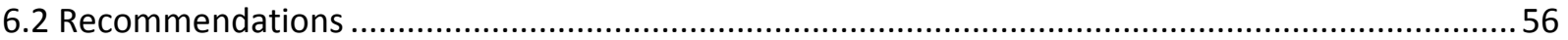

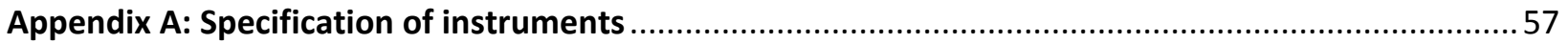

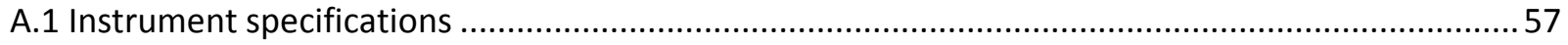

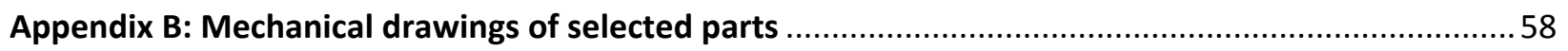

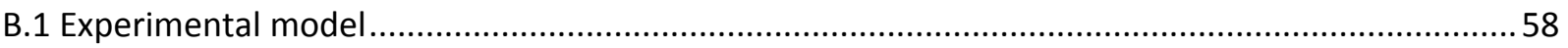

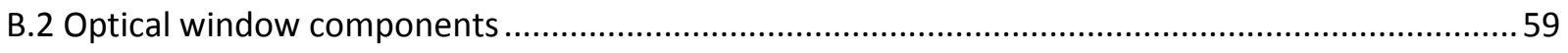

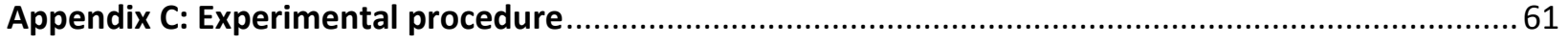




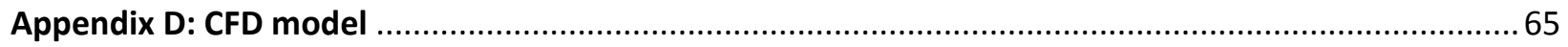

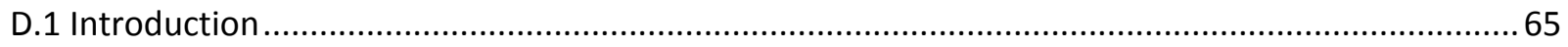

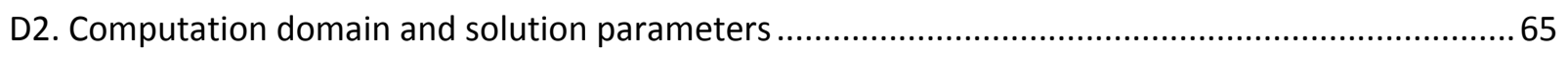

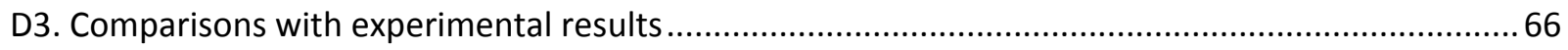

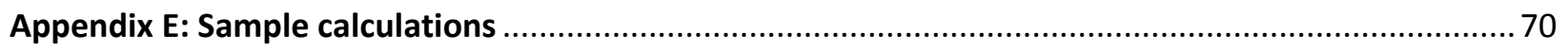

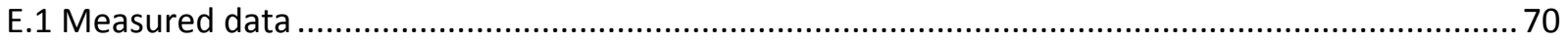

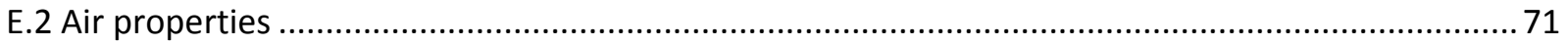

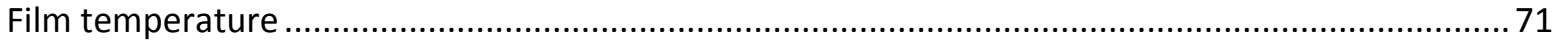

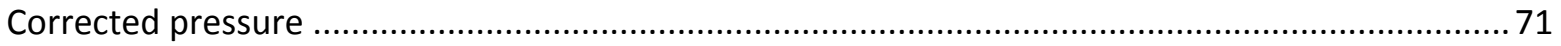

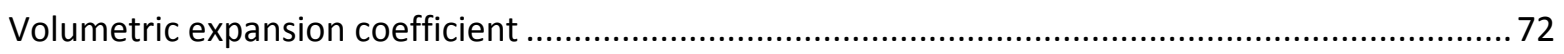

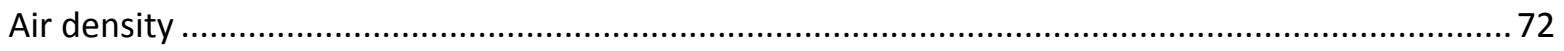

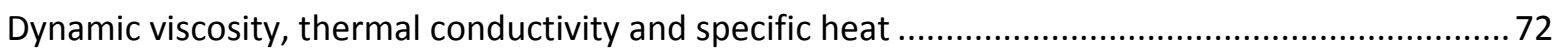

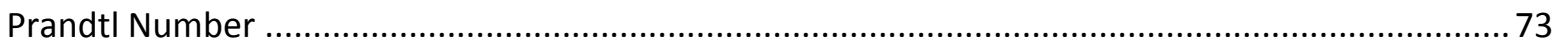

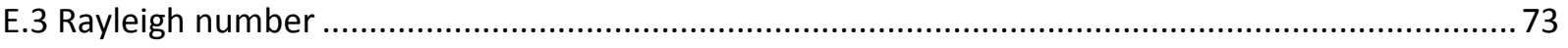

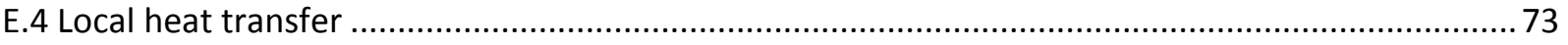

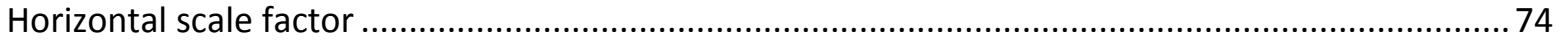

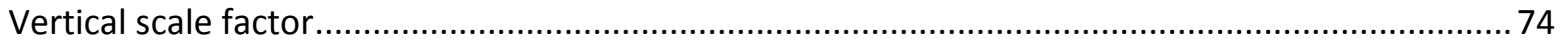

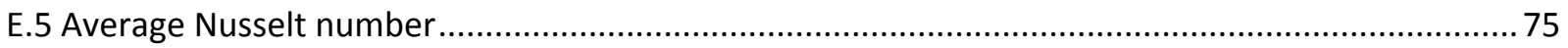

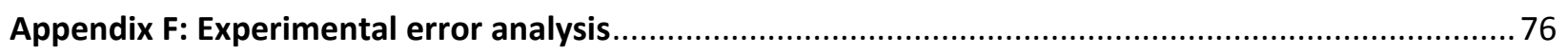

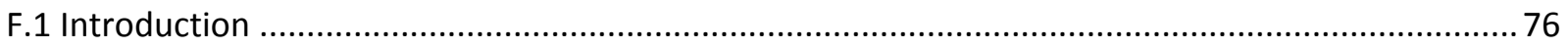

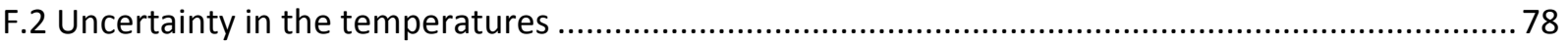

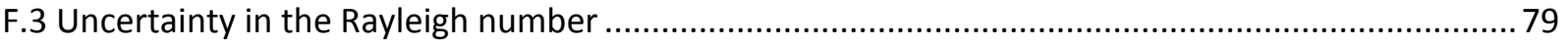

F.4 Uncertainty in local and average Nusselt number ................................................................... 80

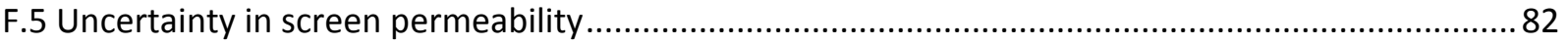

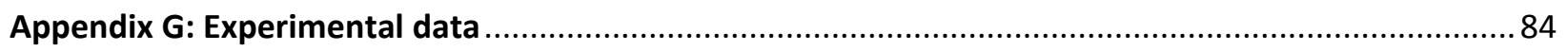

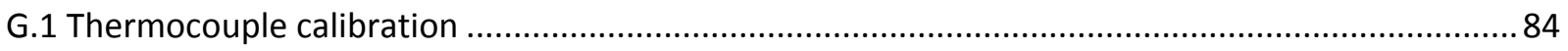

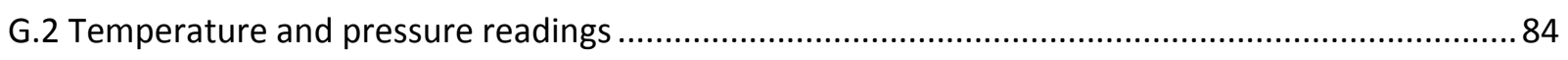

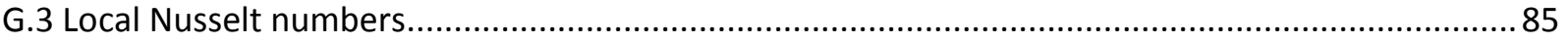


References 


\section{List of Tables}

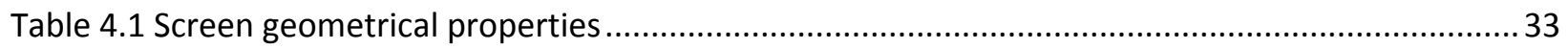

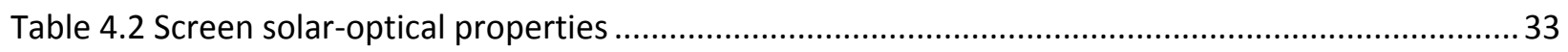

Table 4.3 Screen permeabilities from current experiment compared to similar screens from Miguel

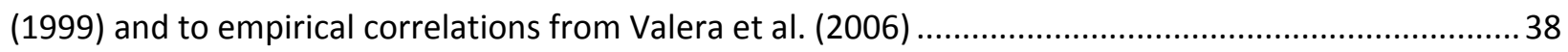

Table 5.1 Measured and numerical average Nusselt numbers .......................................................... 49

Table A.1 Thermocouple reader specifications …........................................................................... 57

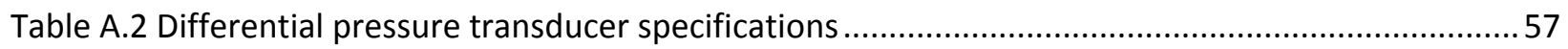

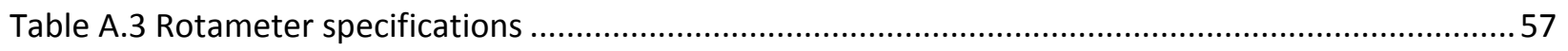

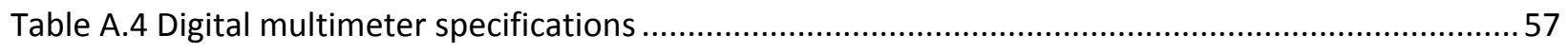

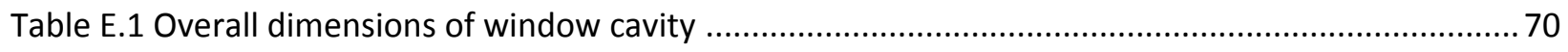

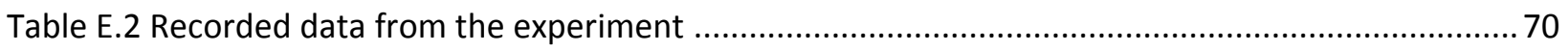

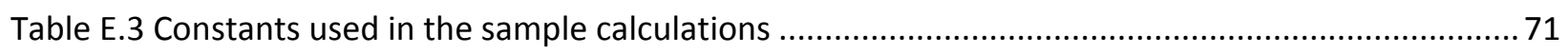

Table F.1 Measured values and their estimated uncertainties .......................................................... 77

Table F.2 Temperature readings for high permeability case with $b=2 \mathrm{~cm}$ (upper shot) showing

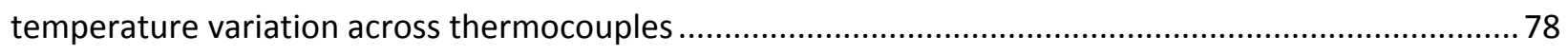

Table F.3 Relative uncertainty of measured values used to calculate uncertainty in Rayleigh number .... 80

Table F.4 Relative error of measured values used to calculate uncertainty in Nusselt number ................81

Table F.5 Relative error of measured values used to calculate uncertainty in permeability .................... 83

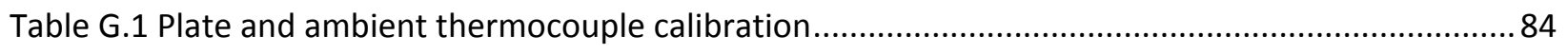

Table G.2 Average plate temperature, ambient temperature and uncorrected pressure for each case .. 84

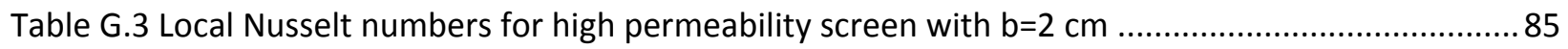

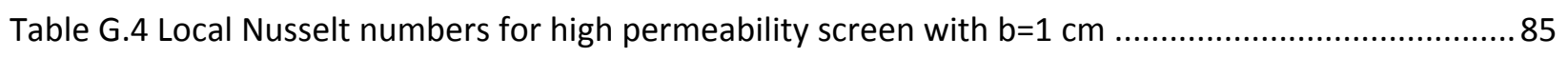

Table G.5 Local Nusselt numbers for no screen case …...................................................................... 86 


\section{List of Figures}

Figure 1.1 Problem geometry (Naylor et al., 2012) ......................................................................... 3

Figure 2.1 Schematic diagram of Mach-Zehnder interferometer.................................................... 12

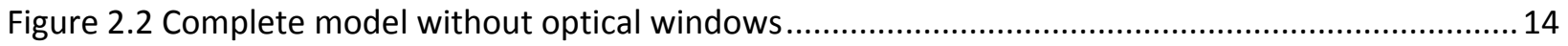

Figure 2.3 Side view of the model showing the screen frame (center) and adjustment butterfly nuts .... 16

Figure 2.4 Back view of hot plate showing overall dimensions and location of thermocouples and plate

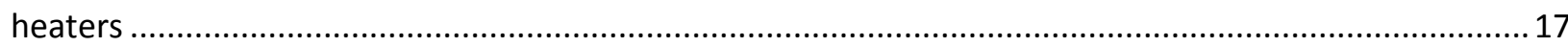

Figure 2.5 Overall dimensions of screen frame and screen temperature thermocouple locations........... 18

Figure 3.1 Comparison between infinite and finite fringe interferograms for case (b) ........................22

Figure 4.1 Two sample screens in-between three sample sections of tube ......................................... 32

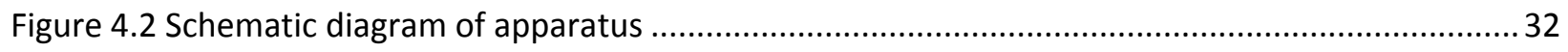

Figure 4.3 Photograph of (a) high permeability screen and (b) low permeability screen (Scale $1 \mathrm{~cm}) \ldots . . .34$

Figure 4.4 Plot of differential pressure vs. air velocity for high permeability screen ............................. 37

Figure 4.5 Plot of differential pressure vs. air velocity for low permeability screen .............................. 37

Figure 5.1 Composite infinite fringe interferograms for: (a) no screen (b) low permeability screen $b=2 \mathrm{~cm}$

(c) high permeability screen $b=2 \mathrm{~cm}$ (d) high permeability screen $b=1 \mathrm{~cm}$

Figure 5.2 Similarity solution for boundary layer flow on an isolated vertical flat plate (Ostrach, 1953)

and experimental results for the no screen case showing the error uncertainty in the local Nusselt

numbers

Figure 5.3 Local Nusselt numbers for no screen and high and low permeability cases at a fixed aspect

ratio $\mathrm{H} / \mathrm{b}=17.2$ .46

Figure 5.4 Local Nusselt number of high permeability screen with two different aspect ratios .47

Figure 5.5 Vertical component of velocity at $\mathrm{y} / \mathrm{H}=0.5$ for case (c) and (d) 48 
Figure 5.6 Dimensionless parameter illustrating the difference in convective heat transfer between the two limits and showing the where cases (b), (c) and (d) fit in the scale ..............................................52

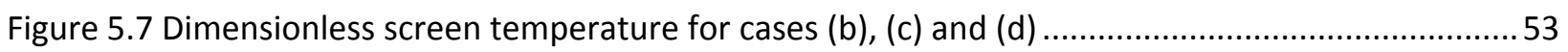

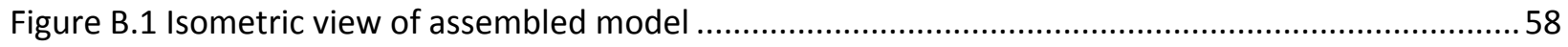

Figure B.2 Dimensions of optical window mount (Roeleveld, 2013) .....................................................59

Figure D.1 Temperature contour of CFD model compared to experimental results for no screen case ...68 Figure D.2 Temperature contour of CFD model compared to experimental results for high permeability

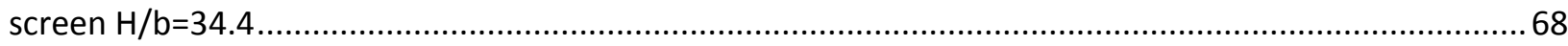

Figure D.3 Temperature contour for CFD model compared to experimental results for high permeability

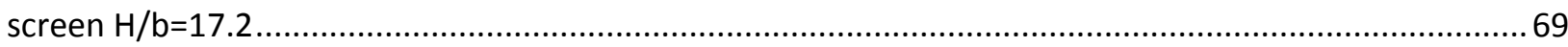

Figure D.4 Temperature contour for CFD model compared to experimental results for low permeability screen $\mathrm{H} / \mathrm{b}=17.2$ 69 


\section{Nomenclature}

A

$A_{0}$

b

C

$\mathrm{c}_{0}$

$c_{p}$

Da*

e

$\mathrm{F}$

g

G

Gr

$\mathrm{H}$

I

$\mathrm{I}_{0}$

k

$\mathrm{k}_{\mathrm{s}}$

$k_{f}$

K

n

$\mathrm{Nu}$

$\mathrm{Nu}_{\mathrm{y}}$

$\mathrm{P}$

$P_{u}$

Pr

q

$\mathrm{q}_{\mathrm{y}}$ amplitude of a light wave

maximum amplitude of wave

window to screen spacing, $m$

speed of light, $\mathrm{m} / \mathrm{s}$

speed of light in a vacuum, $\mathrm{m} / \mathrm{s}$

constant pressure specific heat of fluid, J/KgK

modified Darcy number

percent openness

rate of change of phase, $\mathrm{rad} / \mathrm{m}$

gravity, $\mathrm{m} / \mathrm{s}^{2}$

Gladstone-Dale constant, $\mathrm{m}^{3} / \mathrm{Kg}$

Grashof number

window or screen height, $\mathrm{m}$

pixel intensity

maximum pixel intensity

thermal conductivity of fluid, $\mathrm{W} / \mathrm{mK}$

thermal conductivity of fluid at the surface temperature, $\mathrm{W} / \mathrm{mK}$

thermal conductivity of fluid at the film temperature, $\mathrm{W} / \mathrm{mK}$

screen permeability, $\mathrm{m}^{2}$

index of refraction

average Nusselt number

local Nusselt number

absolute pressure, $\mathrm{Pa}$

uncorrected absolute pressure, $\mathrm{Pa}$

Prandtl number

heat flux, $\mathrm{W} / \mathrm{m}^{2}$

local heat flux, $\mathrm{W} / \mathrm{m}^{2}$ 


\begin{tabular}{|c|c|}
\hline $\mathrm{R}$ & gas constant, J/kgK \\
\hline $\mathrm{Ra}$ & Rayleigh number \\
\hline$S$ & thread spacing, $\mathrm{mm}$ \\
\hline $\mathrm{t}$ & time, $\mathrm{s}$ \\
\hline $\mathrm{t}$ & nominal screen thickness (Chapter 4) \\
\hline $\mathrm{T}$ & temperature, ${ }^{\circ} \mathrm{C}$ or $\mathrm{K}$ \\
\hline$T_{s}$ & surface temperature, ${ }^{\circ} \mathrm{C}$ or $\mathrm{K}$ \\
\hline$\forall$ & volumetric flow rate, $\mathrm{m}^{3} / \mathrm{s}$ \\
\hline v & fluid velocity (Chapter 4), m/s \\
\hline W & plate width, m \\
\hline$W_{0}$ & optical length, $\mathrm{m}$ \\
\hline$W_{t}$ & thread width normal to screen, $\mathrm{mm}$ \\
\hline$x$ & Cartesian coordinates (normal to the window), $m$ \\
\hline$x_{1}$ & location of first pixel \\
\hline y & Cartesian coordinates (parallel to the window), $m$ \\
\hline Y & pore inertia factor \\
\hline z & coordinate in the test beam direction \\
\hline
\end{tabular}

\section{Greek Symbols}

$\beta$

$\varepsilon$

$\varepsilon$

$\theta$

$\lambda$

$\lambda_{0}$

$\mu$

$\rho$

$\rho$

$\tau$ volumetric thermal expansion coefficient, $\mathrm{K}^{-1}$

fringe shift order

effective emissivity (Chapter 4)

dimensionless temperature

wavelength of light, $\mathrm{m}$

wavelength of light in a vacuum, $m$

dynamic viscosity of fluid, $\mathrm{Ns} / \mathrm{m}^{2}$

density of fluid, $\mathrm{Kg} / \mathrm{m}^{3}$

effective reflectivity (Chapter 4)

effective transmissivity 


\section{$\underline{\text { Subscripts }}$}

$\begin{array}{ll}\text { H } & \text { horizontal direction } \\ \text { HP } & \text { high permeability screen } \\ \text { LP } & \text { low permeability screen } \\ \text { REF } & \text { reference beam } \\ \text { TEST } & \text { test beam } \\ V & \text { vertical direction } \\ \infty & \text { ambient }\end{array}$




\section{Chapter 1: Introduction and general review}

\subsection{Introduction}

Windows are an integral part of both commercial and residential buildings. Windows let natural light in, which makes for a more comfortable environment. On the other hand, windows increase heating and cooling loads due to their lower insulation properties as compared to the rest of the building envelope. Advances in window technology have increased the thermal performance of windows tremendously through double/triple glazing, low conductivity filler gasses, low-e coatings and shading devices; offering potential savings for the end customer and reducing the environmental footprint of buildings.

Window and building simulation software have also made tremendous advances and have become an integral part of building and window design. Software like VISION and WINDOW allows the user to determine the thermal performance of countless different fenestration designs. The user can specify the number and thickness of glazings, the spacing between them, filler gas and coatings, and obtain the Solar Heat Gain Coefficient (SHGC) and U-value of the window. However, no software to date can accurately model the effect of insect screens on natural convection from the indoor glazing.

Software like VISION treats insect screens (and other shading devices) as a blockage of short and long wave radiation. In the case of louvered blinds, for example, this blockage would depend on the blind angle. This method helps determine the SHGC of the fenestration and gives good estimates of the solar thermal performance, but neglects the effect the screen has on natural convection near the glazing as well as the radiant exchange between the room and the screen.

Insect screens reduce the overall thermal transmission through the window (U-value) by obstructing natural convective flow near the window and by reducing the thermal radiation exchange between the 
glazing and indoor surfaces. The flow blockage effect is complex and depends on screen permeability, placement, thermal conditions and window geometry. At the same time, this air-flow will affect the screen temperature. The screen temperature will affect the thermal radiation exchange between the screen, indoor glazing and the room surfaces. So, the long-wave radiation heat transfer rates are coupled to the convection. For this reason, it is of interest to be able to predict the screen temperature.

Numerical models using computational fluid dynamics (CFD) that investigate this convective resistance have recently been developed by Naylor, Foroushani \& Zalcman (2012). The problem geometry is shown in Figure 1.1. In this study, they use scale analysis to propose a dimensionless parameter that characterizes the convective flow for a given window geometry and insect screen.

$$
G r_{h}{ }^{1 / 2} D a^{*}=\sqrt{\frac{g \beta\left(T_{w}-T_{\infty}\right) \rho^{2} H^{3}}{\mu^{2}}} \frac{K}{H t}
$$

Where $\mathrm{Gr}_{\mathrm{h}}$ is the Grashof number based on the height of the window and Da* is a modified Darcy number based on the height of the porous media.

As this parameter approaches zero the screen acts like an impermeable barrier and the window glazing and screen cavity can be approximated as a vertical enclosure with a free convective boundary layer on the indoor-side of the screen (i.e. outside the cavity). As the parameter approaches infinity, the screen provides virtually no obstruction to the free convective flow, and the heat transfer can be approximated as free convection from a flat plate.

The numerical model agrees with standard correlations at both asymptotic limits, but experimental validation is necessary to confirm its accuracy between the limits. The purpose of this study is to provide detailed experimental data that can be used to validate numerical modelling, such as the recent study by Naylor et al. (2012). 


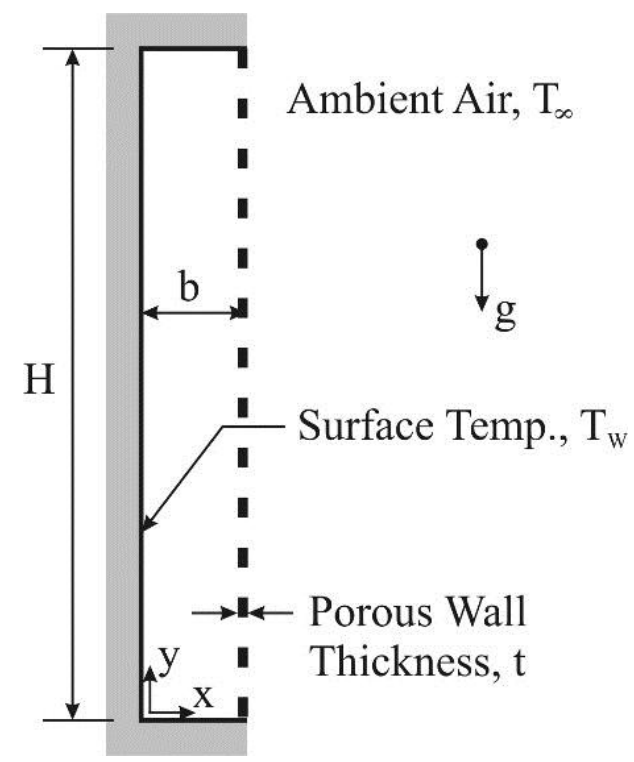

Figure 1.1 Problem geometry (Naylor et al., 2012)

In the present work, the local convective heat transfer along the window will be determined using a Mach-Zehnder Interferometer (MZI). Unlike energy balance experiments, MZI provides the operator with precise measurements of the local heat flux, not just the resulting overall heat transfer rate. It also provides temperature-field visualization.

Hence, the objective of the current experimental study is to obtain detailed measurements of the effect of an insect screen on the free convective heat transfer rates at an indoor glazing surface. These data are needed to validate predictions from computational fluid dynamics models. These numerical models can then be used to develop simplified models for use in fenestration design and thermal performance analysis (ISO Standard 15099, 2003). Simplified models of the effect of screens on fenestration are also needed in whole building energy simulation software like ESP-r (2013).

\subsection{Literature review}

The aim of this study is to investigate the effect of an insect screen on the convective heat transfer from a window. First, a brief overview of fenestration ratings is given. Then, a summary of studies 
investigating the permeability of insect screens. Lastly, an overview of studies investigating the effect of screens on window thermal performance.

\subsubsection{Fenestration ratings}

Heat flow in fenestration systems can happen in three ways: conductive and convective heat transfer caused by temperature differences between the indoors and outdoors, long-wave (above $2500 \mathrm{~nm}$ ) radiant exchange between the fenestration and its surroundings as well as between glazing layers and short-wave (below $2500 \mathrm{~nm}$ ) solar radiation incident on the fenestration, either directly from the sun, or reflected from the ground or other nearby objects.

Since temperatures of the sky, ground and surrounding objects (and hence their radiant emission) correlate with outdoor air temperature, radiant interchanges are approximated by assuming all these surfaces are at the same temperature as the outdoor air. This assumption simplifies calculations of the steady state heat flow through fenestrations, Q:

$$
Q=U * A_{p f}\left(T_{\text {out }}-T_{\text {in }}\right)+(S H G C) A_{p f} E_{t}
$$

Where $Q$ is the heat transfer rate, $U$ is the overall coefficient of heat transfer ( $U$-factor), $A_{p f}$ is the total projected area of the fenestration, $\mathrm{T}_{\text {in }}$ and $\mathrm{T}_{\text {out }}$ are the indoor and outdoor temperatures, respectively, SHGC is the solar heat gain coefficient and $E_{t}$ is the total incident irradiance.

$\mathrm{U}$ and SHGC are steady state performance indices that characterize a fenestration. Equation (1.2) is very practical, since it combines all the linked radiant, convective and conductive energy transfer processes into $U$ and SHGC. On the other hand, it is not exact. These quantities can vary because (1) convective heat transfer rates vary as fractional powers of temperature differences or free-stream speeds, (2) variations in temperature caused by weather or climate are small on the absolute temperature scale 
that controls radiant heat transfer rates, (3) fenestration systems always involve at least two thermal resistances in series, and (4) solar heat gain coefficients depend on solar incident angle and spectral distribution.

\section{U-factor (Thermal transmittance)}

The U-factor is a measure of the heat transfer through fenestration systems in the absence of sunlight, air infiltration and moisture condensation; and is represented by the first term of Equation (1.2). So, Ufactor is a measure of the heat transfer due to convection, radiation and conduction.

Wright (2008) developed a method for calculating the center-glass performance indices of fenestration with shading devices, or more generally, multilayer systems. This method uses a resistor network to quantify both convective and radiant heat exchange in multilayer systems. Each resistor represents heat exchange between layers or between layers and the ambient. Thus, this method allows accurate modelling of fenestration with any kind of attachment, as long as the attachment thermal resistance is known. As discussed below, the radiant thermal resistance between insect screens and indoor glazings is currently understood, but the convective one is not. The current study focuses on the effect of the screen on the convection at the indoor glazing.

For more detailed information on how these individual $U$ values are obtained, refer to ASHRAE Handbook-Fundamentals (2013).

\subsubsection{Screens}

Insect screens are used throughout the world in many different configurations. They let fresh air in when the window is open while keeping insects and other debris outside. Insect screen placement varies depending on window type. They are mounted on the indoor side of casement windows, and on the 
outdoor side of double hung windows. Most operable windows have an insect screens, particularly in residential applications.

Insect screens can be made out of different materials: stainless steel, aluminum and synthetic fibers like polyethylene. Synthetic fibres seem to be the most common as they are inexpensive and do not corrode. Screens also come in different geometries, dictated by the thread diameter and spacing; with most common screens for residential use having a thread diameter of about $0.2 \mathrm{~mm}$ and an open area of about 60 to $80 \%$.

In order to model insect screens in CFD software, it is necessary to know the screens permeability and inertial factor. Then, the screen can be modeled as a porous media instead of as an actual 3D model; which would be computationally expensive and tedious to create.

The actual resistance to flow can be characterized using the table look-up method, or permeability and inertial factor coefficients that describe the pressure drop across the medium as a function of fluid velocity:

$$
\frac{d P}{d x}=\frac{\mu}{K} v+\frac{\rho Y}{\sqrt{K}} v^{2}
$$

Miguel (1999) used experimental methods to determine these parameters for a wide range of insect screens in Darcian flow and in the non-linear regime. He found that a screen's permeability and inertial factor are only dependant on the openness, as described in Equations (1.4) and (1.5), respectively. In other words, the shape of the thread and the mesh geometry have a negligible effect on airflow characteristics of screening material.

$$
\begin{aligned}
& K=3.44 \times 10^{-9} e^{1.6} \\
& Y=4.30 \times 10^{-2} / e^{2.13}
\end{aligned}
$$


Valera, Álvarez \& Molina (2006) tested 11 different screens with openness ranging from 0.29 to 0.48 in a wind tunnel and proposed the following correlation:

$$
\begin{gathered}
K=-1.81 \times 10^{-8} e^{2}+2.22 \times 10^{-8} e-4.47 \times 10^{-9} \\
Y=5.96 \times 10^{-2} e^{-1.18}
\end{gathered}
$$

None of these studies give an approximation of the variability of permeability for a given openness. Further, none of these correlations account for thread shape and mesh geometry. Both studies conclude that these have only a slight influence in the permeability of a screen.

Teitel (2010) argued that many of the existing correlations for the pore inertia factor incorporate data that is outside the Forchheimer regime $(1<\operatorname{Re}<150)$ or data that encompass different flow regimes; using screens of varying porosities and geometries in order to find a correlation between $Y$ and $\varepsilon$ resulted in screens being tested outside the desired flow regime. A later study by Teitel (2011) showed that Forchheimer coefficients vary with Reynolds number, but not significantly below Re=130-160. He also found that using Forchheimer coefficients based on percent openness alone can lead to erroneous results, and points out the inherent difficulty in determining a woven screen thickness; which is necessary to determine pressure drops accurately. This is because the Forchheimer equation expresses pressure drop per unit thickness across the porous media, rather than the absolute pressure drop. He recommends obtaining $\mathrm{K}$ and $\mathrm{Y}$ through CFD modeling of the screen geometry rather than using existing correlations based on openness.

Once the permeability and inertial factor are known, the screen can be modeled as porous media. The porous media approach has been used extensively in agricultural models, where insect screens play a very important role. For example: Fatnassi, Boulard, Poncet, \& Chave (2006) used CFD to model a greenhouse and optimize the airflow, temperature and humidity inside. They found that air humidity and temperature rises can be two to three times higher when insect screens are installed. 


\subsubsection{Effect of screens on window thermal performance}

Insect screens have been studied in the context of building energy simulation as well. Using an indoor solar simulator facility, Brunger, Dubrous \& Harrison (1999) measured the Solar Heat Gain Coefficient and U-value of a double glazed window with a black fiberglass insect screen. They found that insect screens placed outdoors can reduce the SHGC by $46 \%$ and the U-value by $7 \%$, and screens placed indoors by $15 \%$ and $14 \%$, respectively. Clearly, both placements have a strong impact on the thermal performance of the fenestration. Outdoor screens reduce cooling loads during the summer thanks to the significant decrease in SHGC, but they increase heating loads during the winter due to the loss in solar heat gain. Indoor screens also have this effect, albeit reduced. However, indoor screens have a more pronounced reduction on $\mathrm{U}$-value than screens placed outdoors. Lastly, it is worth mentioning that a $14 \%$ decrease in U-value is substantial, considering the double glazed window makes up most of the thermal resistance. This result suggests that the insect screen has a large effect on the convective heat transfer coefficient and thermal radiation at the indoor glazing surface.

With that last point in mind, Norris \& Collins (2008) conducted a preliminary numerical study to determine the effect on natural convection of different window and screen configurations. They found that screens do reduce the heat transfer coefficient, depending on window height, sill size and screen permeability. Moreover, they show that for low permeability screens, the flow within the cavity resembles that of a vertical enclosure where conduction dominates, and high permeability screens result in very small reductions in heat transfer coefficients as compared to the no-screen case. Clearly, for a given window geometry, the heat transfer coefficient is within two limits, depending on the permeability of the screen; a vertical enclosure and an isothermal vertical flat plate. These results were confirmed by Naylor et. al. (2012) who used CFD to demonstrate the existence of a similarity parameter that characterises the free convective flow between these limits. 
Many studies have looked at the solar optical effect of screens on window thermal performance (Kotey, Wright \& Collins, 2009; Kotey, Wright, Barnaby \& Collins, 2009; Laouadi \& Parekh, 2007). Like other shading devices, screens have an impact on the SHGC and long-wave radiation exchange. This information is used in building simulation software to calculate cooling and heating loads. However, the convective effect of screens is not accounted for since it has not yet been investigated. Further, convection has an impact of screen temperature, which exchanges long-wave radiation with its surroundings. Validated numerical models can be used to predict the effect on convection and screen temperature in order to create empirical correlations for use in building simulation software.

\subsubsection{Summary}

It is clear that insect screens have a marked effect on window thermal performance, both from the convective effects and solar gain reduction. As was shown in the literature review, there are very few experimental measurements in the open literature. As building energy simulation software continues to become an indispensable tool in the design and evaluation of energy efficient buildings, it is important to be able to model all fenestration currently in use. However, there are currently no models that predict convective effects due to insect screens or the temperature of said screen, which exchanges thermal radiation with its surroundings.

\subsection{Scope of current study}

The purpose of this experimental study is to obtain measurements of the convective heat transfer of a window with an indoor mounted insect screen. These measurements will provide insight into the effect of an insect screen on the convective heat transfer rates and the temperature field. In addition, these measurements are needed for validating computational fluid dynamics models. 
The window will be modelled as an isothermal vertical flat plate, made out of aluminum and polished to reduce radiant exchange. Thermocouples placed along the screen will be used to measure its temperature at various points. The MZI used in this study allows full temperature-field visualization using the infinite fringe mode. This will be useful for validating and possibly improving numerical models. 


\section{Chapter 2: Experimental equipment and apparatus}

\subsection{Introduction}

There are many optical techniques used to measure temperature and heat transfer rates (Goldstein, 1976). These optical techniques are especially useful for measuring convection because they do not disturb the flow. The current study uses a Mach-Zehnder interferometer (MZI) to measure convective heat transfer rates.

This instrument splits a collimated laser beam in two; one goes through the test sample, the other is a reference beam. The sample, or experimental model, induces changes to the temperature of the fluid surrounding it. In the present study, the fluid is air. Changes in the temperature of the fluid result in changes of its density, which result in a change in its index of refraction. Hence, light passing through the sample will travel at a slightly different velocity than the reference beam. This means that when the two beams are recombined, they will be out of phase. So, constructive interference will occur at points where the light is in phase, and destructive interference occurs when the light is out of phase. The output of the interferometer consists of lines of constructive and destructive interference, and the spacing between these fringes is proportional to the temperature gradient. The temperature gradient near the surface of the plate is used to calculate the heat flux. A top view schematic of the MZI interferometer used in this study is shown in Figure 2.1

A disadvantage of laser interferometry is that the equipment is difficult to operate, expensive, and post processing of data can be more time consuming as compared to other heat transfer measurement techniques (such as heat balance, i.e. calorimetry). In addition, the absolute error of the measurements is limited by the optics. Imperfections in the optics (flatness, dirt, vibration) limit the accuracy to about 
$10 \%$ in the current experiment, whereas heat balance approaches or thermocouples can achieve greater accuracy.

Another disadvantage of interferometry is that it has limitations for the study of turbulent and three dimensional flows. This is not an issue in the current work, as the temperature field is steady and strongly two-dimensional. More information on interferometry can be found in (Hauf \& Grigull, 1970) and (Naylor, 2003).

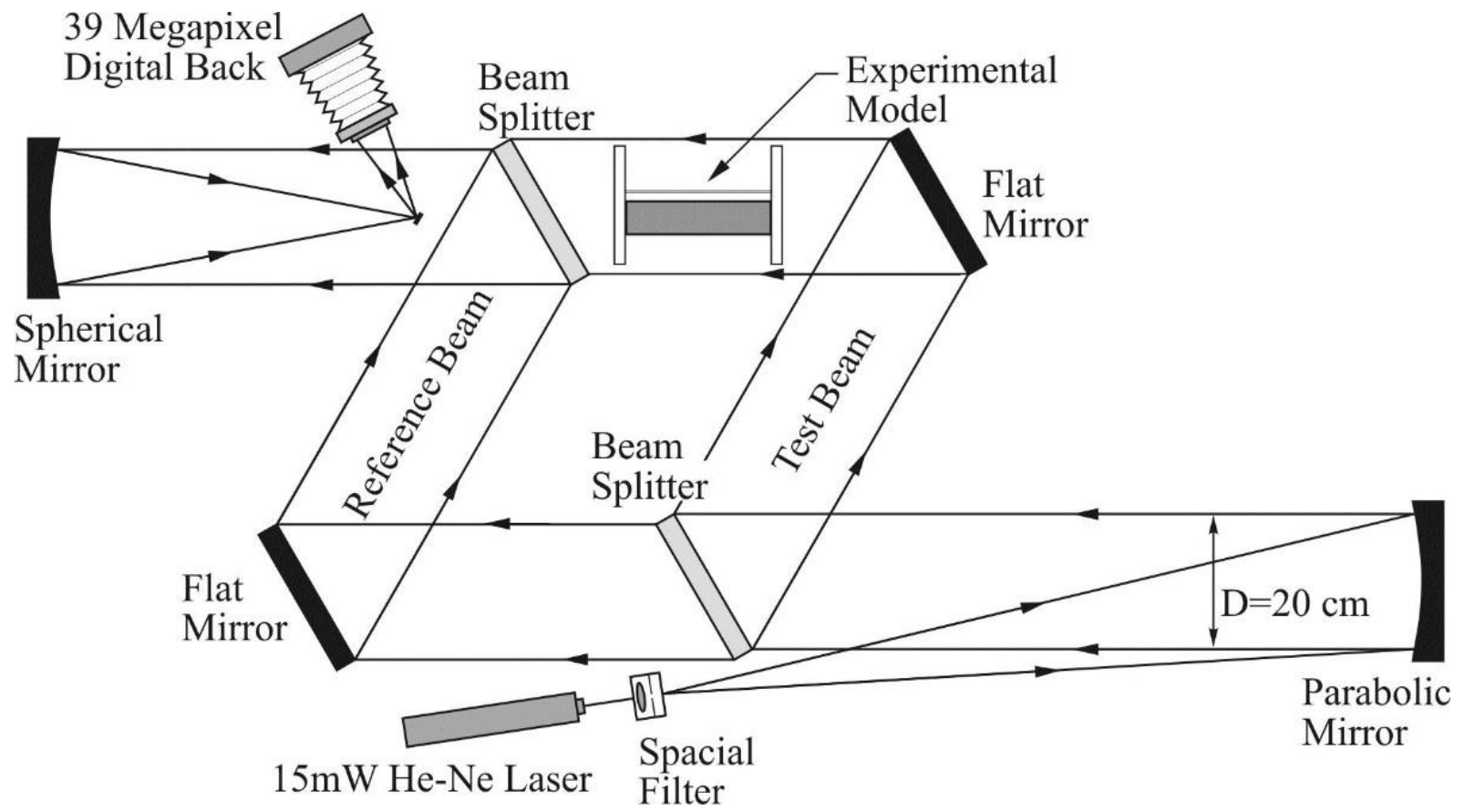

Figure 2.1 Schematic diagram of Mach-Zehnder interferometer 


\subsection{Mach-Zehnder interferometer}

A Mach-Zehnder Interferometer was used to obtain the local convective heat transfer rates. The diameter of the test beam was $20 \mathrm{~cm}$. The detailed optical specifications of the interferometer used in the current study can be found on (Roeleveld, 2013), who used an identical setup.

\subsection{Experimental model}

The experimental model used in this study is a modified version of the setup used by Lai (2004). The model originally consisted of two vertical isothermal walls; one was heated using ohmic heaters, while the other used a constant temperature water bath. Because the current study needs only one heated surface, the electrically heated wall was kept due to its simplicity and ease of operation. A photo of experimental model is shown in Figure 2.2. The screens were held by a thin metal frame and its distance to the heated wall was controlled through a butterfly nut; as shown in Figure 2.3. To simulate the frame of a real window, insulating spacers were installed at the top and bottom of the plate. Two different spacers were constructed in order to accommodate for the testing of different aspect ratios; $b=1 \mathrm{~cm}$ and $\mathrm{b}=2 \mathrm{~cm}$ spacers resulting in aspect ratios of $\mathrm{H} / \mathrm{b}=34.4$ and $\mathrm{H} / \mathrm{b}=17.2$, respectively. Lastly, the cavity was sealed at the sides through the use of optical windows mounted in acrylic sheet, identical to those used by Roeleveld (2013). 


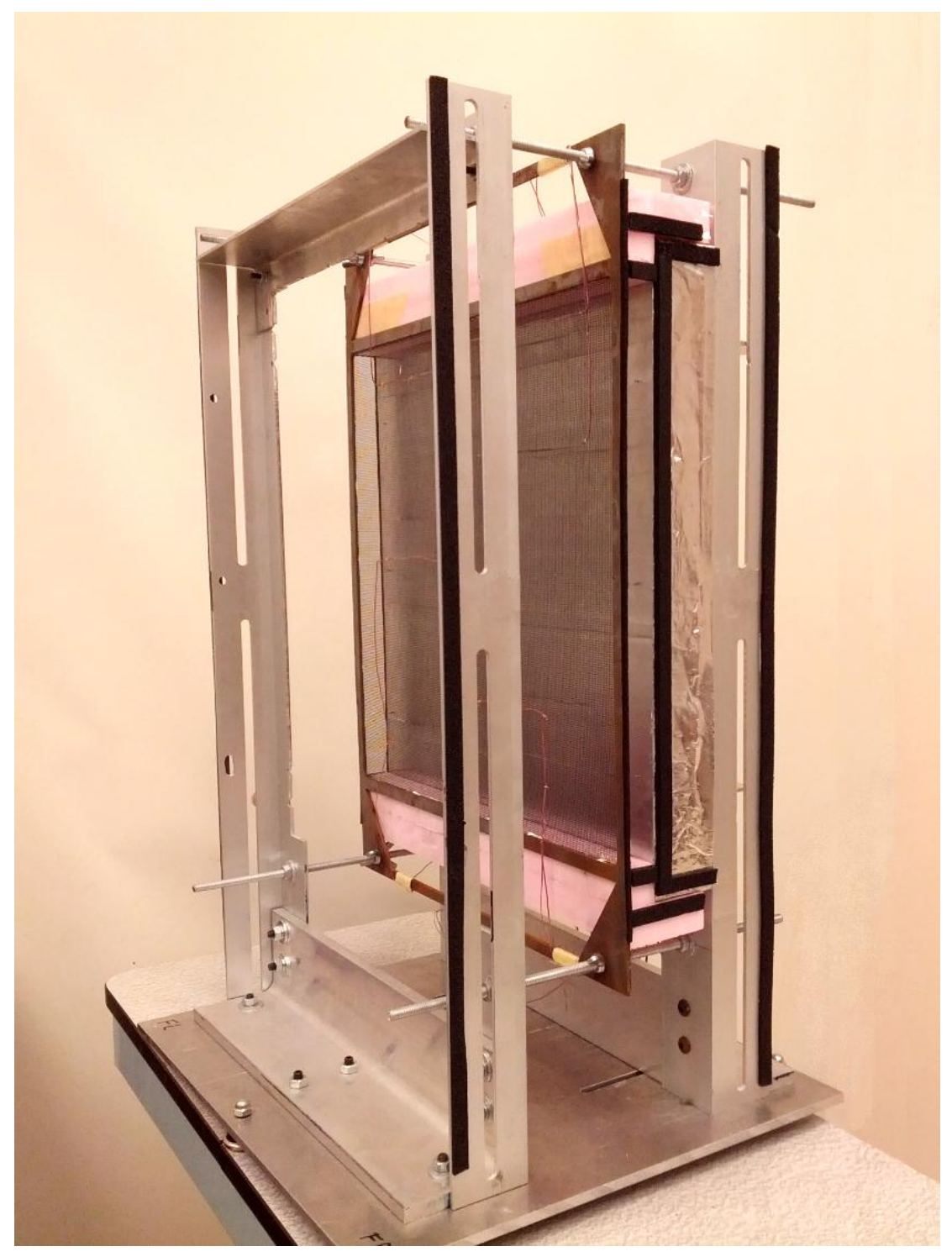

Figure 2.2 Complete model without optical windows

\subsubsection{Hot plate}

The hot wall consists of a $12.7 \mathrm{~mm}$ thick aluminum plate, six resistance heaters and two insulating layers on the back. The front face of the aluminum plate was milled in the beam direction to a flatness of 0.12 $\mathrm{mm}$ on a CNC milling machine. This flatness is critical for aligning the laser beam with the measurements surface of the model, which is important for obtaining accurate results. Twelve holes were drilled on the 
front face at precise locations for locating pins to be used for alignment of the model in the interferometer. These pins also provide precise reference locations for the interferogram analysis.

Because the height of the window $(\mathrm{H}=34.3 \mathrm{~cm})$ is greater than the diameter of the laser beam $(20 \mathrm{~cm})$, two shots are needed to capture the interferogram. Bottom shots are taken first and cover the bottom half of the model. The model is then translated vertically to capture the top half of the model. Locating pins at $\mathrm{y} / \mathrm{H}=0.5$ facilitate this process.

The height of the window in this model also helps to accentuate the effect of the insect screen. From Equation (1.1), the $\mathrm{Gr}^{1 / 2} \mathrm{Da}$ * parameter is proportional to the root of window height. Therefore, smaller windows result in a smaller number for this parameter. This means that for any given screen, a shorter window will see a larger reduction in convective heat transfer compared to a taller window.

The width of the plate was determined based on the sensitivity of the interferometer. A width of 35.6 $\mathrm{cm}$ (14 inches) was sufficient to obtain 7 fringes with the temperature difference used in this experiment.

Six rectangular resistance heaters were adhered to the back of the plate and cover most of that area. Holes drilled in the back (to within $2 \mathrm{~mm}$ from the front surface) were used to install 4 thermocouples. The location of the thermocouples is shown in Figure 2.4, and was chosen to capture the temperature of the entire plate and confirm the temperature was uniform.

The back side was covered by a $2.5 \mathrm{~cm}$ thick polystyrene foam ( $\mathrm{k}=0.028 \mathrm{~W} / \mathrm{mK})$ and then by a $1 \mathrm{~cm}$ thick wood laminate. This helped prevent heat loss from the back side, create a more uniform temperature on the plate, and significantly reduced the rising plume of air from the back; which could interfere with the measurements. 


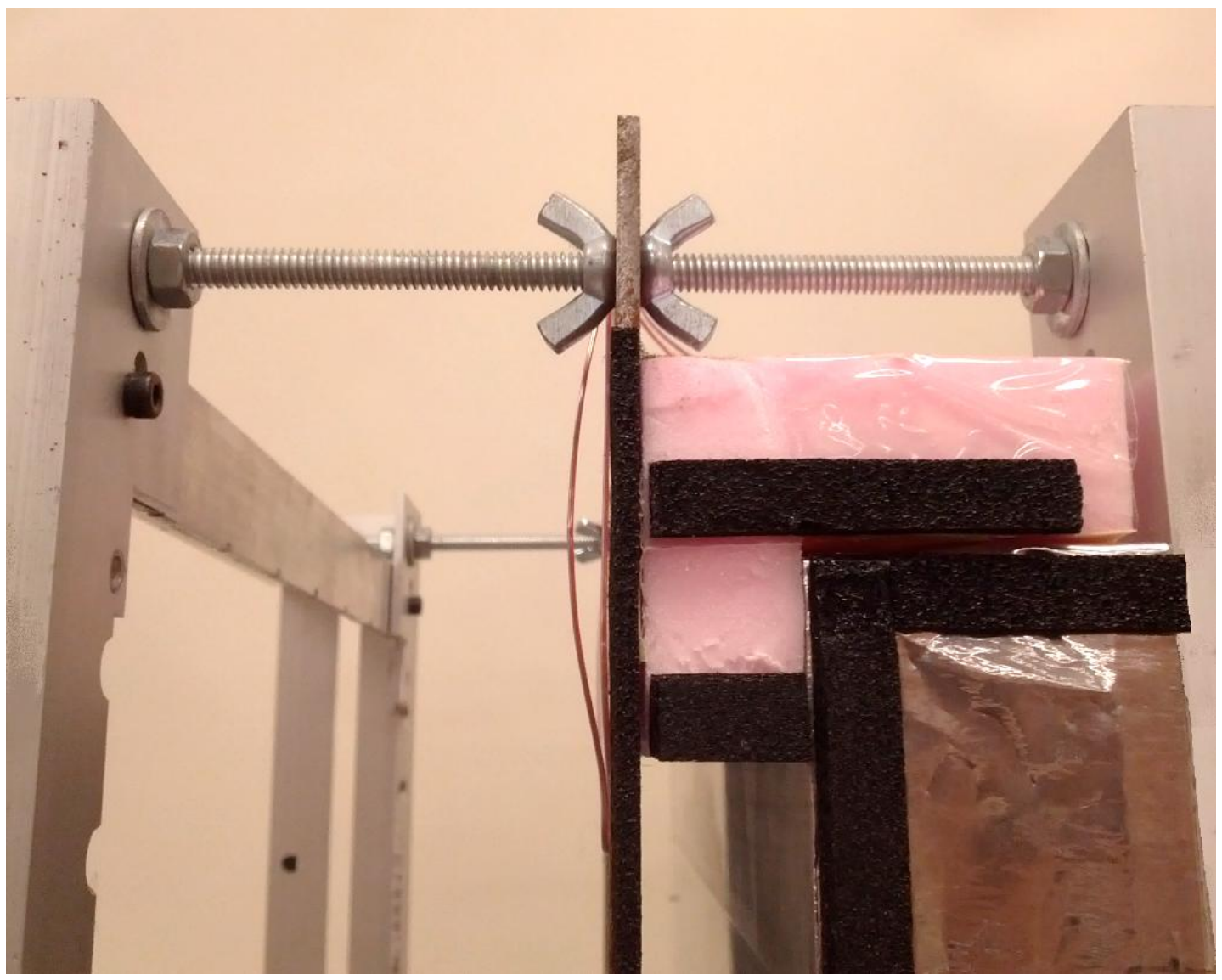

Figure 2.3 Side view of the model showing the screen frame (center) and adjustment butterfly nuts

\subsubsection{Screen frames and screen}

Two identical screen frames were used to hold each of the two screens. A front view is shown in Figure 2.5. The frames are made from a $1 / 8$ inch thick cold-rolled chromoly steel plate. This thickness was chosen so as to obstruct the view as little as possible, while being rigid enough to remain flat and provide a uniform gap spacing. The plates were water jet cut to an accuracy of $1 \mathrm{~mm}$. Water jet cutting was chosen over $\mathrm{CNC}$ milling so as to reduce warping that may result from the clamping or the cutting force of the milling machine. 


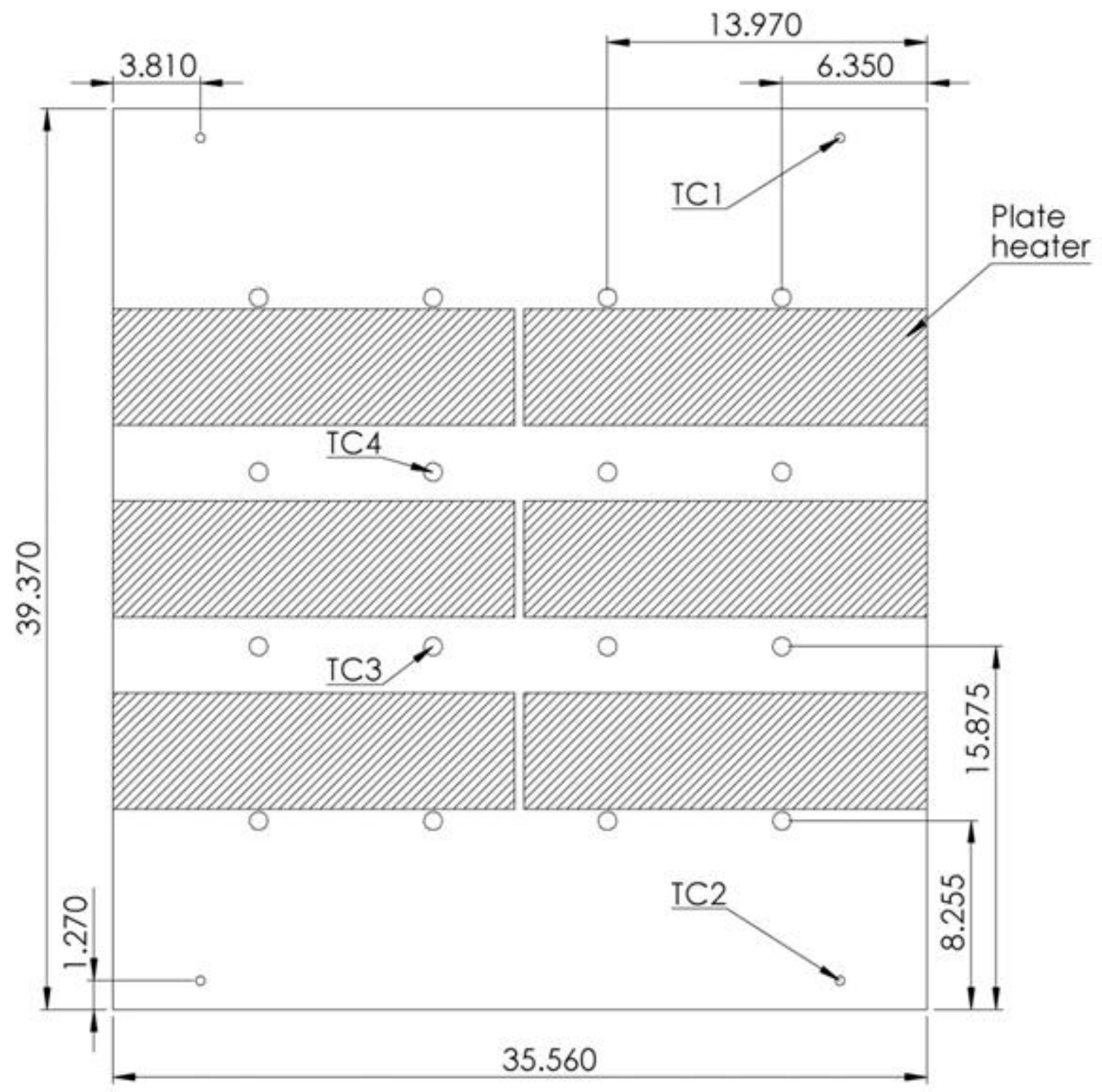

Figure 2.4 Back view of hot plate showing overall dimensions and location of thermocouples and plate heaters

\subsubsection{Model assembly}

The assembled model is shown in Figure 2.2. The hot plate assembly is attached to aluminum angle using glass fiber reinforced plastic screws, which reduce heat transfer to the support frame. The base plate has three legs which can be adjusted to align the model. 


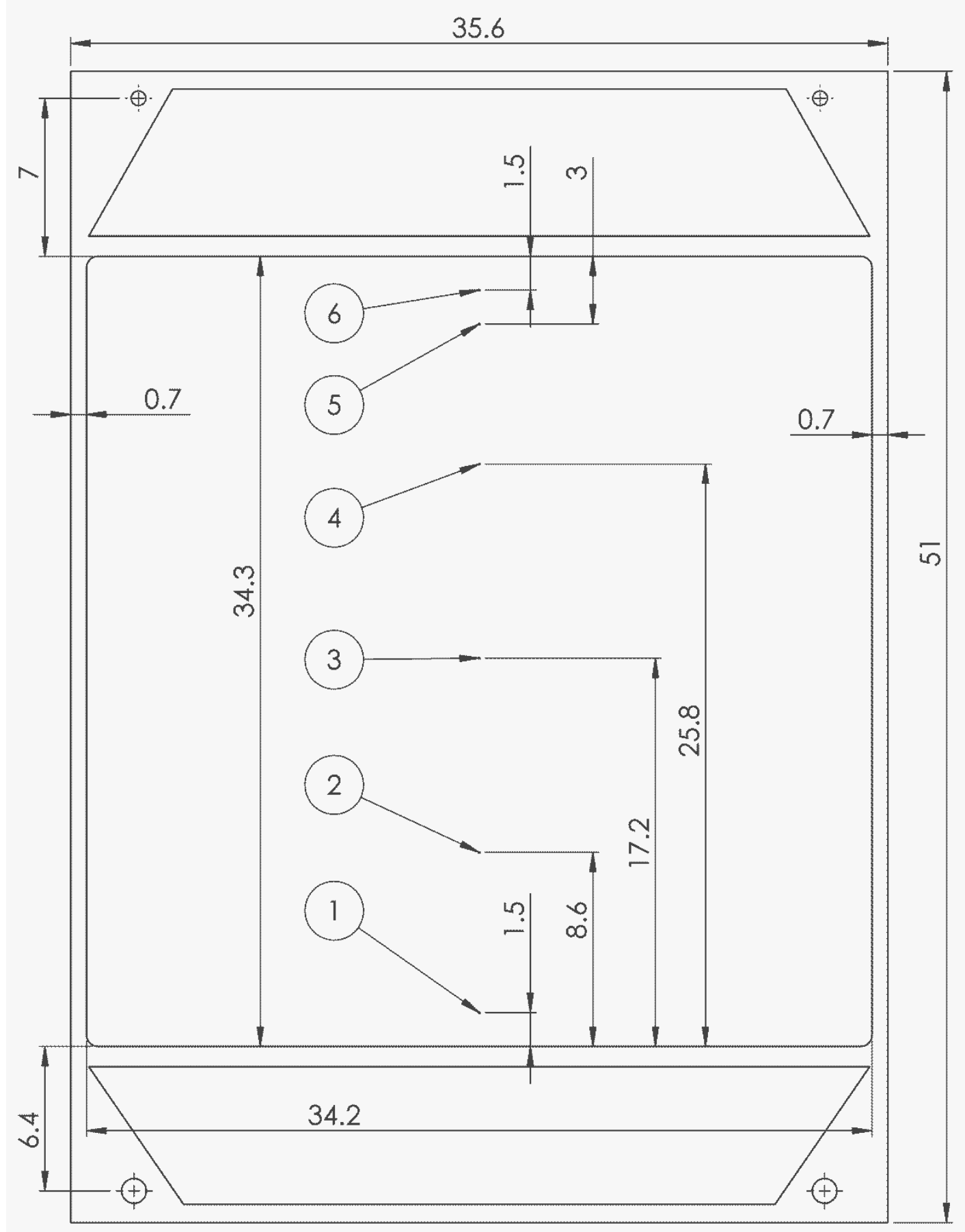

Figure 2.5 Overall dimensions of screen frame and screen temperature thermocouple locations

The screen was glued to the screen frame carefully in order to prevent waviness in the screen. Waviness creates uneven gap spacing and also results in lower quality visualization images. The screen was laid on a flat surface. Then glue was applied to the borders in the screen frame, which was subsequently placed 
on top of the screen. This procedure ensured the screen remained flat. Once the glue was dry, six thermocouples were installed at different positions along the screen. With these precautions, there was still some waviness in the screen surface, estimated to be approximately $\pm 1 \mathrm{~mm}$. Lastly, the screen frame was placed in the model such that the side with the screen was closest to the hot plate.

In order to promote two dimensional flow inside the cavity, the sides of the model were sealed to prevent air from being drawn in. This is accomplished using optical windows. Optical windows are needed because transparent Plexiglas is not flat enough, and therefore creates interference patterns that become superimposed on the interference patterns created by the temperature field in the model. The 8 inch optical windows, flat to within $1 / 20$ of a wavelength, are held in place with special acrylic holders, shown in Figure E.2.

A wooden frame covered with high permeability cloth was constructed to place over the model in the test beam. This eddy tent prevented large air disturbances in the room from affecting the flow near the model. More information on the eddy tent can be found in (Roeleveld, 2013).

\subsection{Temperature monitoring}

The temperature of the hot plate was measured using four thermocouples. These were strategically located along the height and width of the plate in order to detect whether the isothermal condition was met. The thermocouples are 20 gauge type T. The tips were coated in a high thermal conductivity and low electrical conductivity epoxy, and the tips placed inside previously drilled holes.

The ambient temperature was measured using two thermocouples, using the same thermocouple wire and prepared in the same way as the hot wall thermocouples. One was placed near the bottom of the model and the other just above but well away from the plume from the model. The thermocouple tips 
were wrapped in aluminum foil in order to shield them from radiant heat from the room walls or other sources.

The screen temperature was measured with 40 gauge type $T$ thermocouples, placed at different locations along the height of the screen and glued using a high thermal conductivity cement. Small gauge thermocouple wire was chosen to reduce lead conduction effect and to avoid disturbing the flow through the screen. The locations of the screen thermocouples are shown in Figure 2.5.

All the thermocouples were calibrated in an isothermal water bath against a precision glass thermometer with calibration traceable to national standards. Calibration data is shown in Appendix G.

\subsection{Cameras and data acquisition}

A Phase One P45 digital back with a resolution of $5412 \times 7216$ pixels (39 megapixels) is used to capture the output of the interferometer.

The camera is connected to a dedicated computer where the raw captures are further processed. Capture One Pro was used to convert the raw images to TIFF format, as well as to set the proper settings for the image (for details on the settings used, see Appendix C). These settings are crucial for obtaining accurate results from the MATLAB processing code. 


\section{Chapter 3: Experimental procedure and analysis}

\subsection{Introduction}

A total of eight finite and infinite interferograms were used for analysis of the four cases studied. These were done using the same nominal plate and ambient temperature, but different screens and spacing; as described in Chapter 5.

A plate temperature approximately $15{ }^{\circ} \mathrm{C}$ above ambient was used for all four experiments. Ambient temperature inside the interferometer room was about $23^{\circ} \mathrm{C}$. Therefore, the plate temperature was roughly $38{ }^{\circ} \mathrm{C}$. A $15{ }^{\circ} \mathrm{C}$ temperature difference was especially needed in cases (b) and (d), in order to obtain sufficient fringes inside the cavity for areas of low heat transfer (i.e. near the top). High temperature differences between the plate and ambient help create stronger convective flow, which helps contrast the differences in heat transfer rates between the no screen case (a) and the other cases.

As discussed in Chapter 2, the height of the model was slightly less than twice the test beam diameter; so the interferometer output was captured in two images. For each case, the bottom shots were done first. The finite fringe interferograms were taken first, after which the optics were set in infinite fringe mode to take infinite fringe interferograms. Then, the optics were set in finite fringe mode, the model was lowered, and the same process was repeated for the upper part of the model.

Infinite fringe interferograms are difficult to obtain because they require very precise adjustment of the optics. Therefore, perfect infinite fringe interferograms are hard to obtain. For this reason, finite fringe interferograms were used for analysis, and infinite fringe ones were used for temperature field visualization. Figure 3.2 shows the difference between finite and infinite fringe interferograms for case (b). This chapter describes the procedure used to obtain the heat transfer results presented in Chapter 5. 

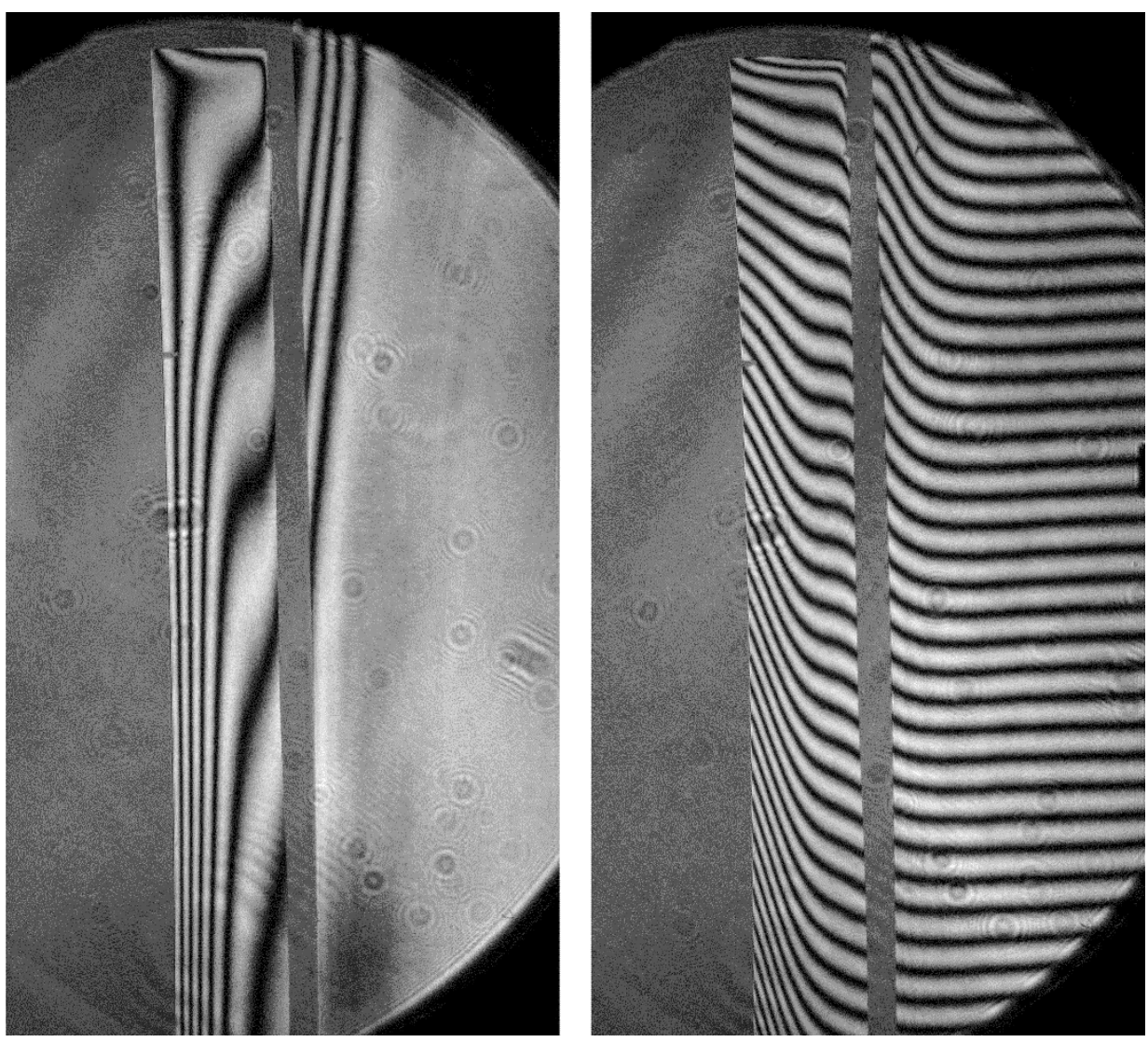

Figure 3.1 Comparison between infinite and finite fringe interferograms for case (b)

\subsection{Experimental procedure}

The experimental procedure outlined in this chapter is adapted from Machin, Naylor, Harrison \& Oosthuizen (1998) but modified slightly because of differences in the experimental model. The checklist that was used when conducting the experiments is included in Appendix C.

First, coarse alignment of the interferometer was performed. This entails leveling the optical bench, collimating the beam, and then adjusting the mounts to ensure that the beam is centered on each optic. Then, the experimental model was prepared for the experiments. The channel spacing was adjusted roughly using the butterfly nuts, and then gauge blocks were used to ensure uniform spacing along the channel. The thermocouples were plugged in and the thermocouple reader and computer was turned on. The optical windows were installed next, ensuring alignment between each other. The electric 
heaters were turned on and allowed sufficient time to reach a steady temperature. The model was deemed to be at steady state once the temperature stayed within $0.2{ }^{\circ} \mathrm{C}$ over a period of 5 minutes. This step takes roughly 2 to 3 hours due to the large thermal inertia of the plate and relatively low power of the electric heaters. While the plate reaches the desired temperature, the model was moved into the test beam of the interferometer and aligned. Alignment of the model consisted of adjusting the height of the table so that the optical windows and test beam were aligned, then leveling it horizontally using a spirit level and lastly aligned vertically using a plumb bob. To reduce the effect of room air disturbances, a fabric eddy tent was placed over the experimental model on the vertically adjustable table.

Then, fine alignment of the beam was performed. This entails aligning the test beam with the experimental model and obtaining the desired fringe pattern by near field-far field focusing.

Next the camera was prepared. This included adjusting the height of the camera, the position and orientation of the small mirror, the orientation of the camera with respect to the small mirror and the focus. Again, a more detailed description of the camera alignment procedure can be found in Appendix C.

Lastly, the reference beam is blocked and a horizontal scale reference is placed on the test beam. The lights are turned off and a picture of the model and horizontal scale is taken. Once this step is complete, the reference beam is unblocked and the scale removed from the beam.

At this point, the model has reached its desired temperature and is aligned with the beam, which is set on the desired interference pattern. The camera is also aligned and adjusted, and so it is ready to capture the interferograms. Photos are taken of the finite fringe interferograms, and the barometric pressure and thermocouple readings are recorded for use in the analysis of the data. 
After taking the finite fringe interferograms, the interferometer is set on infinite fringe mode and the interferograms are captured once again. Then, the model is lowered, the optical windows repositioned so they are in the upper half of the model, and fine alignment of the model is performed again before capturing interferograms of the upper half of the model.

The images taken by the high resolution digital back are in full colour. So, once the photographs are taken, they are converted to 256 greyscale ( 8 bit) and processed using a custom MATLAB code to obtain the fringe spacing data. This data is then used to obtain the heat transfer rates using a spreadsheet program based on the theory described in the next section.

\subsection{Interferogram analysis}

In general, interferometry utilizes the wave nature of light to measure the phase shift between two light waves. As described in Chapter 2, an interferometer splits a laser beam into two, one of which passes through undisturbed air, and the other through the experimental model. The experimental model changes the temperature of the air surrounding it and therefore changes its density (since for an ideal gas at constant pressure density changes with temperature). This change in density causes a small change in the index of refraction of the air, which changes the speed of light in that region. This causes the two beams to be out of phase and form an interference pattern in the output when the two beams are recombined. A complete overview of interferometry is given by Goldstein (1970).

Laser light is monochromatic and its amplitude can be expressed as:

$$
A=A_{0} \sin \left(\frac{2 \pi}{\lambda}(c t-z)\right)
$$

Where $A_{0}$ is the maximum amplitude, $\lambda$ is the wavelength of the laser, $c$ the speed of light and $z$ the position. The amplitude of the reference beam at a fixed position is: 


$$
A=A_{0} \sin \left(\frac{2 \pi c t}{\lambda}\right)
$$

And the amplitude of the test beam at a fixed point is:

$$
A=A_{0, t e s t} \sin \left(\frac{2 \pi c t}{\lambda}-\varphi\right)
$$

Where $\varphi$ is the phase shift between the two light waves due to the difference in the index of refraction in the two paths.

Given that the amplitude of the two beams are equal $\left(A_{0}=A_{0, \text { test }}\right)$, as the two beams recombine in the output of the interferometer the intensity at any one point can be expressed as:

$$
A=A_{0}\left[\sin \left(\frac{2 \pi c t}{\lambda}\right)+\sin \left(\frac{2 \pi c t}{\lambda}-\varphi\right)\right]
$$

Therefore, Intensity is a maximum (constructive interference) when $\varphi / 2 \pi$ is an integer and a minimum (destructive interference) when $\varphi / 2 \pi+1 / 2$ is an integer. Thus, a phase difference equivalent to one wavelength exists from fringe center to fringe center between the two beams.

The fringe shift $\varepsilon$ between the reference and test beams is related to the difference in the number of waves in the two beams, as follows:

$$
\varepsilon=\frac{\Phi}{2 \pi}=\int_{R E F} \frac{d z}{\lambda_{R E F}}-\int_{T E S T} \frac{d z}{\lambda}
$$

Where $\lambda$ is the local wavelength of the light and $\mathrm{dz}$ is the path length of the beam of light. From the definition of the index of refraction ' $n$ ' of a medium:

$$
n=\frac{c_{0}}{c}=\frac{\lambda_{0}}{\lambda}
$$


Where $c_{0}$ is the speed of light in a vacuum and $c$ is the speed of light in the medium, in this case air; $\lambda_{0}$ is the wavelength of the laser light in a vacuum and $\lambda$ is the wavelength of the laser light in the medium. Using this definition, Equation (3.5) becomes:

$$
\varepsilon=\frac{1}{\lambda_{0}} \int_{0}^{W_{o}}\left(n_{R E F}-n\right) d z
$$

Where $W_{o}$ is the width of the experimental model over which the refractive index varies according to the local temperature. Equation (3.7) shows that the interferometer averages the change in refractive index along the beam. Because this study is steady state, the index of refraction is constant along a line of constant density. The index of refraction of the fluid can be related to its density using the GladstoneDale equation:

$$
n=\rho G+1
$$

Where $\mathrm{G}$ is the Gladstone-Dale constant, which depends on the wavelength of light and the type of fluid. Using air and a Helium-Neon laser $G=0.226 \times 10^{-3} \mathrm{~m}^{3} / \mathrm{kg}$. In this study air is considered to behave like an ideal gas. Therefore the relationship between the density and the absolute temperature is:

$$
n=P G / R T+1
$$

Where $\mathrm{P}$ is the absolute pressure and $\mathrm{R}$ is the gas constant. Substituting this into Equation (3.7):

$$
\varepsilon=\frac{W_{o} P G}{R \lambda_{0}}\left(\frac{1}{T_{R E F}}-\frac{1}{T}\right)
$$

\subsubsection{Local and average Nusselt number}

This study uses the direct gradient method to calculate the local Nusselt number along the window (Duarte \& Naylor, 1999). The temperature field is two dimensional, and the fringe shift is: 


$$
\varepsilon(x, y)=\frac{W_{o}}{\lambda_{0}}\left[n_{R E F}-n(x, y)\right]
$$

Differentiating Equation (3.11) with respect to $x$ (i.e. the direction perpendicular to the window) and applying the chain rule gives:

$$
\frac{\partial \varepsilon}{\partial x}=-\frac{W_{o}}{\lambda_{0}} \frac{\partial n}{\partial x}=-\frac{W_{o}}{\lambda_{0}} \frac{\partial n}{\partial T} \frac{\partial T}{\partial x}
$$

So, the temperature gradient in the $\mathrm{x}$ direction is:

$$
\frac{\partial T}{\partial x}=-\frac{\lambda_{0}}{W_{o}} \frac{\partial \varepsilon / \partial x}{\partial n / \partial T}
$$

Differentiating Equation (3.9) with respect to temperature:

$$
\frac{\partial n}{\partial T}=-\frac{P G}{R T^{2}}
$$

Substituting Equation (3.14) into Equation (3.13) and applying the result at the window surface:

$$
\left.\frac{\partial T}{\partial x}\right|_{x=0}=\left.\frac{R \lambda_{0} T_{S}^{2}}{W_{o} P G} \frac{\partial \varepsilon}{\partial x}\right|_{x=0}
$$

Where $T_{s}$ is the absolute temperature at the window surface.

The regression technique used in the custom MATLAB code analyzes the interferogram output and returns the fringe gradient at the surface, $\left.\frac{\partial \varepsilon}{\partial x}\right|_{x=0}$, which is then used to calculate the temperature gradient $\left.\frac{\partial T}{\partial x}\right|_{x=0}$. Then, the heat transfer rates are calculated using:

$$
q_{s}=-\left.k_{s} \frac{\partial T}{\partial x}\right|_{x=0}
$$

Where $q_{s}$ is the heat flux at the window surface and $k_{s}$ is the conductivity of air at the surface temperature. The local Nusselt number is defined as: 


$$
N u_{y}=\frac{q_{s H}}{\left(T_{s}-T_{\infty}\right) k_{f}}
$$

Where $\mathrm{H}$ is the window height, $T_{S}-T_{\infty}$ is the temperature difference between the window and the ambient and $k_{f}$ is the thermal conductivity of air at the film temperature. Local Nusselt numbers were measured at approximately 60 to 100 locations along the window. The increments between measurement locations was not uniform. The reason the number of measurements varies between cases is that the ambient fringe spacing is not exactly the same for all cases. Additionally, for some cases, it was noticed that certain areas returned highly scattered results, likely due to dust particles. In these cases, reducing the scan density reduced scatter in the results.

The average Nusselt numbers are determined by integrating the local Nusselt numbers using the trapezoidal rule:

$$
N u=\frac{1}{H} \int_{0}^{H} N u_{y} d y
$$

A complete sample calculation is given in Appendix E. Local and average Nusselt numbers have an estimated uncertainty of $10 \%$ and $6 \%$, respectively. A complete analysis of the experimental error is given in Appendix F.

\subsubsection{Regression technique}

A nonlinear regression technique was used to extract the fringe gradient at the window surface from the interferograms. This technique was developed by Poulad, Naylor \& Oosthuizen (2011) based on the nonlinear regression technique of Slepicka \& Cha (1995). For every measurement location along the window height, the pixel intensity along a line perpendicular to the surface is extracted. These scans are

long enough to encompass at least one fringe shift. If there is not at least one full fringe shift along this 
line, the regression technique will not work. Hence, care must be taken to ensure there are enough fringes visible in the output to measure the fringe gradient at all points along the surface.

The pixel intensity along this each of these lines follows a sinusoidal pattern if the temperature profile is linear. Therefore, the pixel intensity near the surface can be expressed as:

$$
I(x)=I_{0}+A_{0} \sin \left[F\left(x-x_{1}\right)+\varphi\right]
$$

Where $I_{0}$ is the mean pixel intensity, $A_{0}$ is the amplitude, $F$ is the rate of change of phase, $\phi$ is the phase shift and $x_{1}$ is the location of the first pixel. Equation (3.19) is fit to the extracted pixel intensity data over the first full period. The mean pixel intensity is taken as the average intensity over the first full period. The other constants $\left(A_{0}, F\right.$ and $\left.\phi\right)$ are adjusted iteratively using a least sum of squares fit between Equation (3.19) and the extracted pixel intensity data. The rate of change of phase is then used to calculate the fringe gradient:

$$
\left.\frac{\partial \varepsilon}{\partial x}\right|_{x=0}=\frac{F}{2 \pi}
$$

The resulting fringe gradient is then used in Equation (3.15) to obtain the surface temperature gradient. This gradient, along with other measured parameters such as surface and ambient temperatures and pressure, is used to calculate the local Nusselt number on a spreadsheet program. 


\section{Chapter 4: Screen permeability measurements}

\subsection{Introduction}

In order to validate numerical models with the results from this experiment, it is paramount to know the permeability of the screens used. Several papers have been published with permeability measurements of insect screens. One such paper is by Miguel (1999), but his experimental setup was designed to measure screens of lower permeabilities than those of a common household insect screen and therefore the experimental uncertainty in his high permeability screen measurements is relatively high. Valera et al. (2006) also measured the permeability of different meshes, but of lower openness than the high permeability screen used in this experiment. Lastly, Teitel (2011) determined the permeability of different meshes through experimental methods and CFD simulations that model the mesh geometry, and compared them to existing correlations. He concludes that using correlations based on openness alone can lead to significant errors and recommends determining the permeability by modeling the screen geometry in CFD.

Finding the permeability using numerical methods is technically possible, but it is very difficult to model the screen geometry with a high degree of accuracy. So, the screen permeabilities were measured experimentally.

\subsection{Experimental equipment and apparatus}

Measuring the permeability of a high openness insect screen is very difficult because the pressure drop across it is very small, especially at low Reynolds numbers. The pressure drop across the screens was measured at flow velocities ranging from 0.05 to $0.25 \mathrm{~m} / \mathrm{s}$, close to the velocities produced by natural 
convection in the current experiment configuration. At these velocities, the pressure drop across each screen is approximately $0.05 \mathrm{~Pa}$.

In order to measure the differential pressure accurately, a highly sensitive and accurate transducer was used (0.01\% FS resolution and $0.3 \% \mathrm{FS}$ accuracy). The specifications of the transducer, along with all the other instrumentation used can be found in Appendix A. The output of the transducer was read using a Fluke handheld multimeter (Model $87 \mathrm{~V}$ ).

In order to increase the overall pressure difference to be measured, several screen samples were placed in series. The number of screen samples used was 14 and 37 for the low and high permeability screens, respectively. The samples were cut into $9 \mathrm{~cm}$ diameter circles and held between sections of $7.62 \mathrm{~cm}$ internal diameter acrylic pipe, each approximately $2.5 \mathrm{~cm}$ long; shown below in Figure 4.1. This internal diameter was chosen because it resulted in the desired flow velocity range given the volumetric flow capacity of the compressed air source. The acrylic sections were glued using silicone and the joints checked for air leaks.

The flow velocity was calculated from the volumetric flow-rate, measured using an air rotameter (RMC103, Dwyer Instruments Inc.). A flow conditioner was positioned immediately after the flow inlet, inside the test section, to promote uniform flow. A diagram of the apparatus is shown in Figure 4.2 


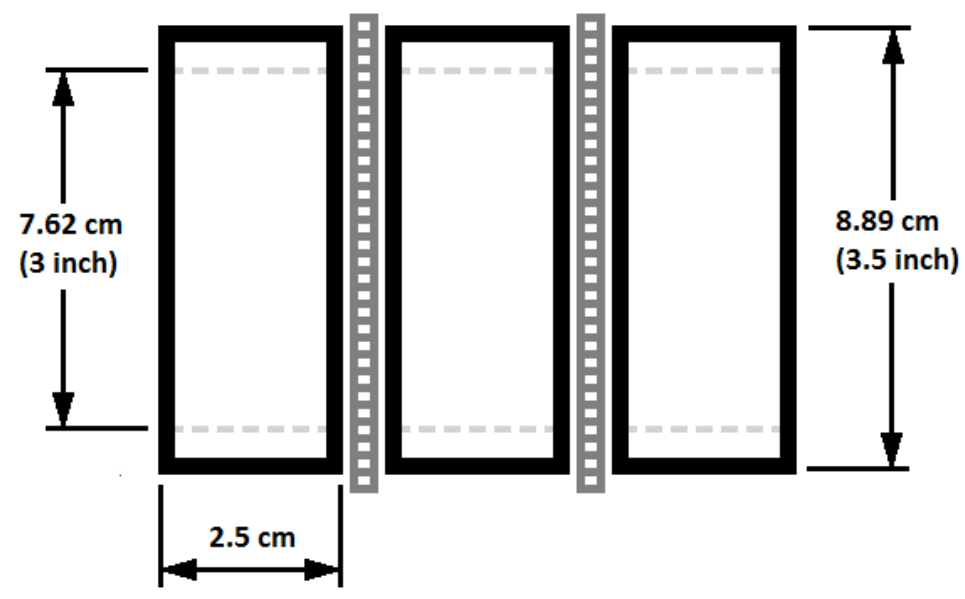

Figure 4.1 Two sample screens in-between three sample sections of tube

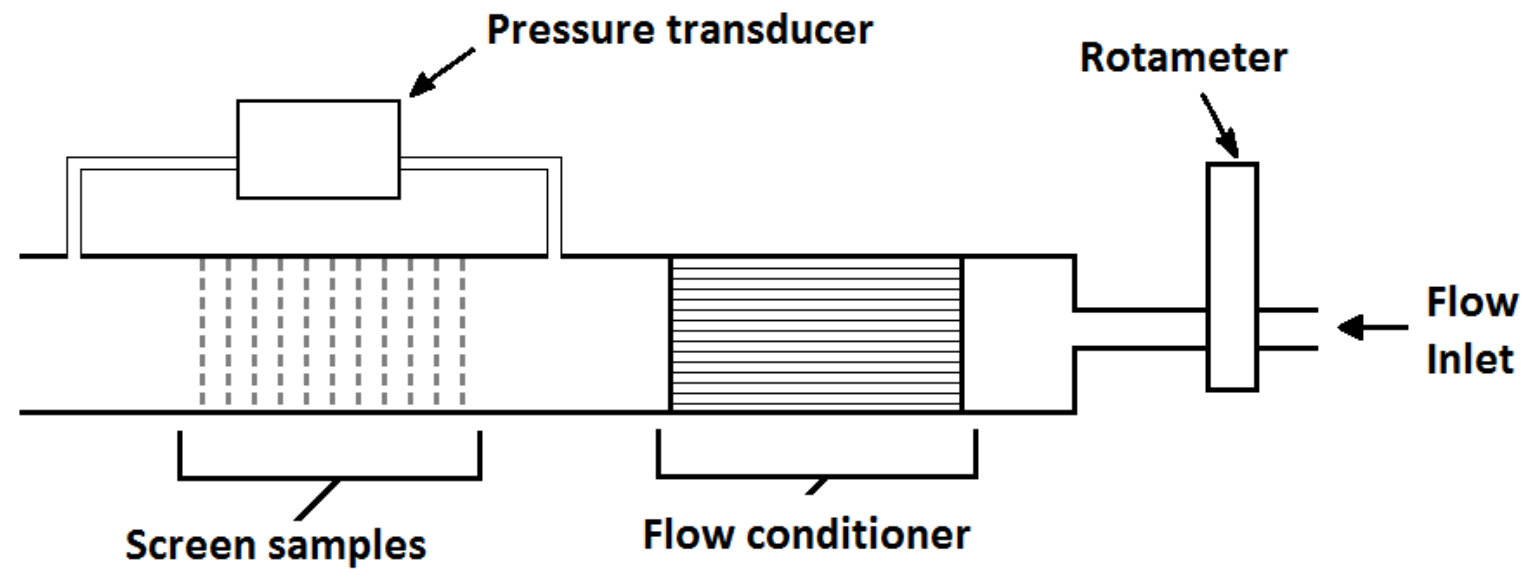

Figure 4.2 Schematic diagram of apparatus

The high permeability screen is sold as an insect screen for residential use, while the low permeability screen is used for in industrial applications. However, some regions require blocking very small insects (such as sand flies) and so would employ screens similar to the low permeability screen used in this study.

The screen geometrical properties are listed below in Table 4.1 and photographs of the screens are shown in Figure 4.3. All the dimensions except for the screen thickness were measured using a high 
resolution scanner and a glass reticle scale with a resolution of $0.1 \mathrm{~mm}$. The thread width was measured to an accuracy of $0.01 \mathrm{~mm}$ because the high resolution scanner allowed a resolution of 20 pixels per $0.01 \mathrm{~mm}$. The width of five different threads was measured and averaged. The screen thickness was measured using a micrometer with a resolution of $0.01 \mathrm{~mm}$. Lastly, the openness was calculated as follows:

$$
e=\frac{\left(S_{H}-W_{t}\right)\left(S_{V}-W_{t}\right)}{S_{H} * S_{V}}
$$

Table 4.1 Screen geometrical properties

\begin{tabular}{|c|c|c|c|c|c|}
\hline Screen & $\begin{array}{c}\text { Openness, } \\
\mathrm{e}\end{array}$ & $\begin{array}{c}\text { Screen } \\
\text { thickness, } \mathrm{t}\end{array}$ & $\begin{array}{c}\text { Thread } \\
\text { width, } \mathrm{W}_{\mathrm{t}}\end{array}$ & $\begin{array}{c}\text { Horizontal thread } \\
\text { spacing, } \mathrm{S}_{\mathrm{H}}\end{array}$ & $\begin{array}{c}\text { Vertical thread } \\
\text { spacing, } \mathrm{S}_{\mathrm{V}}\end{array}$ \\
\hline High permeability & 0.62 & $0.29 \mathrm{~mm}$ & $0.35 \mathrm{~mm}$ & $1.50 \mathrm{~mm}$ & $1.85 \mathrm{~mm}$ \\
\hline Low permeability & 0.41 & $0.65 \mathrm{~mm}$ & $0.23 \mathrm{~mm}$ & $0.635 \mathrm{~mm}$ & $0.655 \mathrm{~mm}$ \\
\hline
\end{tabular}

The transmissivity and reflectivity of the insect screens was measured using a Gier-Dunkle DB-100 infrared reflectometer using the procedure developed by Christie \& Hunter (1984) for thin diathermanous films and are shown below in Table 4.2. The emissivity is then calculated using Kirchhoff's law of thermal radiation.

Table 4.2 Screen solar-optical properties

\begin{tabular}{|c|c|c|c|c|}
\hline Screen & Material & Transmissivity,$\tau$ & Reflectivity, $\rho$ & Emissivity, $\varepsilon$ \\
\hline High permeability & Polyester & 0.75 & 0.04 & 0.213 \\
\hline Low permeability & Aluminum & 0.48 & 0.40 & 0.123 \\
\hline
\end{tabular}




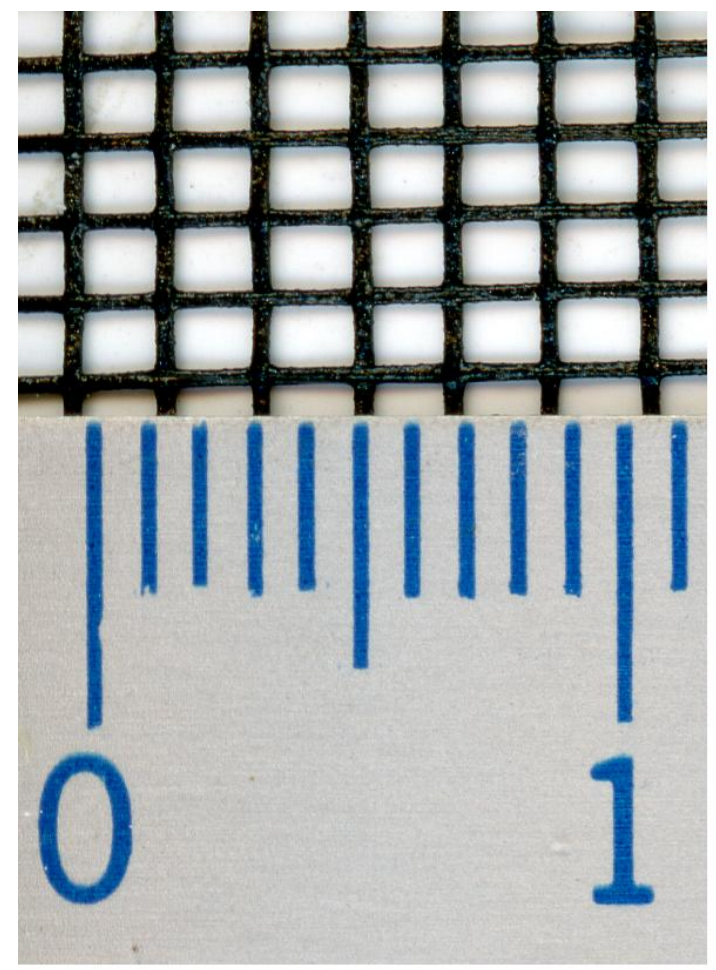

(a)

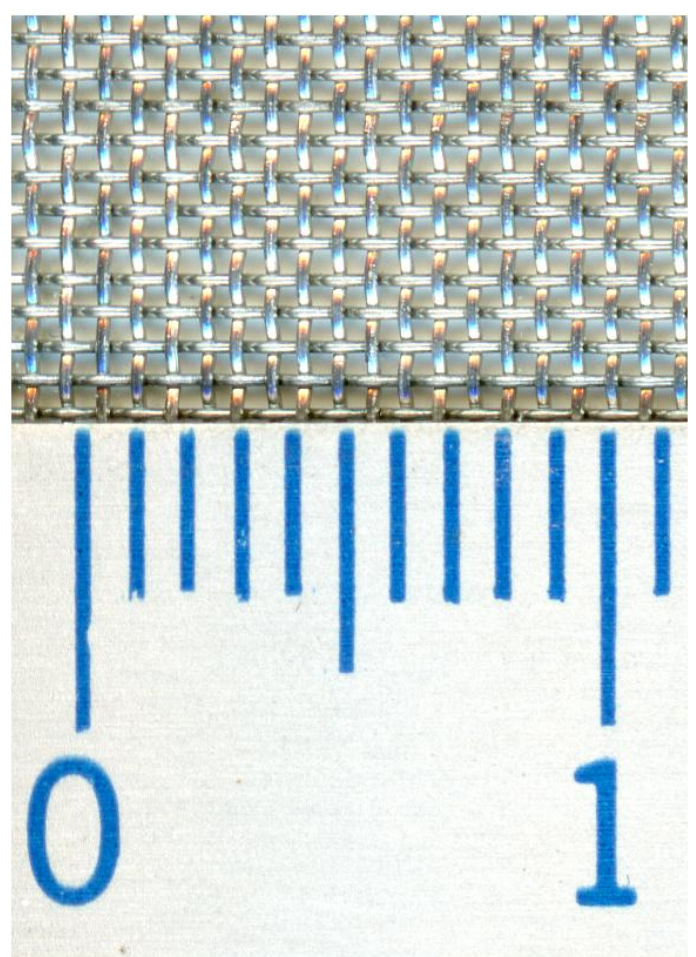

(b)

Figure 4.3 Photograph of (a) high permeability screen and (b) low permeability screen (Scale $1 \mathrm{~cm}$ )

\subsection{Experimental procedure and analysis}

\subsubsection{Introduction}

Two different screens were measured: a low permeability monofilament aluminum screen and a high permeability polyester screen designed for household use. The screens were tested on velocities ranging from 0.05 to $0.25 \mathrm{~m} / \mathrm{s}$ (corresponding to $0.3<\operatorname{Re}<1.5$ where the Reynolds number is based on the screen permeability and upstream velocity, $\mathrm{Re}=\rho \mathrm{uK}^{1 / 2} / \mu$ ). Additionally, a control experiment with no screens was conducted in order to gauge the pressure drop from a tube of comparable length, which was found to be negligible. 


\subsubsection{Experimental procedure}

First, transducer was turned on and allowed to warm up for approximately 30 minutes. After this warm up period, the transducer was checked for correct calibration at zero flow.

After calibration was completed, the flow valve from the compressed air source was opened slowly. The system was allowed to settle and the reading from the multimeter and rotameter was recorded. The multimeter was set on a mode that allowed averaging the output over time, reducing the noise in the output. Then, the flow rate was increased slightly and again the multimeter output and rotameter reading was recorded. This procedure was repeated until the flow rate reached the limit of the air source.

Lastly, the valve was closed and the null reading of the transducer was checked again. The room temperature and pressure were recorded.

Following completion of all the tests, aerosol from a Draeger tube (Model CH 25301, DraegerWerk AG \& Co. KGaA) was used to visualize flow inside the tube and ensure flow was even and unidirectional throughout the test section.

\subsubsection{Analysis of raw data}

The results from the experiments were analyzed using a spreadsheet program. The pressure drop was plotted against the velocity and a line of least squares best fit was applied. The lines of best fit were first order linear and the coefficient of correlation for both cases was found to be high.

Darcy's law states that the pressure gradient across a porous medium is proportional to the velocity (v) and dynamic viscosity $(\mu)$ of the fluid medium, and inversely proportional to its permeability $(\mathrm{K})$ :

$$
\frac{d P}{d x}=\frac{\mu}{K}(v)
$$


For a Reynolds number greater than unity a non-linear flow regime exists and can be accounted for by adding an extra term to Equation (4.1) known as the Forchheimer term:

$$
\frac{d P}{d x}=\frac{\mu}{K}(v)+\rho \frac{Y}{\sqrt{K}}\left(v^{2}\right)
$$

Where ' $Y$ ' is known as the pore inertia factor.

Because this study deals with flow regimes at Reynolds numbers near unity, the pore inertia factor was not determined. The permeability coefficient is sufficient to characterize flow through screens at flow velocities encountered in this experiment. So, Equation (4.1) can be rearranged as:

$$
P=\frac{\mu t}{K}(v)
$$

Where ' $\mathrm{t}$ ' is the nominal thickness of the screen. Therefore, if ' $\mathrm{m}$ ' is the slope obtained from the line of best fit from the pressure vs. velocity data:

$$
K=\frac{\mu t}{m}
$$

The error in the permeability has been estimated to be below $\pm 7 \%$.

\subsection{Presentation and discussion of results}

Figures 4.5 and 4.6 show the pressure drop at different velocities for the two screens. The lines of best fit shown in the graphs are then used to calculate the permeability of each screen. These results are shown in Table 4.3. The permeability of similar screens from Miguel (1999) and the permeability obtained using the correlations by Valera et al. (2006) are shown as well for comparison. An error analysis of these results is shown in Appendix F.5. 


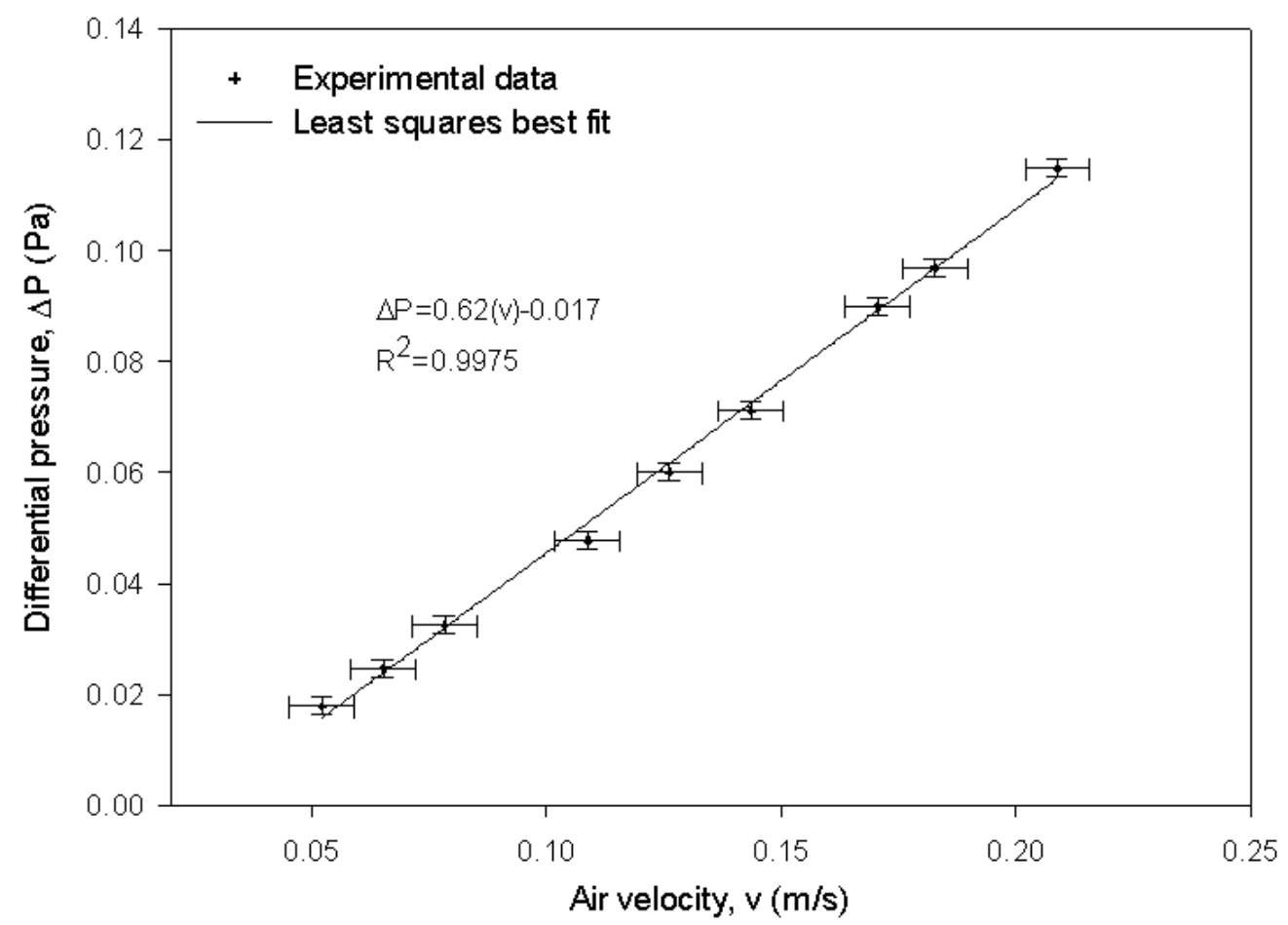

Figure 4.4 Plot of differential pressure vs. air velocity for high permeability screen

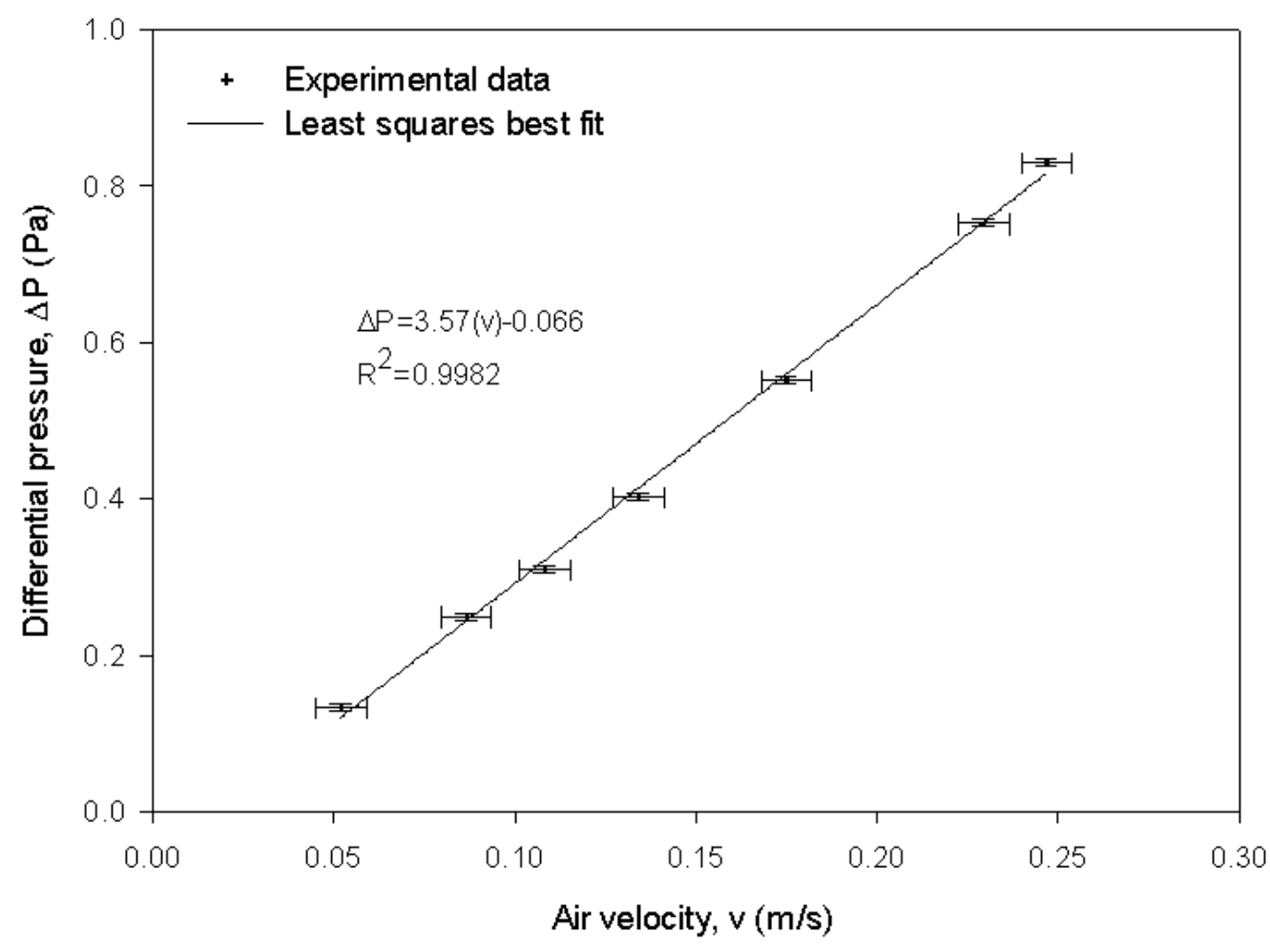

Figure 4.5 Plot of differential pressure vs. air velocity for low permeability screen 
Table 4.3 Screen permeabilities from current experiment compared to similar screens from Miguel (1999) and to empirical correlations from Valera et al. (2006)

\begin{tabular}{|c|c|c|c|c|}
\hline Screen & Openness & $\begin{array}{c}\text { Thickness, } \mathrm{t} \\
(\mathrm{mm})\end{array}$ & $\begin{array}{c}\text { Permeability, } \mathrm{K} \\
\left(\mathrm{m}^{2}\right)\end{array}$ & $\begin{array}{c}\text { Pore Inertia } \\
\text { factor, } \mathrm{Y}\end{array}$ \\
\hline High permeability & 0.62 & 0.29 & $8.74 \times 10^{-9}$ & $\mathrm{n} / \mathrm{a}$ \\
\hline $\begin{array}{c}\mathrm{R}_{63} \text { Polyester rectangular mesh } \\
\text { (Miguel, 1999) }\end{array}$ & 0.63 & 0.12 & $2.11 \times 10^{-9}$ & 0.116 \\
\hline $\begin{array}{c}\text { Permeability derived from } \\
\text { Equation (1.6) }\end{array}$ & 0.62 & $\mathrm{n} / \mathrm{a}$ & $2.33 \times 10^{-9}$ & $\mathrm{n} / \mathrm{a}$ \\
\hline $\begin{array}{c}\text { Low permeability } \\
\mathrm{R}_{\mathrm{w} 36} \text { Woven screen rectangular } \\
\text { mesh (Miguel, 1999) }\end{array}$ & 0.41 & 0.65 & $3.40 \times 10^{-9}$ & $\mathrm{n} / \mathrm{a}$ \\
\hline $\begin{array}{c}\text { Permeability derived from } \\
\text { Equation (1.6) }\end{array}$ & 0.41 & 0.25 & $3.20 \times 10^{-10}$ & 0.380 \\
\hline \multicolumn{2}{|c|}{$\mathrm{n} / \mathrm{a}$} & $1.58 \times 10^{-9}$ & $\mathrm{n} / \mathrm{a}$ \\
\hline
\end{tabular}

From these results it is clear that there is a significant difference in the permeabilities of the high and low openness screens. The low permeability screen offers approximately six times as much resistance to flow per screen as the high permeability one, even though the open area is only $50 \%$ less.

Additionally, it can be seen that the permeabilities of similar screens varies significantly. The correlations given by Miguel (1999) and Valera et al. (2006) are not especially useful in determining the resistance to flow of a screen with a high degree of accuracy. It is clear that current correlations for permeability based on open area alone can have a wide margin of error, since they do not account for thread shapes and other geometrical properties. It is unclear exactly how large this margin of error is. Most studies that aim to characterize flow resistance of insect screens measure screens of different openness at different velocities, instead of the variation across screens of equal openness but different thread patterns. Hence the margin of error of the above mentioned correlations is unknown. 


\subsection{Summary}

The Darcy permeability of two insect screens was measured using many screen samples in series and a highly sensitive pressure transducer. Accurate characterization of the screens used in this experiment is important for validating numerical models. For the purpose of validation, the error in the permeability is estimated to be below $\pm 7 \%$. A more accurate technique for estimating the uncertainty in results obtained using the best fit method is given by Coleman \& Steele (2009). 


\section{Chapter 5: Presentation and discussion of results}

\subsection{Introduction}

An experimental study of free convection inside a window cavity with an insect screen attachment was conducted using laser interferometry. The present study investigated four different cases: one with no screen, one with a low permeability screen, and the remaining two with common residential screens. The last two cases had different aspect ratios, in order to investigate this effect on the heat transfer on the window. The permeability of the two screens used in the experiment was measured, as outlined in Chapter 4.

The temperature field and convective heat transfer were determined using a Mach-Zehnder interferometer. Finite fringe interferograms were used for calculating heat transfer rates, and Infinite fringe interferograms were used for visualizing the temperature field. Local and average heat transfer rates were also measured.

A commercial CFD package (SolidWorks Flow Simulation) was used to aid design the experimental model. The screen was modelled as a thin layer of homogeneous porous medium, with pressure data at each mean velocity entered in a look-up table. This approach reduces the complexity of the problem, as it is not necessary to model the geometry of the screen. The detailed implementation of this problem in SolidWorks Flow Simulation is discussed in Appendix D. The results from the numerical solutions are also shown in this chapter for comparison purposes. However, it should be noted that the CFD solution is not the focus of the current thesis. SolidWorks Flow Simulation is a general purpose CFD package that is targeted for industrial applications and can be used by the non-expert. SolidWorks Flow Simulation does not offer advanced controls to the user (e.g. convergence criteria for the residuals). For this reason, it is 
not a research-grade CFD package. Nevertheless, the results are helpful for comparison purposes and aid in the interpretations of the experimental results.

\subsection{Temperature field results: Infinite fringe interferograms}

Figure 5.1 shows composite infinite fringe interferograms of the four cases investigated. The constructive and destructive interference fringes are isotherms. So, these images provide visualization of the temperature field inside and outside the window cavity. The screen frame appears as a thick vertical shadow in Figure (b), (c) and (d). As described in Chapter 2, the screen is located on the left side of the screen frame, on the side closest to the hot plate. It should also be noted that these interferograms are composites of two separate images taken at the bottom and top of the window. It can be seen that the fringes do not perfectly align at the interface between these two images. The imperfect alignment is caused by slightly different thermal conditions and the difficulty of setting a perfect infinite fringe setting with the interferometer optics. However, these images were used only for visualization. As discussed in Chapter 3, the finite fringe setting was used to measure the heat transfer rates.

Figure 5.1(a) shows the baseline case with no screen. A thermal boundary layer forms on the surface of the window and its thickness grows up the window; appearing similar to that of an isolated vertical plate. The main difference between this case and the isolated flat plate results from the conductive spacers at the top and bottom of the window. The fringes extend farther from the plate surface at the bottom of the window because the air is slightly preheated as it passes through the warm spacer. Also, the inside corner obstructs airflow in that region. Similarly, at the top of the window, the boundary layer thickens rapidly where the flow turns and departs from the window. 
The effect of a low permeability screen on the temperature field near the window is shown in Figure 5.1(b). Comparing this image to the no screen case, it can be seen that their thermal boundary layer has a similar appearance near the bottom of the window. However, in the upper region there are substantial differences. Because of the blockage effect of the screen, it appears that the flow leaves the enclosure over a broad area of the screen; the thermal plume on the left side of the screen extends farther down the window than for the no screen case. The screen has a large impact on the temperature field in the upper region. In general, over approximately the top third of the enclosure, the fringes are more widely spaced than the no screen case, indicating the convective heat transfer is lower. Inversely, on a cold surface, the bottom region would be affected. In a real window application, the lower convective heat transfer coefficient would result in a larger thermal resistance between the window glazing and the ambient. Consequently, the temperature in the lower region of the indoor glazing would be closer to the outside temperature; in this case, colder. Therefore a more impermeable screen would increase the potential for condensation, something that is not desired in window design.

Figure 5.1 (c) shows the temperature field for the high permeability screen $(H / b=17.2)$. This case is very similar to the no screen case, except near the top of the window. Compared to the low permeability case the impact of the screen on the temperature field is visibly reduced. The high permeability screen affects the temperature over a much smaller region near the top of the window. However, it still reduces heat transfer in this region and can increase the potential for condensation like case (b).

Figures 5.1(c) and (d) show the effect of the window height to screen spacing (aspect ratio) on the temperature field. In Figure 5.1(d), where the screen is located close to the window, the outer edge of the thermal boundary layer extends outside the screen over a large part of the cavity. It can also be seen that the smaller spacer for the high aspect ratio cavity has a smaller effect on the temperature field at the very top and very bottom of the window. 


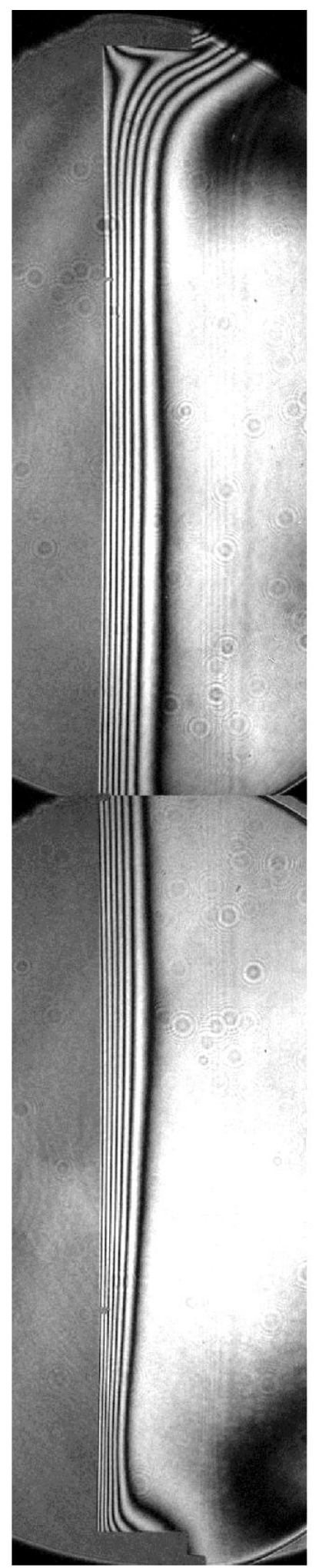

(a)

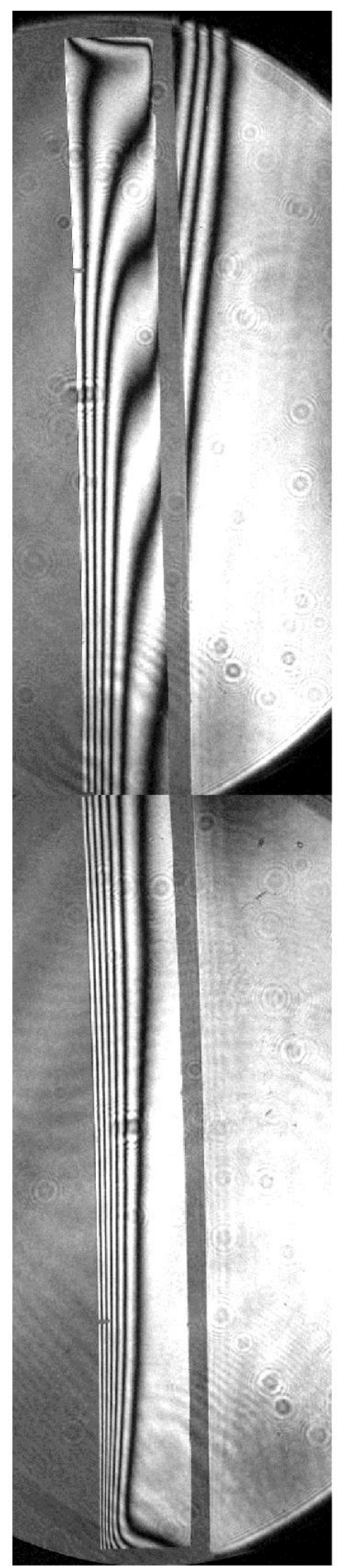

(b)

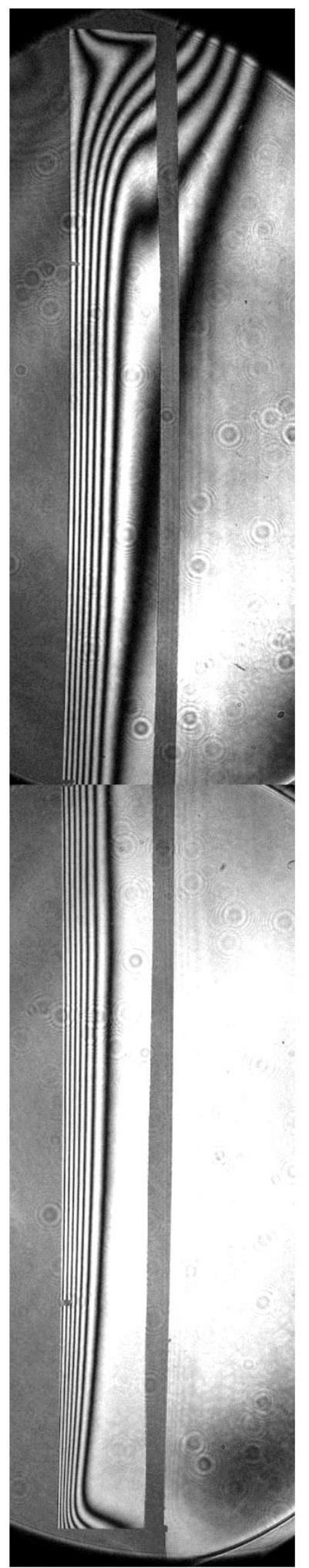

(c)

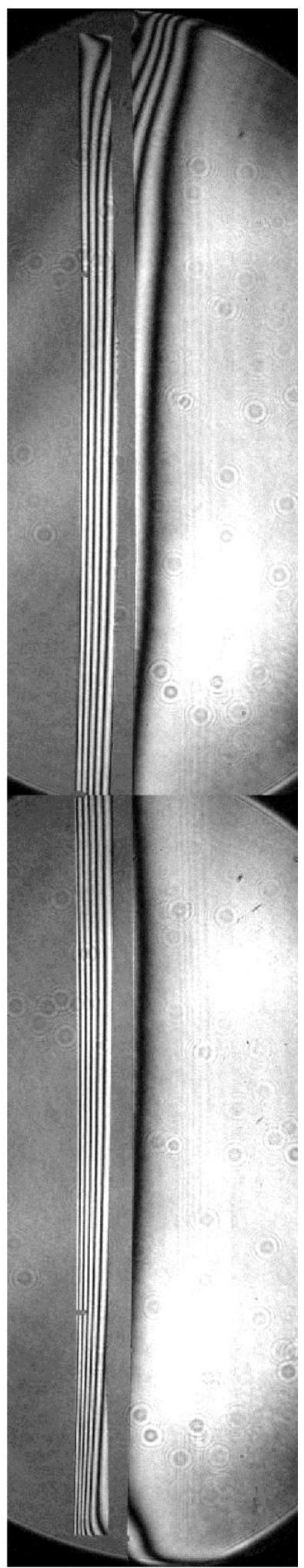

(d)

Figure 5.1 Composite infinite fringe interferograms for: (a) no screen (b) low permeability screen b=2 cm (c) high permeability screen $b=2 \mathrm{~cm}$ (d) high permeability screen $b=1 \mathrm{~cm}$ 


\subsection{Local Nusselt number results}

An initial experiment was done without the screen in place. Comparisons with these baseline results will demonstrate the effect of the insect screen on the free convective heat transfer. Figure 5.2 shows the measured local Nusselt number distribution along the window. It should be noted that the $b=2 \mathrm{~cm}$ wide spacers $(H / b=17.2)$ were left in place; as shown in the infinite fringe interferogram, Figure 5.1(a). The similarity solution of Ostrach (1953) for boundary layer flow on an isolated vertical flat plate has been added for comparison. It can be seen that in the centre region of the window, there is very good agreement between the measured local convective heat transfer and the analytical prediction. As expected, there are large differences in the results at the top and bottom of the window because of the effects of the spacers. In the similarity solution the thermal boundary layer thickness approaches zero at the leading edge. Hence, the local Nusselt number has a singularity at $\mathrm{y} / \mathrm{H}=0$. In contrast, the convective heat transfer in the experiment decreases near the top and bottom of the window because the spacers obstruct the flow. The increased fringe spacing near the spacers can be seen clearly in the interferogram. The average Nusselt numbers are in close agreement, with the current measurements being about $4 \%$ lower than predicted by the analytical solution. Again, this is likely caused by the flow obstruction of the upper and lower spacers. 


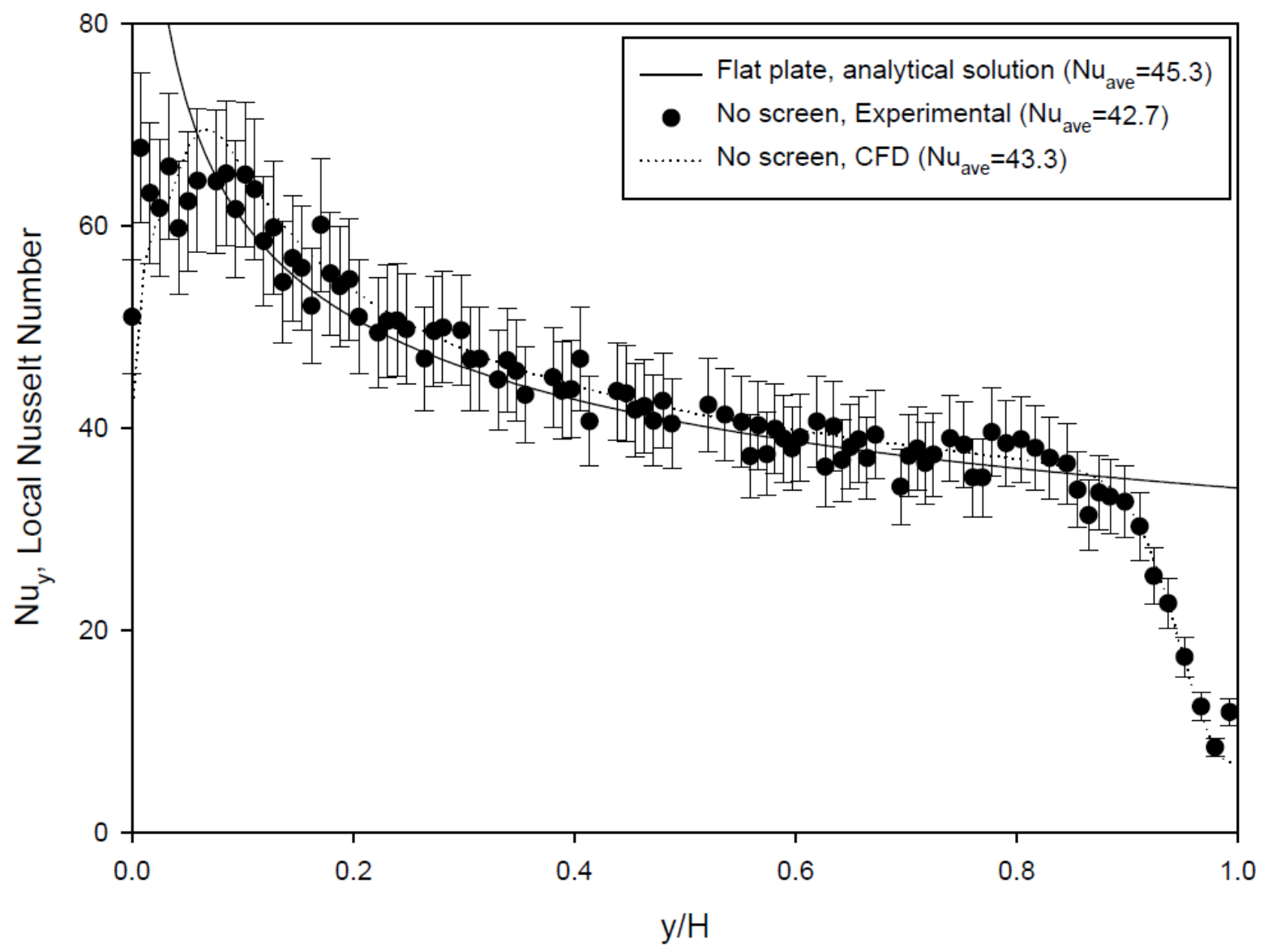

Figure 5.2 Similarity solution for boundary layer flow on an isolated vertical flat plate (Ostrach, 1953) and experimental results for the no screen case showing the error uncertainty in the local Nusselt numbers

The effect of the screen permeability on the local convective heat transfer from the window is shown in Figure 5.3. In these results, the window to screen spacing has been fixed to give an aspect ratio of $H / b=17.2$. This figure shows a comparison between the current experimental measurements and the CFD predictions obtained from SolidWorks Flow Simulation. It can be seen that there is generally good agreement between the measured and predicted local Nusselt number distributions over the entire window. As expected, as the permeability of the screen is decreased, the convective heat rate decreases. But, this effect is not uniform. The heat transfer rate is only affected a small amount near the very bottom of the window. The screen has a more pronounced effect on the centre portion of the window and the largest reductions in heat transfer occur at approximately the top third of the window. 
This can also be seen qualitatively in the corresponding interferograms, Figure 5.1(a), (b) and (c). The effect of the screen on the fringe spacing for these three cases is mainly visible at the top of the window.

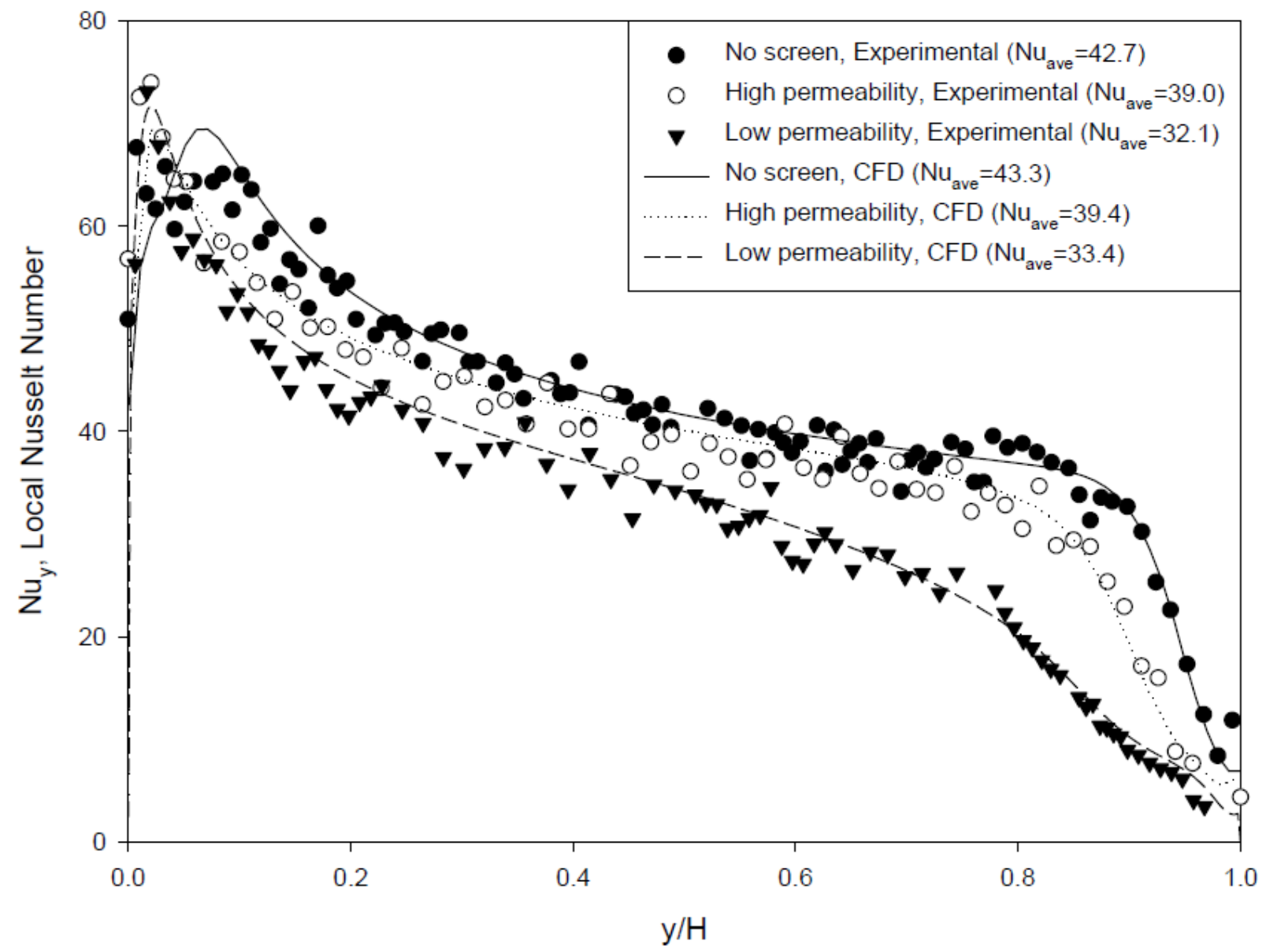

Figure 5.3 Local Nusselt numbers for no screen and high and low permeability cases at a fixed aspect ratio $\mathrm{H} / \mathrm{b}=17.2$

Figure 5.4 shows the effect of the cavity aspect ratio on the local Nusselt number distribution on the window. The spacing between the window and screen was adjusted to obtain aspect ratios of $H / b=17.2$ and $H / b=34.4$. Again, the CFD predictions from SolidWorks Flow Simulation are shown for comparison. The corresponding infinite fringe interferograms are Fig. 5.1 (c) and (d). It can be seen that the convective heat transfer decreases as the screen is moved closer to the window. In this case, the 
average heat transfer rate decreases by about $2 \%$ in the experimental results and approximately $7 \%$ in the CFD. However, there is a small exception at the top of the window. In both the experiment and the numerical predictions, the heat transfer at the very top is slightly higher for the closer screen spacing. In this case this is likely the effect of the spacer. The $b=1 \mathrm{~cm}$ screen spacing presents less of an obstruction to the flow near the top of the window. It should be noted that for taller windows, this effect would likely be small compared to the overall effect of moving the screen closer to the window.

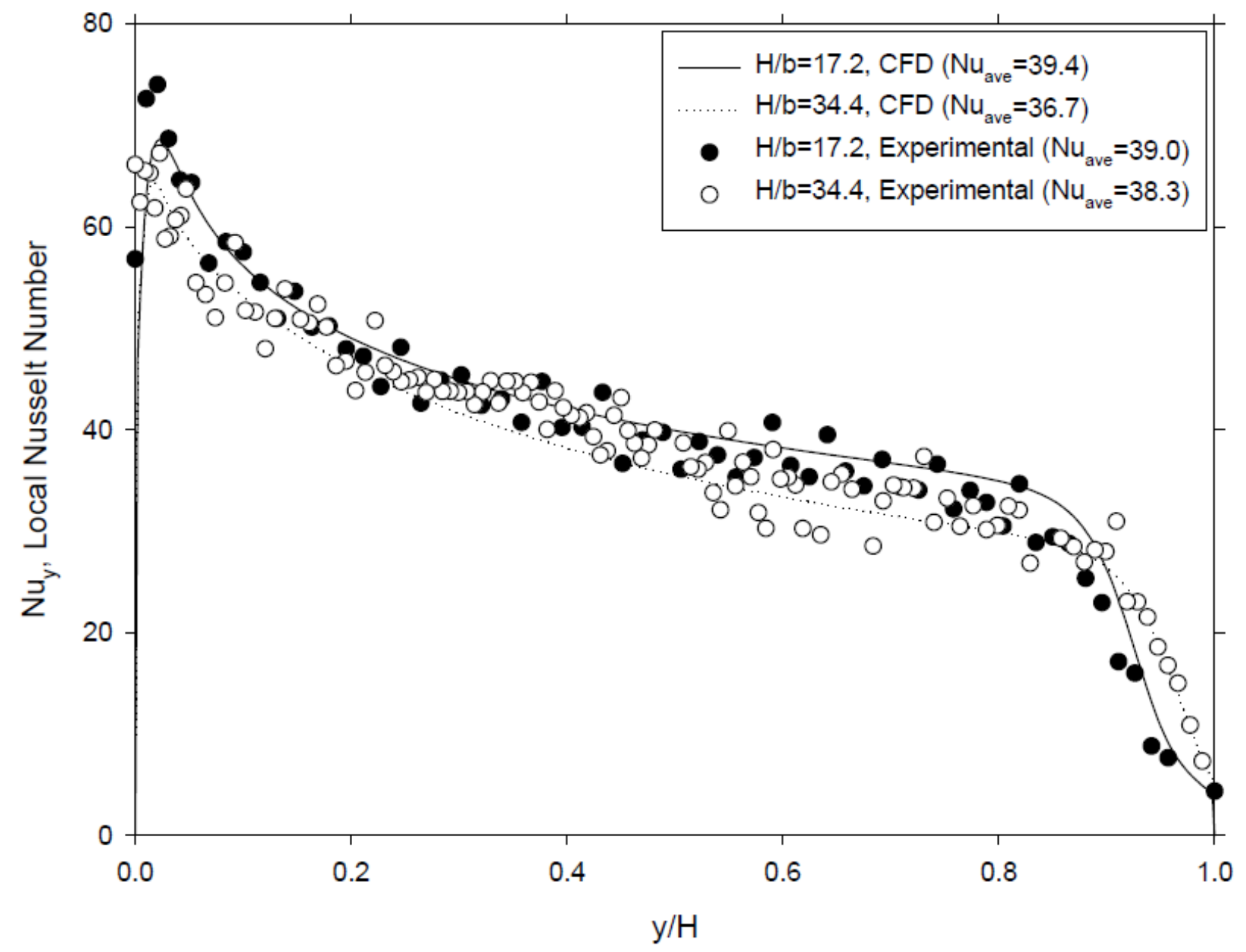

Figure 5.4 Local Nusselt number of high permeability screen with two different aspect ratios

It is interesting to consider why the convective heat transfer is generally reduced when the screen is moved closer to the window. Figure 5.5 shows a plot of the vertical component of the velocity across 
the cavity at $\mathrm{y} / \mathrm{H}=0.5$ from the CFD solution. While the velocity is the same for both cases up to the maximum at $x=0.4 \mathrm{~cm}$, it is significantly reduced thereafter for the case with $b=1 \mathrm{~cm}$. It can also be seen that for this case, the velocity approaches zero in the immediate vicinity of the screen, but subsequently increases up to the maximum at $x=1.4 \mathrm{~cm}$, which is outside of the window cavity. So, the screen is clearly inside the boundary layer and impeding the flow. Additionally, viscous drag at the screen interface is further inhibiting flow inside the cavity. The no slip condition at the solid component of the screen produces a shear stress that reduces the flow rate of air and further reduces convective heat transfer.

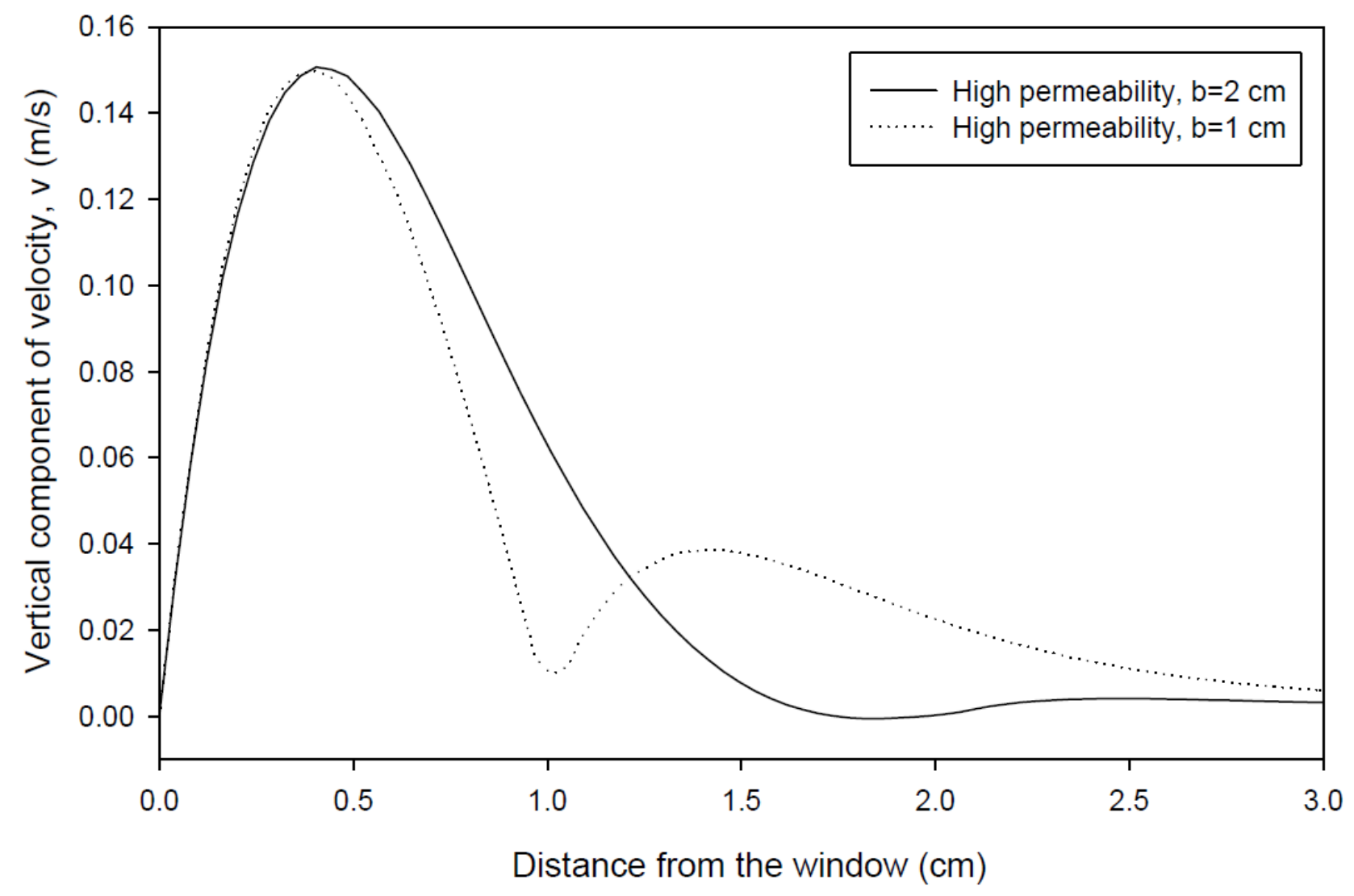

Figure 5.5 Vertical component of velocity at $\mathrm{y} / \mathrm{H}=0.5$ for case (c) and (d) 


\subsection{Average Nusselt number results}

Table 5.1 shows a summary of the average Nusselt number results for the experiment and CFD simulation. It can be seen that there is consistently good agreement in these results, with the average difference being less than 3\%. As discussed in Chapter 4, the high permeability screen corresponds most closely to a typical residential insect screen. These results show a typical insect screen reduces convection at the indoor glazing by about $10 \%$. If the screen is mounted closer to the window the screen causes slightly more reduction in the convective heat transfer. As discussed in the previous section, this is likely caused by two factors. The viscous drag of the screen on the buoyancy induced flow near the window surface and the screen being inside the boundary layer and impeding the flow.

Table 5.1 also shows results for a screen with a permeability that is much lower than is typically found in residential applications. It was found that this screen reduced the convection by about $23 \%$. Although the permeability of this screen may not correspond to a real-world window application, this results will be of value for establishing similarity parameters for this problem. Such parameters allow the generalization of the results for a wide range of thermal conditions and window geometries.

Table 5.1 Measured and numerical average Nusselt numbers

\begin{tabular}{|c|c|c|c|c|}
\hline Case & $\mathrm{H} / \mathrm{b}$ & $\begin{array}{c}\mathrm{Nu}_{\text {ave }} \\
\text { Experiment }\end{array}$ & $\begin{array}{c}\mathrm{Nu}_{\text {ave }} \\
\mathrm{CFD}\end{array}$ & $\begin{array}{c}\text { Reduction compared } \\
\text { to no screen } \\
\text { experiment }\end{array}$ \\
\hline \hline No Screen & 17.2 & 42.7 & 43.3 & -- \\
\hline High Permeability & 17.2 & 39.0 & 39.4 & $8.7 \%$ \\
\hline High Permeability & 34.4 & 38.3 & 36.7 & $10.3 \%$ \\
\hline Low Permeability & 17.2 & 32.1 & 33.4 & $24.8 \%$ \\
\hline
\end{tabular}


As discussed in Chapter 1, a scale analysis on the current problem has been performed by Naylor et al. (2012) which shows that a key dimensionless parameter for this problem is:

$$
G r^{1 / 2} D a^{*}=\left[\frac{g \beta\left(T_{w}-T_{\infty}\right) \rho^{2} H^{3}}{\mu^{2}}\right]^{1 / 2} \frac{K}{H t}
$$

Where Gr is the Grashof number based on the height of the hot plate and Da* is a modified Darcy number. This parameter assumes both the heated surface and screen are the same height.

Figure 5.6 shows the experimental and CFD predicted average convective heat transfer rates for different $\mathrm{Gr}^{1 / 2} \mathrm{Da} *$ values for a Rayleigh number of $10^{8}$. In this figure the ordinate axis is the average Nusselt number divided by the Rayleigh number to the power of $1 / 4$. For laminar free convection from an isolated vertical plate, the average Nusselt number is proportional to $\mathrm{C} \times \mathrm{Ra}^{1 / 4}$. So, by dividing by $\mathrm{Ra}^{1 / 4}$, the upper asymptote becomes a constant value $(C \approx 0.52)$ (Ostrach, 1953). The data used for the dashed curve was obtained using CFD in a window cavity with an aspect ratio $\mathrm{H} / \mathrm{b}=25$ by Naylor et al. (2012). It should be mentioned that the parameters for the current experiment were not identical to those in the CFD study $\left(\mathrm{Ra}_{\mathrm{H}}=5 \times 10^{7}, \mathrm{H} / \mathrm{b}=17.2\right)$. But, they are sufficiently close to make a meaningful comparison.

It can be seen that the current measurements are in good agreement with the CFD predictions. Both sets of data have the same trend and approach the same upper asymptote. For large values of $\mathrm{Gr}^{1 / 2} \mathrm{Da}^{*}$, the convective heat transfer is close to that of an isolated plate. The experimental measurement for the no screen case is also shown in Figure 5.6, plotted at $\mathrm{Gr}^{1 / 2} \mathrm{Da}^{*}=100$. This data point actually corresponds to $\mathrm{Gr}^{1 / 2} \mathrm{Da}^{*} \rightarrow \infty$ since the permeability is infinite, but as can be seen in Figure 5.6 , values at $\mathrm{Gr}^{1 / 2} \mathrm{Da}^{*}>100$ have already approached the no screen asymptote and behave as if there was no permeable barrier. As $\mathrm{Gr}^{1 / 2} \mathrm{Da}^{*}$ decreases, the flow resistance of the screen reduces the convective heat transfer. For the current experiment, the low permeability screen case corresponds to $\mathrm{Gr}^{1 / 2} \mathrm{Da}^{*}=0.1$. In this case the average Nusselt number is reduced by about $25 \%$ relative to the no screen case. 
Values of $\mathrm{Gr}^{1 / 2} \mathrm{Da}$ * lower than 0.1 are not likely to be found on fenestration with insect screens, with the exception of certain regions with very small insects. However, they can be found on other applications where a porous barrier limits natural convection from a vertical surface. This scenario is especially likely to be encountered on short vertical surfaces, or when the porous barrier is highly impermeable.

From a building science perspective, it is important to note that most residential window applications have a $\mathrm{Gr}^{1 / 2} \mathrm{Da}^{*}$ value close to 0.8 , as in the current high permeability screen case. Based on the current experiment, it can be concluded that typical insect screens have only a minor effect on the average convective heat transfer from the inner glazing. This is a somewhat surprising result. As mentioned in the literature review, Brunger et al. (1999) found that an insect screen reduced the U-value of a double glazed window by $15 \%$. This reduction is caused by a combination of the reduction in the convection and the shielding effect of the screen for long wave radiation. These two effects were not measured separately by Brunger et al. (1999). So, the apparent disagreement in the results of the current experiment could be because radiation shielding plays a large role. The MZI measures only convective heat transfer and the radiative shielding effect of the screen was not measured. 


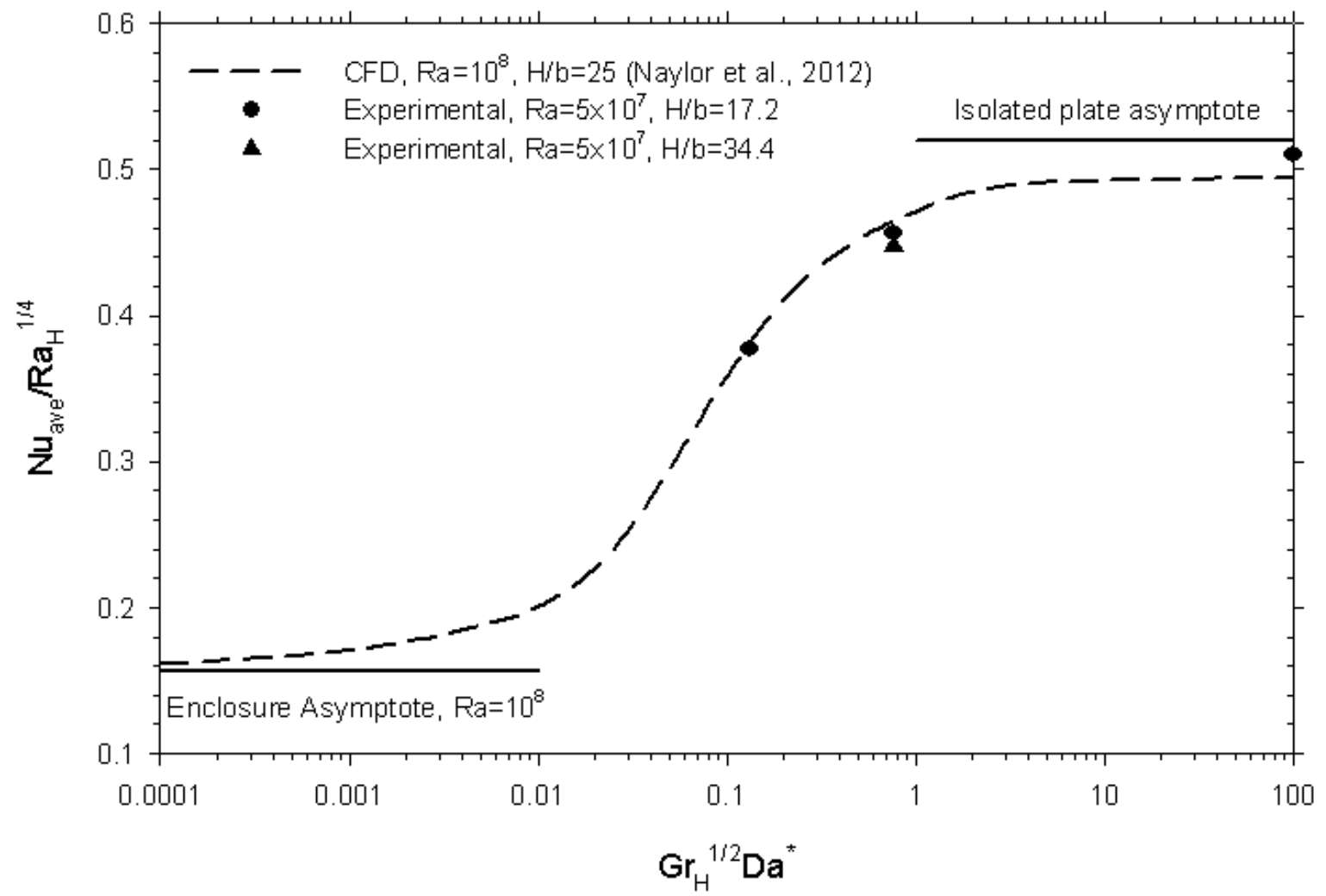

Figure 5.6 Dimensionless parameter illustrating the difference in convective heat transfer between the two limits and showing the where cases (b), (c) and (d) fit in the scale

\subsection{Local screen temperature results}

The measured dimensionless screen temperature is presented in Figure 5.7. The dimensionless screen temperature is defined as:

$$
T^{*}=\frac{T_{\text {screen }}-T_{\infty}}{T_{\text {plate }}-T_{\infty}}
$$

These results are important for modellers because screen temperature has a strong influence on the long wave radiation heat exchange between the window, screen and ambient. It is important to accurately predict the screen temperature in both simplified and advanced CFD modelling in order to predict the total heat transfer at the window surface. 
Near the bottom of the screen, it can be observed that the temperature in both the low permeability and high permeability $(H / b=17.2)$ is higher than for the high permeability $(H / b=34.4)$ case. This makes sense. Placing the screen closer to the boundary layer tends to raise its temperature, whereas placing it farther away puts it outside the boundary layer and therefore lowers its temperature.

However, near the top half of the screen, it can be seen that the temperatures in both the low permeability and high permeability $(H / b=17.2)$ cases are higher than for the $H / b=34.4$ case. For the $\mathrm{H} / \mathrm{b}=34.4$ case, this is intuitive; the boundary layer is thicker at the top and the screen is inside of it. For the low permeability case, it appears the flow cannot exit easily at the top, and so it has to escape through a larger area of the screen. Hence, temperatures in this area are higher as compared to the higher permeability screen. This can be seen more clearly in Figure 5.1.

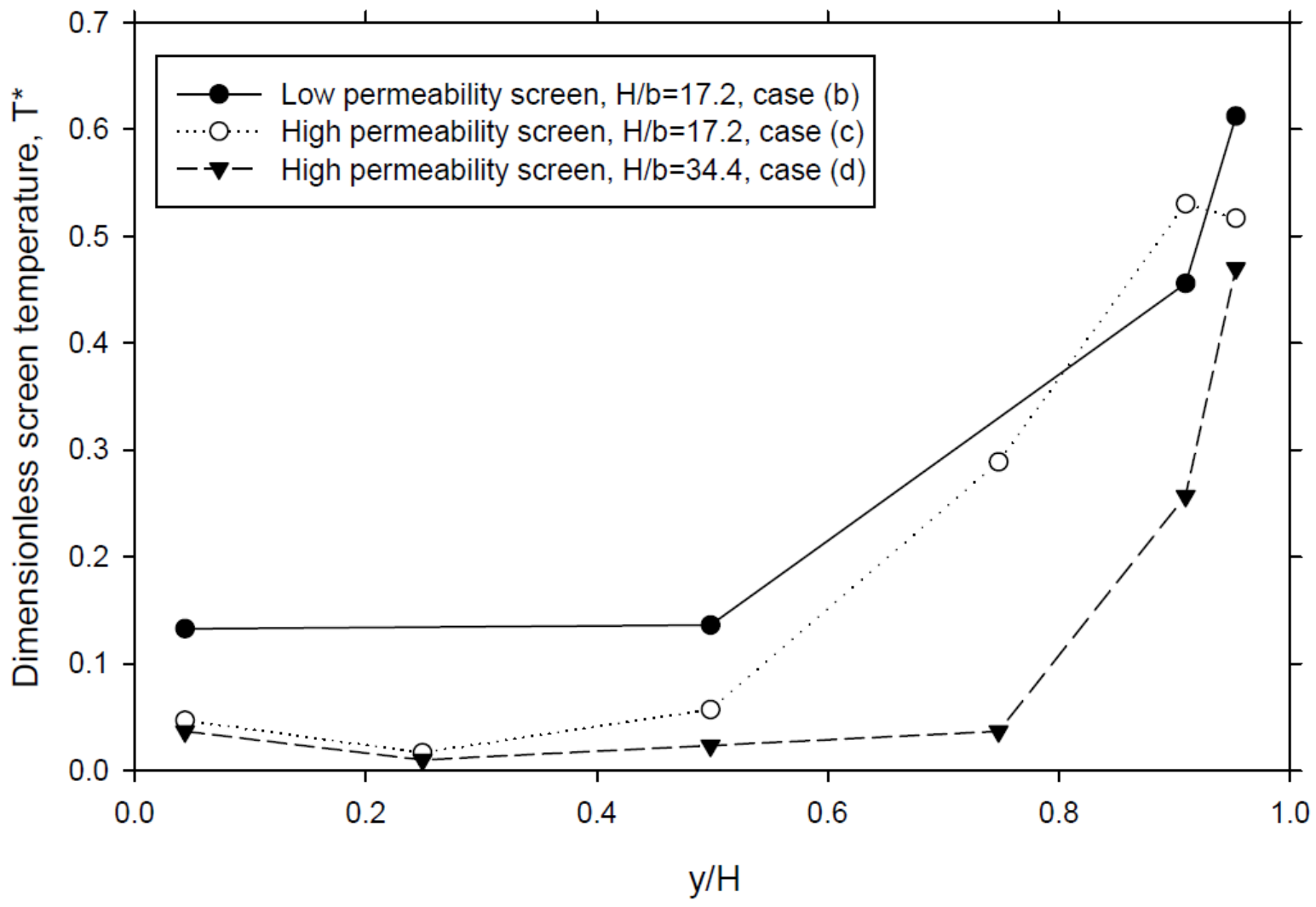

Figure 5.7 Dimensionless screen temperature for cases (b), (c) and (d) 


\section{Chapter 6: Conclusions and recommendations}

\subsection{Conclusions}

The results of an interferometric study on the effect of two different insect screens on an idealized window have been presented. The effect of aspect ratio was also investigated as well as a no screen case for comparison purposes. Hence, four different cases were investigated. Finite fringe interferograms were obtained for all four cases to measure the local and average convective heat transfer rates. Infinite fringe interferograms were obtained for visualization of the temperature field inside and outside the cavity and thermocouples were placed on the screen to measure its temperature. Lastly, the experimental results were compared to a preliminary numerical study of the same problem, and shows good agreement. The conclusions are as follows:

I. The results for the no screen case show good agreement with the analytical isolated flat plate solution from Ostrach (1953), with differences at the top and bottom likely being due to the flow obstruction resulting from the spacers.

II. The low permeability screen affected the convective heat transfer rates considerably. Based on the temperature field from the infinite fringe interferograms, the flow resistance of the screen seems to force the air to exit the cavity over a larger area, compared to the high permeability screen. This significantly reduces heat transfer at the top of the window, while heat transfer rates at the bottom were not considerably affected by the low permeability screen. Reduced convective heat transfer at the bottom of a cold glazing can increase the potential for condensation. 
III. The high permeability screen $(H / b=17.2)$ caused a minor reduction in the convective heat transfer rates, compared to the no screen case. The similarity parameter from Naylor et al. (2012) for this case is similar to that of a typical residential window, suggesting the reduction in convective heat transfer would also be present there as well.

IV. Moving the screen closer to the window resulted in marginally lower convective heat transfer rates compared to the larger spacing. The smaller spacer seems to obstruct the flow less than the larger one; therefore, heat transfer rates at the very top are slightly higher. However, moving the screen closer results in lower heat transfer rates in the center glass region of the window. Viscous drag at the screen surface slows convective flow. Additionally, a larger portion of the screen is inside the boundary layer, further impeding the flow. For a taller window, the effect of the spacers would be reduced, while the effect in the center region would dominate.

V. As discussed by Teitel (2011), correlations of screen permeability based on openness alone can have large margins of error. The screens used for this experiment were measured experimentally in the linear regime and are reported with a margin of error of $\pm 7 \%$.

VI. The openness ratio of the high permeability screen is only $50 \%$ higher than the low permeability one, but its total resistance to flow is 6 times lower, a substantial difference. Low permeability screens such as the one used in this experiment are used in some regions that require blocking smaller particles. Its effect on convection can be significant and should be accounted for. 


\subsection{Recommendations}

The following recommendations are made for future studies:

I. The experimental data from the present study can be used to validate numerical models, which can then be used to develop empirical correlations (such as the one developed by Naylor et al., 2012) to predict the convective heat transfer rates for a variety of insect screens and window configurations.

II. More experimental data is needed at Rayleigh numbers corresponding to turbulent flow, since many real window applications are exposed to that condition. Additionally, more data is needed for cavities with higher aspect ratios, since most window applications have significantly higher aspect ratios than that those in the current experiment.

III. More experimental data corresponding to very low $\mathrm{Gr}^{1 / 2} \mathrm{Da} *$ values might also be necessary for validating numerical models. 


\section{Appendix A: Specification of instruments}

\section{A.1 Instrument specifications}

Tables A.1 to A.4 show the specifications of the thermocouple reader, differential pressure transducer, rotameter and digital multimeter, respectively.

For specifications of the beam splitters, flat mirrors, spherical and parabolic mirrors, optical windows and digital camera, refer to (Roeleveld, 2013).

Table A.1 Thermocouple reader specifications

\begin{tabular}{|c|c|}
\hline Make and model & Barnant 100 Model No. 600-2820 \\
\hline Accuracy & $\pm 0.1 \%$ of reading \\
\hline Resolution & $0.1^{\circ} \mathrm{C}$ \\
\hline
\end{tabular}

Table A.2 Differential pressure transducer specifications

\begin{tabular}{|c|c|}
\hline Make and model & MKS 226A-U2K-BB-BB-K-U2-A-0 \\
\hline Range & $0.02 \mathrm{kPa}$ \\
\hline Accuracy & $\pm 0.3 \%$ of Full Scale $(0.06 \mathrm{~Pa})$ \\
\hline Input & $\pm 15 \mathrm{vdc}$ \\
\hline Output range (linear with pressure) & 0 to $+10 \mathrm{vdc}$ \\
\hline Fittings & $1 / 4^{\prime \prime}$ tube \\
\hline Resolution & $0.01 \%$ of Full Scale $(0.002 \mathrm{~Pa})$ \\
\hline
\end{tabular}

Table A.3 Rotameter specifications

\begin{tabular}{|c|c|}
\hline Make and model & Dwyer Instruments Inc. RMC-103 \\
\hline Range & $20-200$ SCFH Air \\
\hline Accuracy & $\pm 2 \%$ of Full Scale \\
\hline Resolution & 5 SCFH \\
\hline
\end{tabular}

Table A.4 Digital multimeter specifications

\begin{tabular}{|c|c|}
\hline Make and model & Fluke 87 V \\
\hline Resolution (at 6 V range) & $0.001 \mathrm{~V}$ \\
\hline Accuracy (at 6 V range) & $\pm 0.05 \%$ \\
\hline
\end{tabular}


Appendix B: Mechanical drawings of selected parts

\section{B.1 Experimental model}

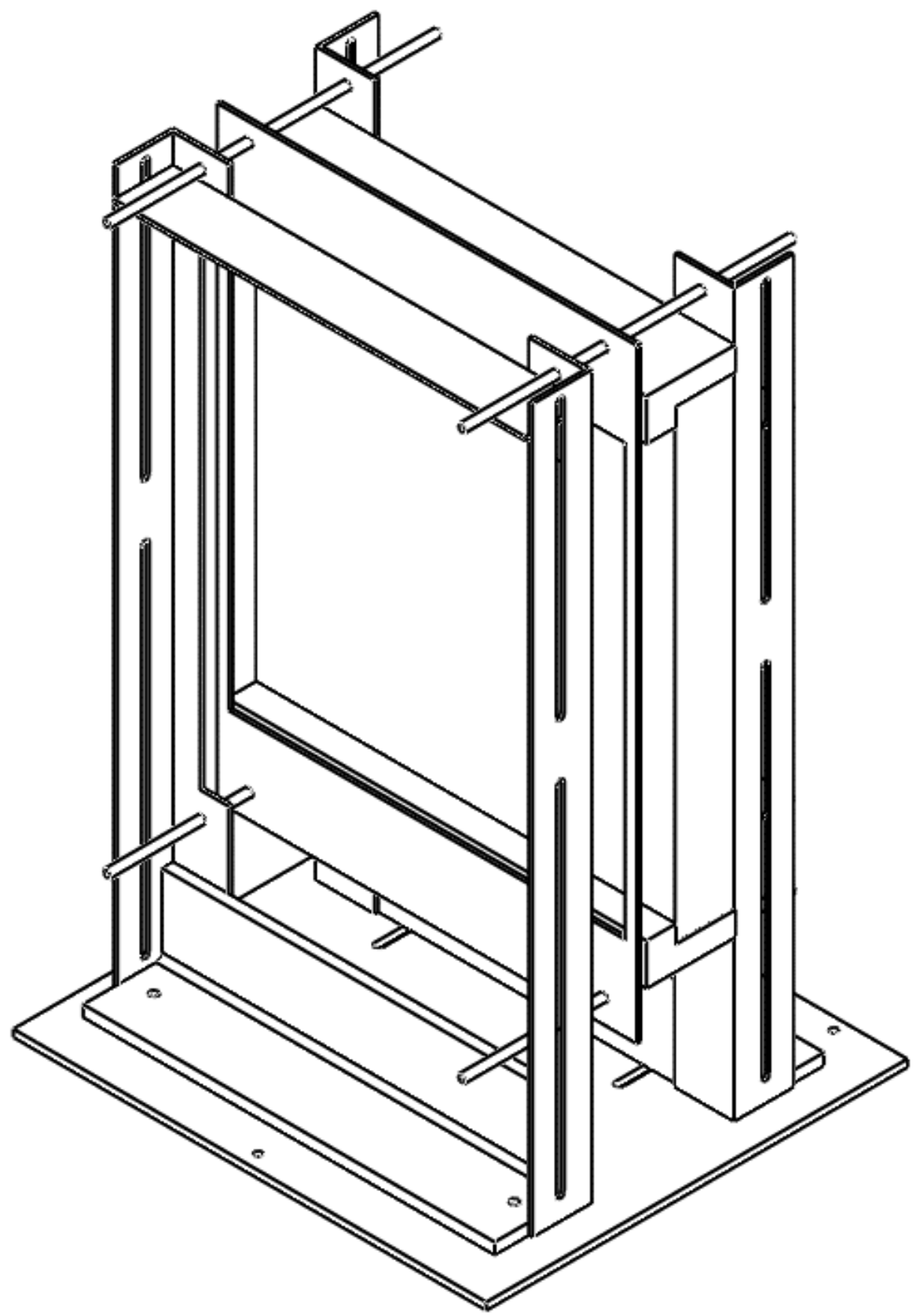

Figure B.1 Isometric view of assembled model 


\section{B.2 Optical window components}

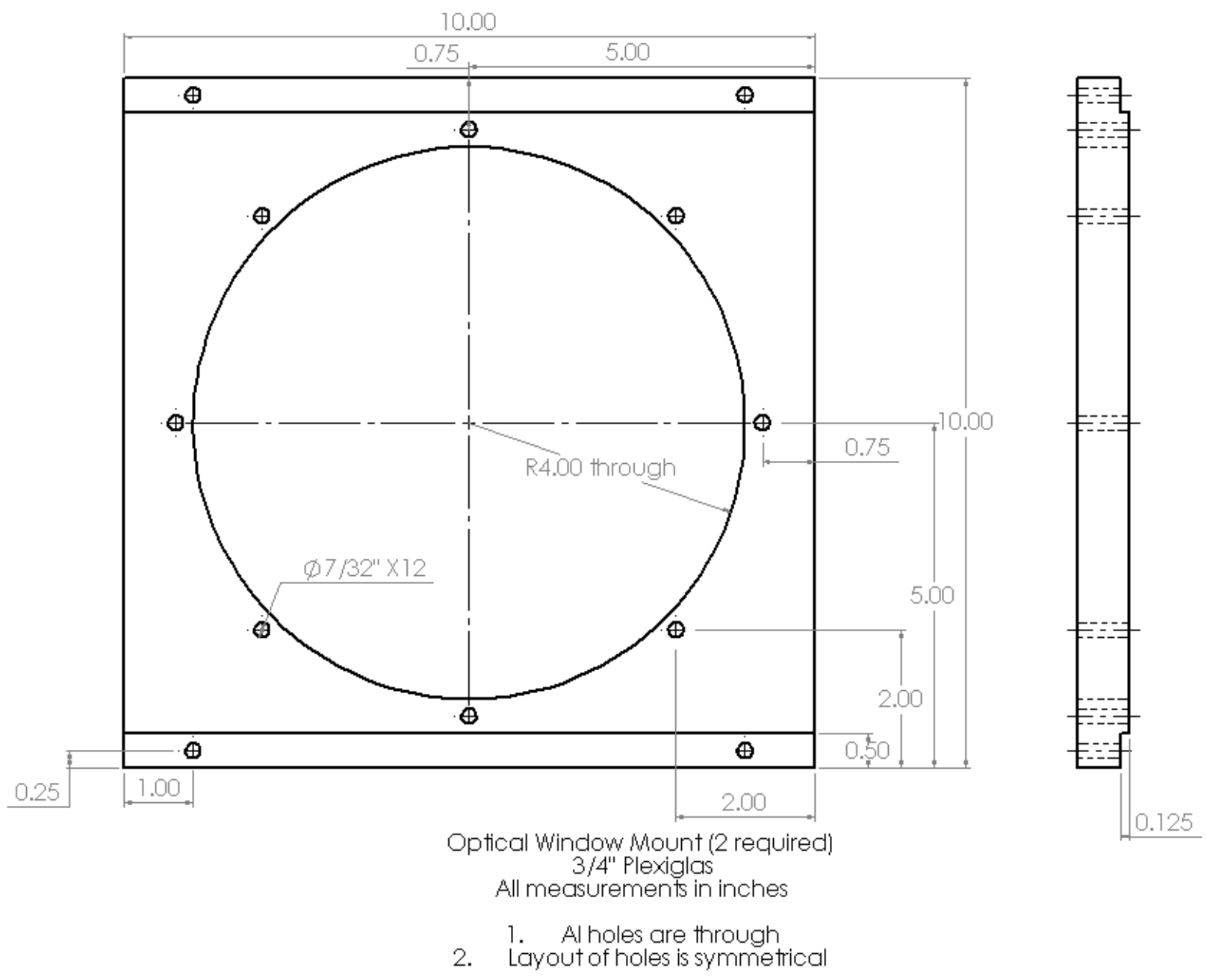

Figure B.2 Dimensions of optical window mount (Roeleveld, 2013) 

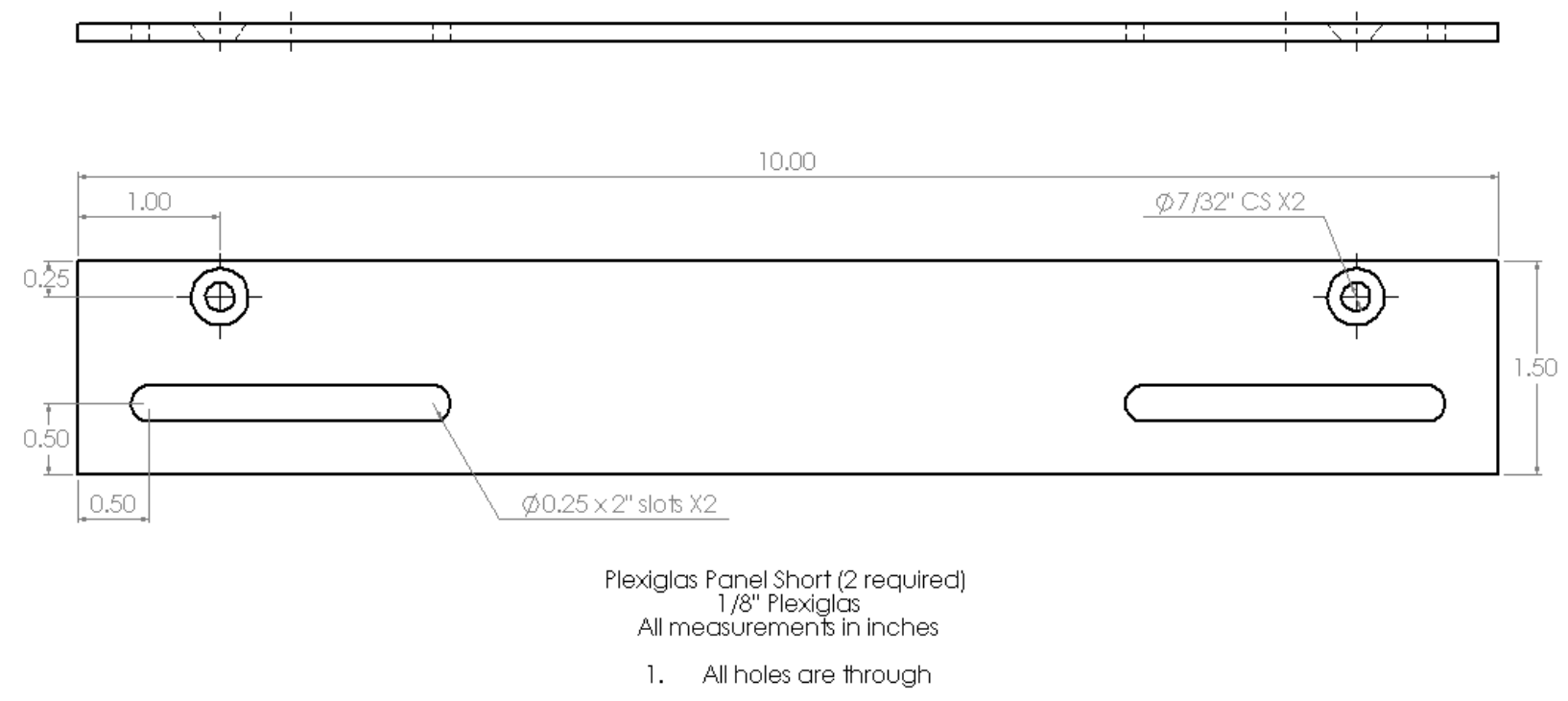

Figure B.3 Sketch and corresponding dimensions of top Plexiglass attachment for the optical mount (Roeleveld, 2013)

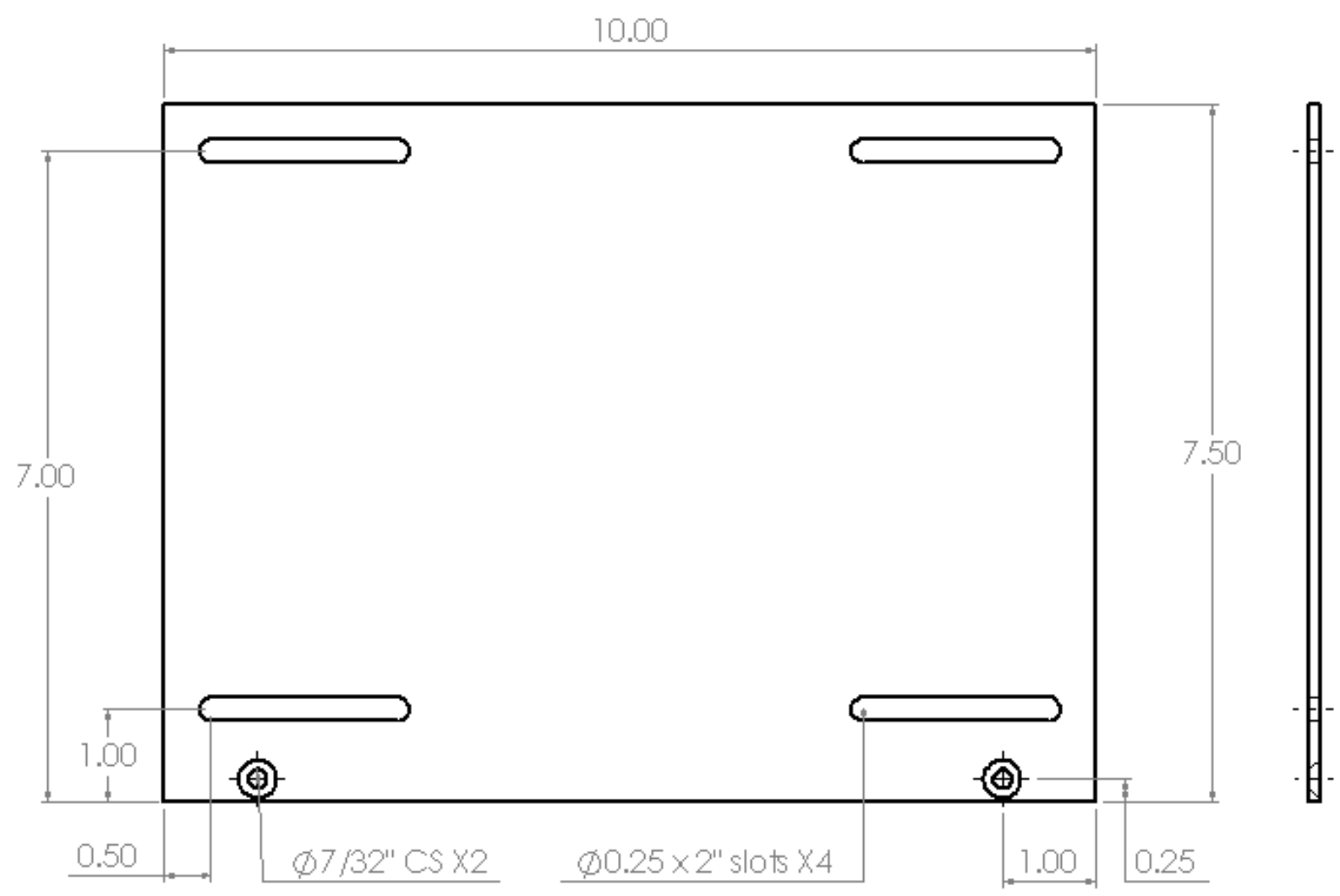

Plexiglas Panel Long (2 required)

$1 / 8$ " Plexiglas

All measurements in inches

1. All holes are through

Figure B.4 Sketch and corresponding dimensions of bottom Plexiglass attachment for the optical mount (Roeleveld, 2013) 


\section{Appendix C: Experimental procedure}

\section{C.1 Sample experimental checklist}

Screen type: Screen Spacing:

Picture: Top / Bottom $T_{\infty}$ :

Date:

Experimental procedure:

1. Level the optical bench via the air bags

2. Collimate the beam

3. Align the optics (Rough alignment using paper cutouts to ensure beam is centered on optics)

4. Prepare the experimental model

a. Adjust window to screen spacing and check with gauge blocks. Make sure screen frame is aligned in beam direction

b. Install optical windows and align them with each other

c. Turn on electric heaters and allow sufficient time to reach desired temperature. This can take up to 2 hours, so continue up until step 9.c

d. Make sure Thermocouples are plugged in

e. Turn on thermocouple readers and computer

5. Place experimental model in the test beam

6. Block the reference beam

a. Adjust the height of the table so optical windows are aligned with optics

b. Align the experimental model using the plumb bob and level

c. Place eddy tent over experimental model

d. Move the table and model to roughly align the test beam by using the reflections off the aluminum plate 
e. Align the test beam more precisely by using a white card beyond the experimental model, inclined to the beam to magnify the locating pins and reflections off the aluminum plate

f. After these steps do not touch $\mathrm{BS}_{1}, \mathrm{M}_{\text {test }}$, or experimental model

7. Unblock the reference beam and focus near and far field

a. Place an object in the far field between the parabolic mirror and $\mathrm{BS}_{1}$

b. Place an object in the near field between $\mathrm{BS}_{2}$ and the spherical mirror (which is covered with a white card to view shadows)

c. Using $\mathrm{M}_{\mathrm{ref}}$ and $\mathrm{BS}_{2}$ focus the two objects on the white card. This is an iterative process that may take several adjustments

d. Once both objects are in focus, carefully adjust $\mathrm{BS}_{2}$ until the desired fringe pattern is achieved

e. After these steps do not touch $\mathrm{M}_{\text {ref }}$ or $\mathrm{BS}_{2}$

8. Camera positioning

a. Remove the white card from in front of the spherical mirror

b. Adjust the camera mirror so that it reflects the image from the spherical mirror $90^{\circ}$ towards the camera and so that the shadow of the mirror is in the center line of the optics (on the same plane as the center of the test and reference beam)

c. Measure the height of the camera mirror (relative to the floor)

d. Measure the height of the shadow of the camera mirror on the wall (relative to the floor)

e. Adjust camera mirror so these two are the same height

f. Place camera in position parallel with the output of the camera mirror

g. Maximize the area on the frosted screen of the camera and level the camera 
h. Plug camera into computer and level camera if necessary

a. Turn off laser and focus the camera on a light point source placed at $1 / 2$ the width of the experimental model

b. Turn laser back on. It is crucial that the camera, optics, and experimental model are not moved beyond this point

9. Taking pictures

a. Start Capture One Pro on the computer. Ensure the capture name and job name are set and that the camera is using ISO 50

b. Block the reference beam again and place the horizontal reference into the beam. Put the NDX4 neutral density filter in place in front of the laser. Slide digital back over on camera, close the shutter and cock the camera. Turn off the lights (including computer monitor) and take a scale photo of the model. Check picture.

c. Wait until desired plate temperature is reached. Unblock the reference beam, ensure the model is still aligned with the desired fringe pattern. Check that finite fringes bend up on hot surface (they bend down on the camera as the image is flipped vertically)

d. Cock camera, turn lights off, move into position away from the model, wait five minutes to allow air in room to settle. Take picture of the heated model. Turn lights on and check picture.

e. Record data from the thermocouples (plate and ambient) and room pressure:
TC
TC
$\mathrm{TC}_{\text {plate_3}:}$
$\mathrm{TC}_{\text {plate_4 }}$ :
$\mathrm{TC}_{\infty_{-} 1}:$ $\mathrm{TC}_{\infty} 2_{2}:$
$\mathrm{T}_{\text {barometer: }}$ Uncorrected pressure:

f. Repeat step d to record additional pictures

g. Set interferometer to infinite fringe mode, repeat step $d$.

10. Post processing 
a. Set image settings in Capture Pro

1) Starting with the Quick Tab: make sure the following are set

2) ICC Profile - Phase One P 45 B\&W

3) Curve - Linear Response

4) Mode-Custom

5) Kelvin $-1155 \mathrm{~K}$

6) Tint -0

7) The Exposure Tab: leave all settings at 0

8) The Lens Tab: do not use any lens correction

9) The Details Tab: Sharpening can be ignored as it will be disabled. Leave the Noise Reduction settings at default

10) Luminance -25

11) Color -40

12) The Output Tab: Make sure the sharpening tick box is checked to disabled and the ICC profile is set to Embedded Camera Profile. Set the output name and click the process button. The picture is exported as an 8 bit TIFF format.

13) Open the picture file in Adobe Photoshop and convert the photo to grayscale (go to Image toolbar-mode-grayscale). Re-save the file. 


\section{Appendix D: CFD model}

\section{D.1 Introduction}

SolidWorks Flow Simulation, an engineering design package oriented for the non-expert CFD user, was used to aid in the design of the experimental model. To facilitate use by the non-expert, the complexity of the user inputs has been reduced and many of the solution controls have been hidden from the user. The use of an embedded grid approach further simplifies the mesh generation procedure, but can sometimes reduce the accuracy of the CFD solution, compared to a body-fitted mesh. Hence, while the results presented here might not be as accurate as those from a research grade CFD package, they can still be used to qualitatively analyze each case and compare them to the experimental results, as well as to aid in the design of the experimental model.

SolidWorks Flow Simulation solves the partial differential equations for mass (continuity), momentum (Navier-Stokes) and energy using the control volume method to convert the partial differential equations to a set of linear algebraic equations that are solved iteratively. Further details about SolidWorks Flow Simulation can be found in the technical reference (SolidWorks Flow Simulation Technical Reference, 2010).

The problem was modelled in 2D, steady state, with laminar flow and using air with variable properties. The screen was modelled as a porous medium and the permeability was set using a table look-up. The permeability of the screen was set as isotropic.

\section{D2. Computation domain and solution parameters}

A sample mesh for the $2 \mathrm{~cm}$ gap, high permeability screen is shown below in Figure D.2. A total of $450 \times 10^{3}$ control volumes were used for this particular case, after refinement. The grid was tested by 
increasing the total number of elements in the initial mesh until the heat transfer rates in the window remained constant.

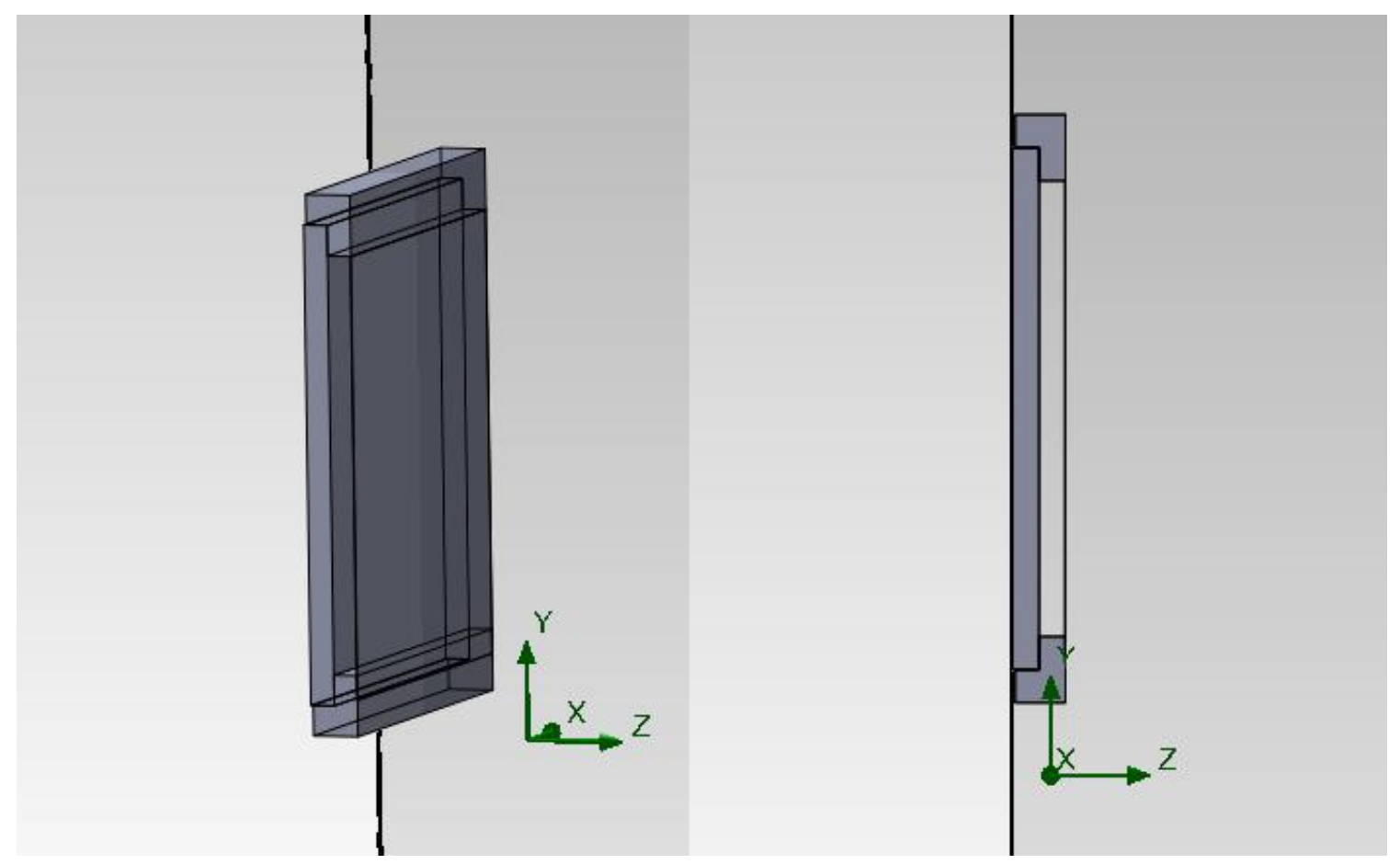

Figure D.1 SolidWorks model showing the hot plate (left), insulating spacers (top and bottom) and insect screen (right)

\section{D3. Comparisons with experimental results}

Below, Figures D.3 to D.6 show the temperature field of the experimental model compared to the CFD predictions. There is generally good agreement, but it should be noted that infinite fringe interferograms are for visualization purposes and the isotherms might not always coincide with the numerical solution. 


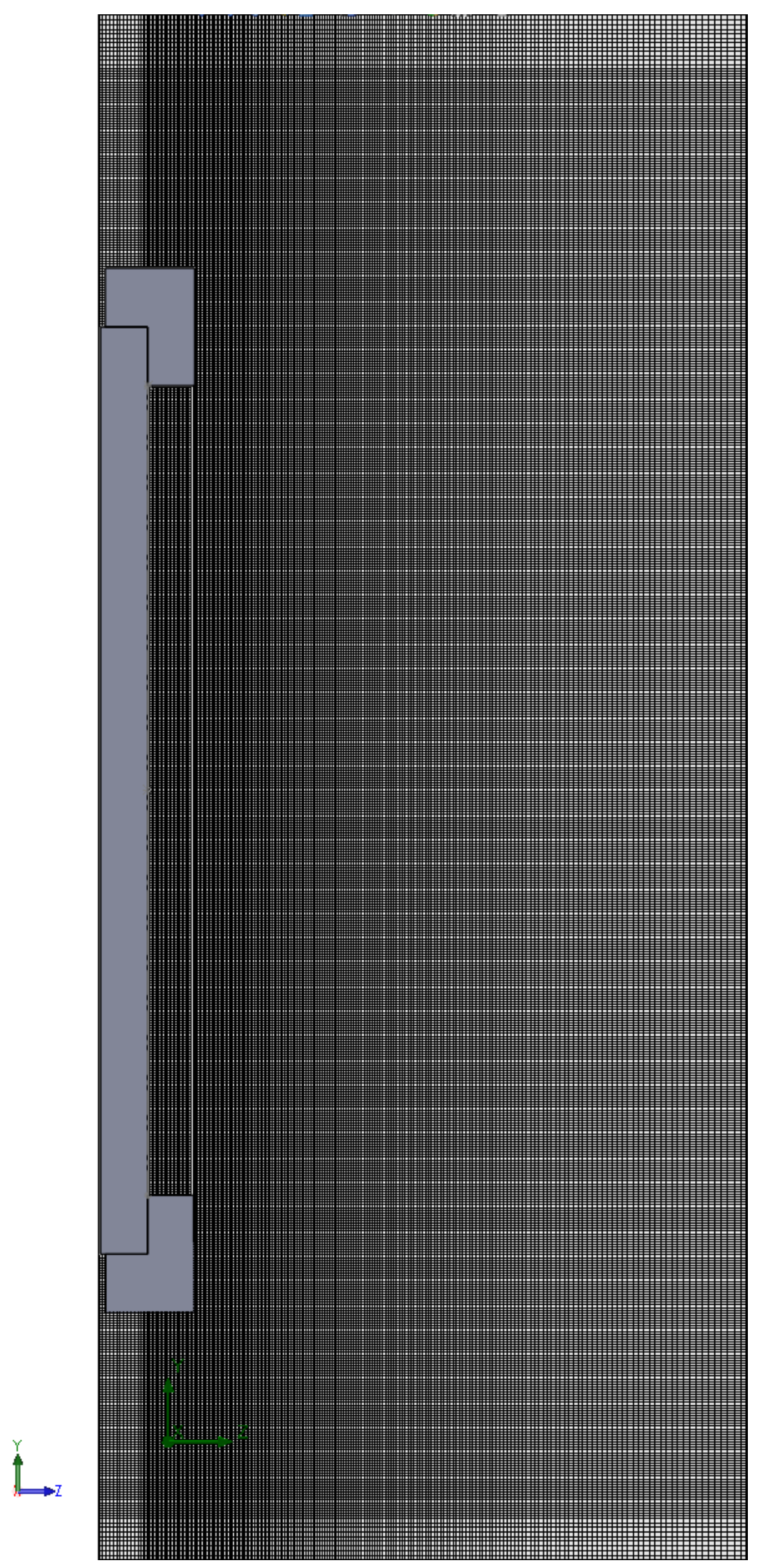

Figure D.2 Sample mesh used for high permeability screen $H / b=17.2$ case 


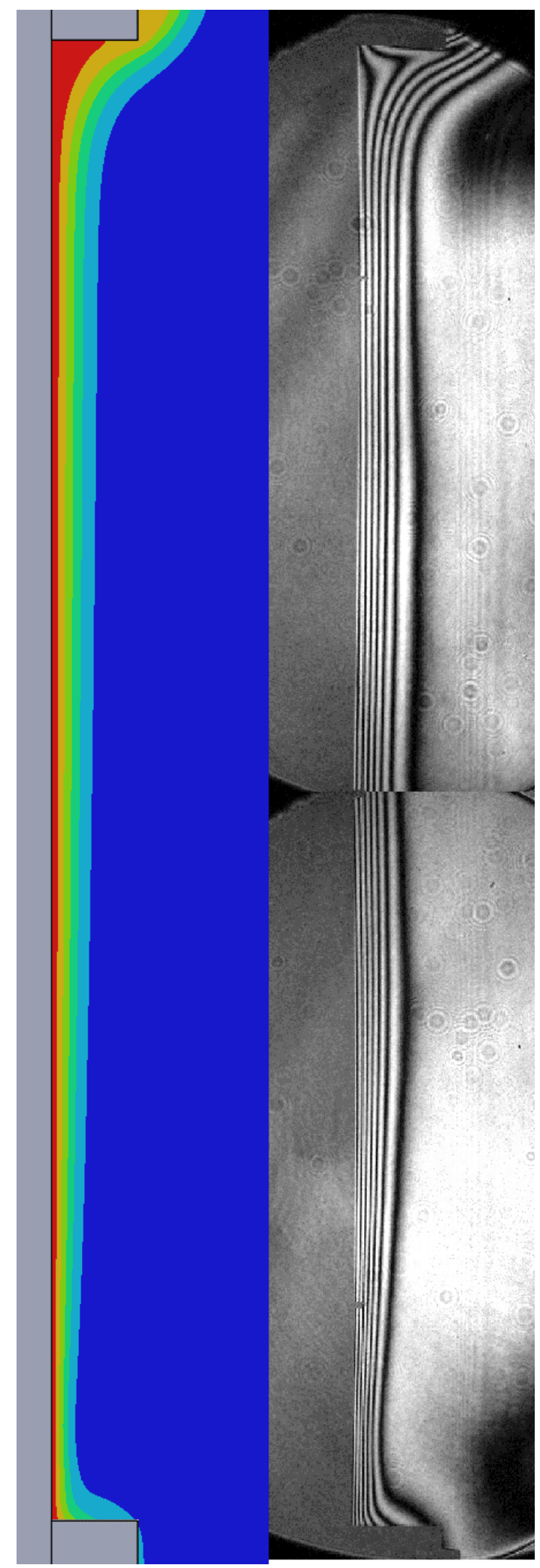

Figure D.3 Temperature contour of CFD model compared to experimental results for no screen case

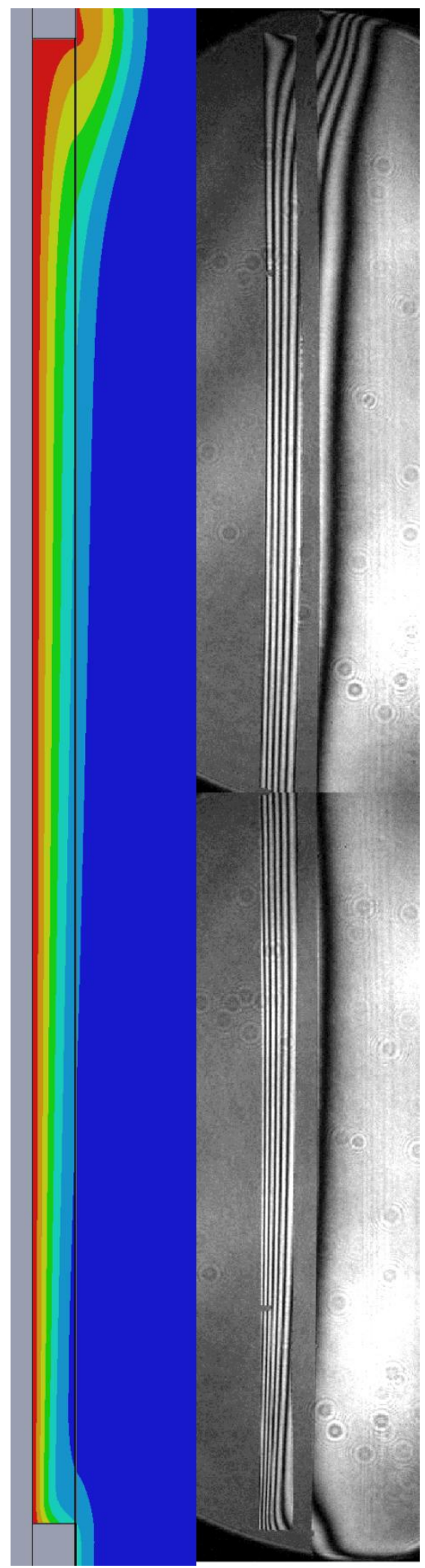

Figure D.4 Temperature contour of CFD model compared to experimental results for high permeability screen $H / b=34.4$ 


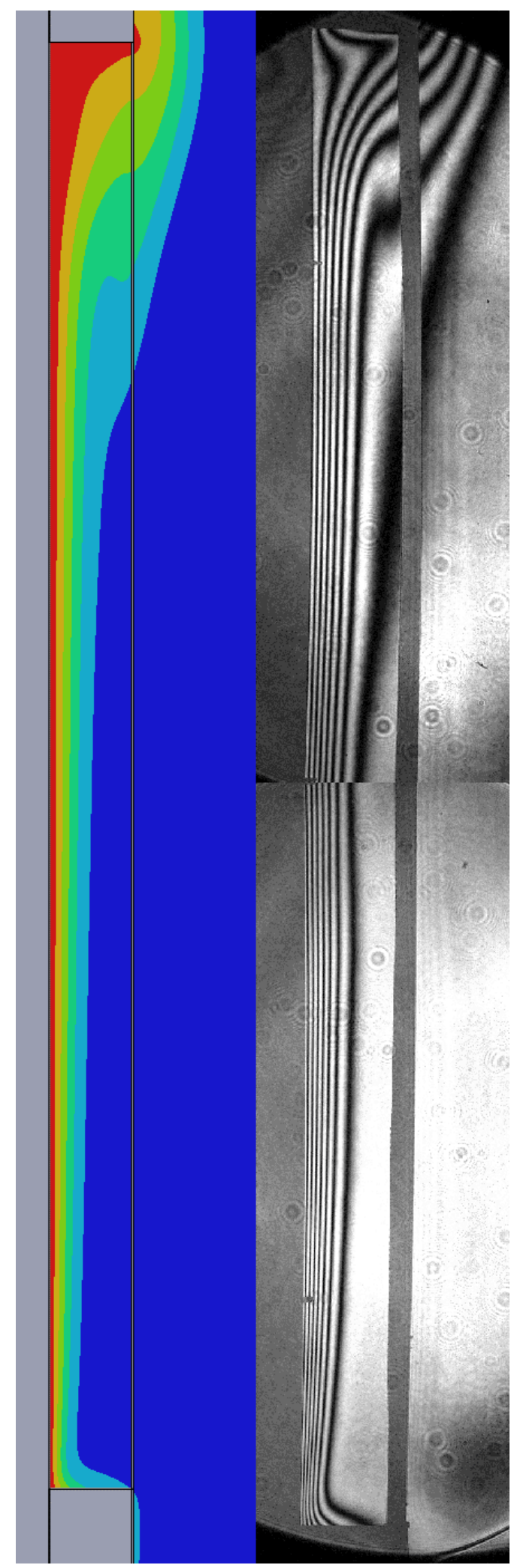

Figure D.5 Temperature contour for CFD model compared to experimental results for high permeability screen $H / b=17.2$

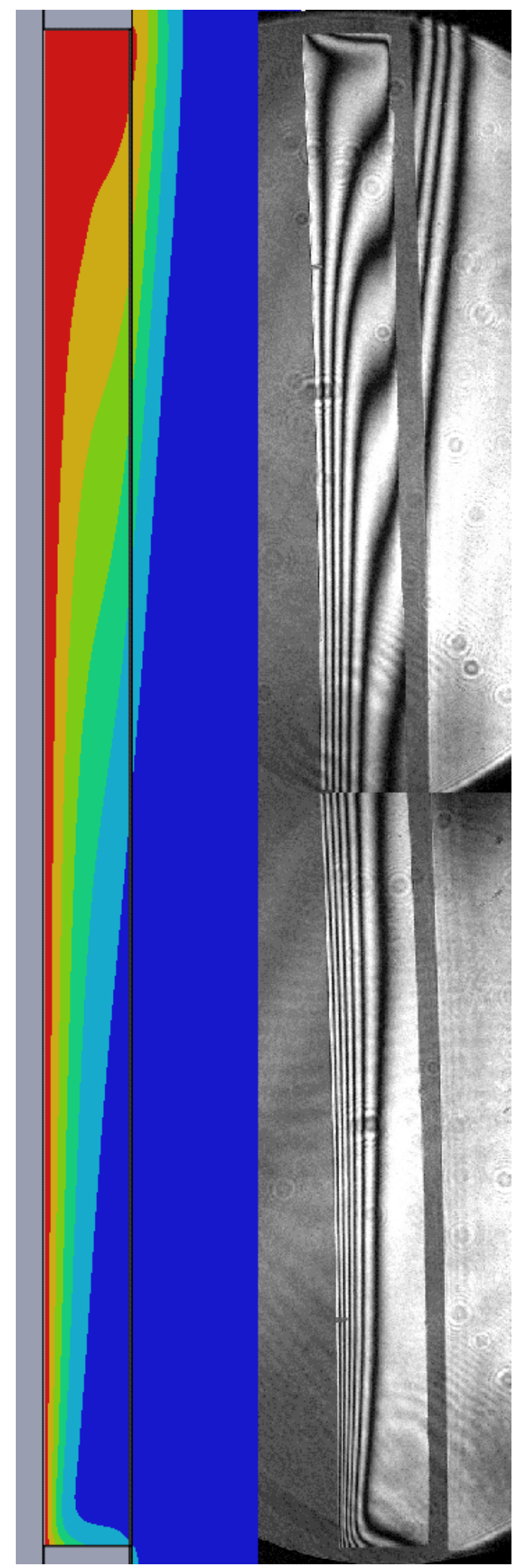

Figure D.6 Temperature contour for CFD model compared to experimental results for low permeability screen $H / b=17.2$ 


\section{Appendix E: Sample calculations}

\section{E.1 Measured data}

A typical set of experimental calculations is provided to demonstrate how the local and average convective heat transfer were obtained. The case analyzed here is for the bottom shot of the polyester high permeability screen with a spacing of $b=2 \mathrm{~cm}$.

The dimensions of the experimental model are given in Table E.5. The thermocouple readings of the hot plate, ambient air, and along the screen are shown below in Table E.6. The Absolute room pressure is also shown in Table E.6, and a sample correction for temperature and gravity is shown below. All other constants required for the sample calculations are shown in Table E.7.

Table E.1 Overall dimensions of window cavity

\begin{tabular}{|c|c|c|c|}
\hline Plate width in beam direction & W & 14 inch & $0.356 \mathrm{~m}$ \\
\hline Plate height & $\mathrm{H}$ & 13.5 inch & $0.344 \mathrm{~m}$ \\
\hline Channel spacing & $\mathrm{b}$ & & $2 \mathrm{~cm}$ \\
\hline
\end{tabular}

Table E.2 Recorded data from the experiment

\begin{tabular}{|c|c|c|}
\hline Hot wall thermocouple 1 & $\mathrm{T}_{\mathrm{hw} 1}$ & $37.9^{\circ} \mathrm{C}$ \\
\hline Hot wall thermocouple 2 & $\mathrm{T}_{\mathrm{hw} 2}$ & $37.6^{\circ} \mathrm{C}$ \\
\hline Hot wall thermocouple 3 & $\mathrm{T}_{\mathrm{hw} 3}$ & $38.1^{\circ} \mathrm{C}$ \\
\hline Hot wall thermocouple 4 & $\mathrm{T}_{\mathrm{hw} 4}$ & $38.1^{\circ} \mathrm{C}$ \\
\hline Ambient air thermocouple 1 & $\mathrm{T}_{\infty 1}$ & $22.65^{\circ} \mathrm{C}$ \\
\hline Ambient air thermocouple 2 & $\mathrm{T}_{\infty 2}$ & $22.9^{\circ} \mathrm{C}$ \\
\hline Barometric pressure (uncorrected) & $\mathrm{P}_{\text {measured }}$ & $760.2 \mathrm{mmHg}$ \\
\hline Barometer temperature & $\mathrm{T}_{\text {barometer }}$ & 21 \\
\hline
\end{tabular}


Table E.3 Constants used in the sample calculations

\begin{tabular}{|c|c|c|}
\hline Gravity & $\mathrm{g}$ & $9.807 \mathrm{~m} / \mathrm{s}^{2}$ \\
\hline Laser wavelength & $\lambda_{0}$ & $632.8 \mathrm{~nm}$ \\
\hline Gladstone-Dale constant & $\mathrm{G}$ & $0.226 \times 10^{-3} \mathrm{~m}^{3} / \mathrm{Kg}$ \\
\hline Gas constant for air & $\mathrm{R}$ & $287 \mathrm{~J} / \mathrm{KgK}$ \\
\hline
\end{tabular}

\section{E.2 Air properties}

\section{Film temperature}

The film temperature is calculated from the hot wall and ambient temperatures and will be used to determine most of the air properties.

$\mathrm{T}_{\mathrm{hw}}=(37.9+37.6+38.1+38.1) / 4=37.9^{\circ} \mathrm{C}$

$\mathrm{T}_{\infty}=(22.6+22.9) / 2=22.7^{\circ} \mathrm{C}$

$\mathrm{T}_{\mathrm{f}}=(37.9+22.7) / 2=30.3^{\circ} \mathrm{C}=303.5 \mathrm{~K}$

\section{Corrected pressure}

The barometric pressure reading needs to be corrected for local gravity and temperature, and converted to SI units. The gravity correction factor for latitude of 43 degrees (in Toronto, Ontario) is $-0.1225 \mathrm{Hg}$ $\mathrm{mm}$ and the temperature correction for 21 degrees Celsius is $-2.26 \mathrm{mmHg}$. These values are added to the pressure reading directly:

$\mathrm{P}=760.2-0.1225-2 \cdot 26=757.81 \mathrm{mmHg}=101033 \mathrm{~Pa}$ 


\section{Volumetric expansion coefficient}

The volumetric expansion coefficient is a function of temperature assuming air is an ideal gas, and is calculated as follows:

$ß=1 / T_{f}=1 / 303.5=3.294 * 10^{-3} \mathrm{~K}^{-1}$

\section{Air density}

The air density is determined using the ideal gas law as follows:

$\rho=P / R T=101033 / 287 * 303.5=1.159 \mathrm{~kg} / \mathrm{m}^{3}$

Dynamic viscosity, thermal conductivity and specific heat

The dynamic viscosity, thermal conductivity and specific heat, as well as their respective uncertainties, were determined by linear interpolation of the data of Touloukian et al. (1975), Touloukian et al. (1970) and Touloukian \& Makita (1970), respectively, Using $\mathrm{T}_{\mathrm{f}}=303.5 \mathrm{~K}$.

$\mu=1.869 \times 10^{-5} \mathrm{~kg} / \mathrm{ms}$

$\mathrm{k}_{\mathrm{f}}=0.02640 \mathrm{~W} / \mathrm{mK}$

$\mathrm{k}_{\mathrm{s}}=0.02695 \mathrm{~W} / \mathrm{mK}$

The specific heat of air was determined using Equation (E.1) from Touloukian and Makita (1970) with $\mathrm{T}=\mathrm{T}_{\mathrm{f}}=303.5 \mathrm{~K}:$

$$
\begin{gathered}
C_{p}=\left(0.2497-7.552 \times 10^{-5} T+1.692 \times 10^{-7} T^{2}-6.461 \times 10^{-11} T^{3}\right) \frac{\mathrm{cal}}{\mathrm{gK}} \\
C_{p}=1006.4 \frac{\mathrm{J}}{\mathrm{kgK}}
\end{gathered}
$$


Prandtl Number

$$
\operatorname{Pr}=\frac{c_{P} \mu}{k_{f}}=\frac{1006.4 * 1.869 \times 10^{-5}}{0.02640}=0.713
$$

\section{E.3 Rayleigh number}

The Rayleigh number based on window height is calculated as follows:

$$
\begin{gathered}
R a=\frac{g \beta\left(T_{s}-T_{\infty}\right) H^{3} \rho^{2} c_{p}}{\mu k_{f}} \\
R a=\frac{9.807 * 3.294 e-3(37.9-22.7) 0.344^{3} * 1.159^{2} * 1006}{1.869 e-5 * 0.2640}=5.48 \times 10^{7}
\end{gathered}
$$

The average Rayleigh number for all cases is $5.30 \times 10^{7}$.

\section{E.4 Local heat transfer}

The pixel dimensions were determined from a scale factor image taken before the experiment with the reference beam turned off to obtain a high contrast, clear picture. The horizontal scale factor was determined from an instrument with 2 pins at known gap distance, while the vertical scale factor was determined from the locating pins in the heated plate. 
Horizontal scale factor

$\mathrm{SF}_{\mathrm{h}}=\mathrm{D}_{\text {actual }} / \mathrm{N}_{\text {pixels }}=0.2744$ inch $/ 231$ pixels $=3.017 \times 10^{-5} \mathrm{~m} /$ pixel

Vertical scale factor

$S F_{h}=D_{\text {actual }} / N_{\text {pixels }}=0.12 \mathrm{~m} / 4024$ pixels $=2.982 \times 10^{-5} \mathrm{~m} /$ pixel

The vertical scale factor is used for calculating the position of each horizontal scan along the hot wall, while the horizontal scale factor is used to calculate the fringe spacing for the fringe gradient. The fringe gradient is obtained from a custom MATLAB code, described in detail in (Roeleveld, 2013). For this sample calculation, a point was picked roughly half way between the two locating pins. The MATLAB code returned the fringe gradient and scan location as 34.3 pixels/fringe and $y=0.08 \mathrm{~m}(\mathrm{y} / \mathrm{H}=0.246)$, respectively.

First, the fringe gradient is converted to fringes per meter:

$$
\left.\frac{\partial \varepsilon}{\partial x}\right|_{x=0}=\left(34.3 \frac{\text { pixels }}{\text { fringe }} * 3.017 \times 10^{-5} \frac{\mathrm{m}}{\text { pixel }}\right)^{-1}=967 \frac{\text { fringe }}{\mathrm{m}}
$$

Next, the temperature gradient at the wall is calculated using the fringe spacing:

$$
\left.\frac{\partial T}{\partial x}\right|_{x=0}=\left.\frac{-R \lambda_{0} T_{s}^{2}}{W P G} \frac{\partial \varepsilon}{\partial x}\right|_{x=0}=\frac{287 * 632.8 \times 10^{-9} * 311.1^{2}}{0.356 * 101033 * 0.226 \times 10^{-3}} * 967=-2091 \frac{\mathrm{K}}{\mathrm{m}}
$$

Therefore, the local heat flux on the heated wall at $\mathrm{y} / \mathrm{H}=0.08 \mathrm{~m}$ is:

$$
q_{y / H=0.08}=-\left.k_{s} \frac{\partial T}{\partial x}\right|_{x=0}=-0.02695 *-2091=56.4 \frac{W}{m^{2}}
$$

The local Nusselt number is:

$$
N u_{y}=\frac{q_{y} H}{\Delta T k_{f}}=\frac{56.4 * 0.343}{(38.04-22.82) * 0.02640}=48.1
$$




\section{E.5 Average Nusselt number}

The average Nusselt number was determined by integrating the local Nusselt numbers over the height of the channel

$$
N u=\int_{0}^{H} N u_{y} d y
$$

This integral was evaluated using the trapezoidal rule:

$$
N u=\sum_{i=1}^{N-1}\left[\frac{y_{i}-y_{i+1}}{2}\left(N u_{y, i}+N u_{y, i+1}\right)\right]
$$

This gives an average Nusselt number of 39.0. 


\section{Appendix F: Experimental error analysis}

\section{F.1 Introduction}

This appendix aims to determine the uncertainty in measured and calculated quantities, as well as to indicate the major sources of error in this experiment. The uncertainty analysis was conducted based on the Kline and McClintock (1953) method. Measured values and their associated uncertainties are listed in Table F.1.

In this study, the uncertainties of four parameters are of interest: $\mathrm{Ra}, \mathrm{Nu}_{\mathrm{y}}, \mathrm{Nu}_{\mathrm{ave}}$, and $\mathrm{K}$.

Consider an experimental result $R$ calculated from $n$ independent variables $x_{1}, x_{2}, \ldots, x_{n}$. Each variable has a random uncertainty of $\delta x_{1}, \delta x_{2}, \ldots, \delta x_{n}$. If the uncertainty in each variable were given the same odds, then the uncertainty of the result $\delta R$ at these odds is:

$$
\delta R=\sqrt{\left(\frac{\delta R}{\delta x_{1}} \delta x_{1}\right)^{2}+\left(\frac{\delta R}{\delta x_{2}} \delta x_{2}\right)^{2}+\cdots+\left(\frac{\delta R}{\delta x_{n}} \delta x_{n}\right)^{2}}
$$

This analysis can be simplified in cases where $\mathrm{R}$ can be expressed as a product of the variables, each raised to some power. If $\mathrm{R}$ is expressed as:

$$
R=x_{1}^{a} x_{2}^{b} \ldots x_{n}^{z}
$$

Then, the relative uncertainty can be calculated as:

$$
\frac{\delta R}{R}=\sqrt{\left(a \frac{\delta x_{1}}{x_{1}}\right)^{2}+\left(b \frac{\delta x_{2}}{x_{2}}\right)^{2}+\cdots+\left(z \frac{\delta x_{n}}{x_{n}}\right)^{2}}
$$


Table F.1 Measured values and their estimated uncertainties.

\begin{tabular}{|c|c|c|c|c|}
\hline Parameter & Symbol & Measured value $\left(\mathrm{x}_{\mathrm{i}}\right)$ & Absolute uncertainty $\left(\delta \mathrm{x}_{\mathrm{i}}\right)$ & Percent uncertainty \\
\hline Window height & $\mathrm{H}$ & $34.3 \mathrm{~cm}$ & $\pm 0.1 \mathrm{~cm}$ & $\pm 0.3 \%$ \\
\hline Optical length & $\mathrm{W}_{\mathrm{o}}$ & $35.6 \mathrm{~cm}$ & $+0.5 \mathrm{~cm}$ & $+1.4 \%$ \\
\hline Specific heat* & $\mathrm{c}_{\mathrm{p}}$ & $1006 \mathrm{~J} / \mathrm{kgK}$ & & $\pm 0.25 \%$ \\
\hline Dynamic viscosity* & $\mu$ & $1.869 \times 10^{-5} \mathrm{~kg} / \mathrm{ms}$ & & $\pm 2 \%$ \\
\hline Thermal conductivity* & $\mathrm{k}_{\mathrm{f}}$ & $0.02640 \mathrm{~W} / \mathrm{m}^{2} \mathrm{~K}$ & & $\pm 1 \%$ \\
\hline Thermal conductivity & $\mathrm{k}_{\mathrm{s}}$ & $0.02695 \mathrm{~W} / \mathrm{m}^{2} \mathrm{~K}$ & & $\pm 1 \%$ \\
\hline Pressure & $\mathrm{P}$ & $760.2 \mathrm{~mm} \mathrm{Hg}$ & $\pm 0.2 \mathrm{~mm} \mathrm{Hg}$ & $\pm 0.03 \%$ \\
\hline Hot wall temperature & $\mathrm{T}_{\mathrm{h}}$ & $37.97^{\circ} \mathrm{C}$ & $\pm 0.25^{\circ} \mathrm{C}$ & $\pm 1.7 \%$ \\
\hline Ambient Temperature & $\mathrm{T}_{\infty}$ & $22.77^{\circ} \mathrm{C}$ & $\pm 0.2{ }^{\circ} \mathrm{C}$ & $\pm 1.3 \%$ \\
\hline Fringe gradient & $\frac{\partial \varepsilon}{\partial x} l_{x=0}$ & \multicolumn{2}{|}{} & $\pm 10 \%$ \\
\hline
\end{tabular}

The fringe gradient error was estimated by Roeleveld (2013). Because the interferometer was newly built, an analysis of the uncertainty caused by optical imperfections was conducted as part of the commissioning process.

In order to find the random error component, a finite fringe interferogram was taken with the test section undisturbed, such that the reference and test sections had the same temperature field. Then using a custom MATLAB code the variations in fringe gradient across the whole field was measured. The maximum error was found to be $10 \%$ and it occurred around the edge of the interferogram, while the error near the center of the field was found to be smaller.

Clearly, this is the dominant error in the local Nusselt numbers. However, this error is mostly random and therefore does not affect the average Nusselt number results as much, as discussed in F.4.

The second largest uncertainty is in the width of the optical length $\left(W_{0}\right)$. This uncertainty arises from the use of sealing strips adhered to the metal frame of the model, which seal the area of contact between 
the optical windows and the frame of the model. The strips are approximately $2.5 \mathrm{~mm}$ wide, so they add roughly $5 \mathrm{~mm}$ to the distance between the optical windows and hence the optical length.

\section{F.2 Uncertainty in the temperatures}

Estimating the uncertainty in the plate temperature is difficult because of the bias error introduced by the location of the thermocouples. Figure 2.4 shows the location of the plate thermocouples and the electric heaters. Thermocouples 3 and 4 are closest to the heaters, while thermocouples 1 and 2 are the farthest away, and thermocouple 2 is at a location of highest heat flux. Hence thermocouples 3 and 4 are going to be biased towards higher temperatures, and thermocouples 1 and 2 towards lower temperatures. This is clearly reflected in all the temperature measurements, See Table F.2 below. The difference between the highest and lowest readings is on average $0.5^{\circ} \mathrm{C}$, so the uncertainty in the plate temperature is estimated to be $\pm 0.25^{\circ} \mathrm{C}$.

Table F.2 Temperature readings for high permeability case with $b=2 \mathrm{~cm}$ (upper shot) showing temperature variation across thermocouples

\begin{tabular}{|c|c|}
\hline Thermocouple & $\begin{array}{r}\text { Temperatures for high permeability } \\
\text { screen with } \mathrm{b}=2 \mathrm{~cm}\end{array}$ \\
\hline$\# 1$ & $37.9^{\circ} \mathrm{C}$ \\
\hline$\# 2$ & $37.6^{\circ} \mathrm{C}$ \\
\hline$\# 3$ & $38.1^{\circ} \mathrm{C}$ \\
\hline$\# 4$ & $38.1^{\circ} \mathrm{C}$ \\
\hline
\end{tabular}

The ambient temperature is calculated from two thermocouples located close to the model. One thermocouple is located near the bottom of the model and the other near the top of the model, directly above the other thermocouple. The second thermocouple reads consistently higher than the first, with 
an average difference of approximately $0.4^{\circ} \mathrm{C}$. Therefore the uncertainty in the ambient temperature will be approximated as $\pm 0.2^{\circ} \mathrm{C}$

Lastly, the uncertainty in the temperature difference between the plate and the ambient, used to calculate the Nusselt and Rayleigh numbers, is calculated using Equation F.1 and found to be $0.3^{\circ} \mathrm{C}$.

\section{F.3 Uncertainty in the Rayleigh number}

The Rayleigh number is calculated as follows:

$$
R a=\frac{g \beta \Delta T \rho^{2} H^{3}}{\mu^{2}} P r
$$

Using:

$$
\begin{gathered}
\operatorname{Pr}=\frac{c_{p} \mu}{k_{f}} \\
\beta=\frac{1}{T_{f}} \\
\rho=\frac{P}{R T_{f}}
\end{gathered}
$$

The Rayleigh number in terms of measured variables is:

$$
R a=\frac{g \Delta T P^{2} H^{3} c_{p}}{\mu k_{f} R^{2} T_{f}^{2}}
$$

Neglecting the uncertainties in the gravity $g$ and gas constant R, and using Equation F.1:

$$
\frac{\delta R a}{R a}=\sqrt{\left(\frac{\delta \Delta T}{\Delta T}\right)^{2}+\left(2 \frac{\delta P}{P}\right)^{2}+\left(3 \frac{\delta H}{H}\right)^{2}+\left(\frac{\delta c_{p}}{c_{p}}\right)^{2}+\left(\frac{\delta \mu}{\mu}\right)^{2}+\left(\frac{\delta k_{f}}{k_{f}}\right)^{2}+\left(2 \frac{\delta T_{f}}{T_{f}}\right)^{2}}
$$

Using the values from Table F.1, the uncertainty in the measured components is: 
Table F.3 Relative uncertainty of measured values used to calculate uncertainty in Rayleigh number

\begin{tabular}{|c|c|}
\hline Component & Relative uncertainty (\%) \\
\hline$\Delta T$ & 2.1 \\
\hline $\mathrm{P}$ & 0.03 \\
\hline $\mathrm{H}$ & 0.3 \\
\hline $\mathrm{C}_{\mathrm{p}}$ & 0.25 \\
\hline$\mu$ & 2.0 \\
\hline $\mathrm{k}_{\mathrm{f}}$ & 1.0 \\
\hline $\mathrm{T}_{\mathrm{f}}$ & 1.0 \\
\hline
\end{tabular}

Using the values from Table F. 3 and Equation (F.5), the uncertainty+ in the Rayleigh number is $\pm 4 \%$

\section{F.4 Uncertainty in local and average Nusselt number}

The local Nusselt number is defined as:

$$
N u_{y}=\frac{q_{y} H}{\Delta T k_{f}}
$$

Where $\Delta T$ is defined as $T_{s}-T_{\infty}$. The local heat flux $q_{y}$ is defined as:

$$
q_{y}=\left.k_{s} \frac{\partial T}{\partial x}\right|_{x=0}
$$

And the temperature gradient is given by:

$$
\left.\frac{\partial T}{\partial x}\right|_{x=0}=\left.\frac{R \lambda_{0} T_{s}^{2}}{W_{o} P G} \frac{\partial \varepsilon}{\partial x}\right|_{x=0}
$$

Where $T_{s}$ is the plate temperature. Substituting these equations into (F.6) gives:

$$
N u_{y}=\left.\frac{H k_{s} R \lambda_{0} T_{s}^{2}}{\Delta T k_{f} W_{o} P G} \frac{\partial \varepsilon}{\partial x}\right|_{x=0}
$$

Using Equation (F.1), the uncertainty in the Nusselt number is: 


$$
\frac{\delta N u_{y}}{N u_{y}}=\sqrt{\left(\frac{\delta H}{H}\right)^{2}+\left(\frac{\delta k_{s}}{k_{s}}\right)^{2}+\left(2 \frac{\delta T_{s}}{T_{S}}\right)^{2}+\left(\frac{\delta \Delta T}{\Delta T}\right)^{2}+\left(\frac{\delta k_{f}}{k_{f}}\right)^{2}+\left(\frac{\delta W_{o}}{W_{o}}\right)^{2}+\left(\frac{\delta P}{P}\right)^{2}+\left[\frac{\delta\left(\left.\frac{\partial \varepsilon}{\partial x}\right|_{x=0}\right)}{\left(\left.\frac{\partial \varepsilon}{\partial x}\right|_{x=0}\right)}\right]^{2}}
$$

Lastly, using the values from Table F.1, the relative uncertainty in the measured variables are given in

Table F.4

Table F.4 Relative error of measured values used to calculate uncertainty in Nusselt number

\begin{tabular}{|c|c|}
\hline Component & Relative uncertainty (\%) \\
\hline $\mathrm{H}$ & 0.3 \\
\hline $\mathrm{k}_{\mathrm{s}}$ & 1.0 \\
\hline $\mathrm{T}_{\mathrm{s}}$ & 0.1 \\
\hline$\Delta \mathrm{T}$ & 2.1 \\
\hline $\mathrm{k}_{\mathrm{f}}$ & 1.0 \\
\hline $\mathrm{W}_{\mathrm{o}}$ & 1.4 \\
\hline $\mathrm{P}$ & 0.3 \\
\hline$\left.\frac{\partial \varepsilon}{\partial x}\right|_{x=0}$ & 10 \\
\hline
\end{tabular}

Using the values from Table F.4 and (F.7), the calculated uncertainty in the local Nusselt number is:

$$
\frac{\delta N u_{y}}{N u_{y}}=10 \%
$$

Roeleveld (2012) conducted a Monte Carlo simulation to determine the error in the average Nusselt number. Because each local Nusselt number has a random component of error, the average will tend to cancel out the positive and negative random errors. A Monte Carlo simulation approximates the total error of the average result accounting for the cancelation of the random component in the error of each measurement. In this simulation, it was found that the average Nusselt number has an error of $\pm 6 \%$. 


\section{F.5 Uncertainty in screen permeability}

The permeability of the screens was calculated using the slope of the Pressure vs. Velocity graph, which was obtained using a least squares best fit line. So, Equation E.1 and E.3 cannot be used to determine the uncertainty in the permeability. In order to get an approximate value of the uncertainty, an alternative method will be used using one measurement from the pressure vs. velocity sample, as follows:

$$
K=\frac{\mu \Delta x V}{\Delta P}
$$

Using measured variables:

$$
K=\frac{\mu \Delta x \Downarrow}{\Delta P \frac{\pi}{4} d^{2}}
$$

Where $\mathrm{K}$ is the permeability, $\forall$ is the volumetric flow rate, $\Delta P$ is the differential pressure across the screen, $\mathrm{d}$ is the diameter of the tube and $\Delta x$ is the thickness of the screen. Applying Equation E.3, and neglecting the error in the thickness of the screen, the relative error is given by:

$$
\frac{\delta K}{K}=\sqrt{\left(\frac{\delta \mu}{\mu}\right)^{2}+\left(\frac{\delta \forall}{V}\right)^{2}+\left(\frac{\delta P}{P}\right)^{2}+\left(2 \frac{\delta d}{d}\right)^{2}}
$$

In order to obtain a conservative estimate, measurements from the middle of the velocity range were used. The relative error of each component is shown in Table F.5: 
Table F.5 Relative error of measured values used to calculate uncertainty in permeability

\begin{tabular}{|c|c|}
\hline Component & Relative uncertainty (\%) \\
\hline$\mu$ & 2.0 \\
\hline$\forall$ & 5.5 \\
\hline P & 2.3 \\
\hline$d$ & 1.3 \\
\hline
\end{tabular}

Using (F.10) and Table F.5, the calculated uncertainty in K for both the low and high permeability screen is $\pm 7 \%$. However, the best fit method averages the random component of the uncertainty and therefore the uncertainty found above is likely to overestimate the error. 


\section{Appendix G: Experimental data}

\section{G.1 Thermocouple calibration}

Calibration of the plate and ambient thermocouples was performed using a constant temperature water bath and a glass thermometer with $0.1{ }^{\circ} \mathrm{C}$ divisions and accuracy of $0.01{ }^{\circ} \mathrm{C}$, with calibration traceable to National Standards for measuring the bath temperature.

Table G.1 Plate and ambient thermocouple calibration

\begin{tabular}{|c|c|c|c|c|c|c|}
\hline \multirow{2}{*}{$\begin{array}{c}\text { Bath } \\
\text { Temperature } \\
\left({ }^{\circ} \mathrm{C}\right)\end{array}$} & \multicolumn{4}{|c|}{ Hot plate thermocouples $\left({ }^{\circ} \mathrm{C}\right)$} & \multicolumn{2}{c|}{$\begin{array}{c}\text { Ambient thermocouples } \\
\left({ }^{\circ} \mathrm{C}\right)\end{array}$} \\
\cline { 2 - 7 } & 1 & 2 & 3 & 4 & 1 & 2 \\
\hline 40.1 & 40.1 & 40.2 & 40.1 & 40.1 & 40.1 & 40.2 \\
\hline 35.0 & 35.1 & 35.0 & 35.1 & 35.1 & 35.1 & 35.0 \\
\hline 30.0 & 30.0 & 30.0 & 30.0 & 30.0 & 30.0 & 30.0 \\
\hline 25.1 & 25.0 & 25.0 & 25.0 & 25.0 & 25.0 & 25.0 \\
\hline 20.0 & 20.0 & 20.0 & 20.0 & 20.0 & 20.0 & 20.0 \\
\hline Correction & 0 & 0 & 0 & 0 & 0 & 0 \\
\hline
\end{tabular}

\section{G.2 Temperature and pressure readings}

Table G.2 Average plate temperature, ambient temperature and uncorrected pressure for each case

\begin{tabular}{|c|c|c|c|c|}
\hline Case & $\begin{array}{c}\text { Pressure } \\
\text { (uncorrected) }\end{array}$ & Section & $\begin{array}{c}\text { Average plate } \\
\text { temperature }\left({ }^{\circ} \mathrm{C}\right)\end{array}$ & $\begin{array}{c}\text { Ambient } \\
\text { temperature }\left({ }^{\circ} \mathrm{C}\right)\end{array}$ \\
\hline $\begin{array}{c}\text { High permeability } \\
\mathrm{b}=2 \mathrm{~cm}\end{array}$ & $760.2 \mathrm{~mm} \mathrm{Hg}$ & Top & 37.91 & 22.72 \\
\cline { 3 - 5 } & Bottom & 38.04 & 22.82 \\
\hline $\begin{array}{c}\text { High permeability } \\
\mathrm{b}=1 \mathrm{~cm}\end{array}$ & $761.5 \mathrm{~mm} \mathrm{Hg}$ & Top & 37.05 & 22.70 \\
\cline { 3 - 5 } & \multirow{2}{*}{$\begin{array}{c}\text { No screen } \\
\mathrm{b}=2 \mathrm{~cm}\end{array}$} & Bottom & 37.05 & 22.70 \\
\hline \multirow{2}{*}{$\begin{array}{c}\text { Low permeability } \\
\mathrm{b}=2 \mathrm{~cm}\end{array}$} & $762.2 \mathrm{~mm} \mathrm{Hg}$ & Top & 36.73 & 22.28 \\
\cline { 3 - 5 } & $762.7 \mathrm{~mm} \mathrm{Hg}$ & Bottom & 36.73 & 22.52 \\
\cline { 3 - 5 } & & Bottom & 38.16 & 23.30 \\
\hline
\end{tabular}




\section{G.3 Local Nusselt numbers}

Table G.3 Local Nusselt numbers for high permeability screen with $b=2 \mathrm{~cm}$

\begin{tabular}{|c|c|c|c|c|c|c|c|}
\hline $\mathrm{y} / \mathrm{H}$ & $\mathrm{Nu}_{\mathrm{y}}$ & $\mathrm{y} / \mathrm{H}$ & $\mathrm{Nu}_{\mathrm{y}}$ & $\mathrm{y} / \mathrm{H}$ & $\mathrm{Nu}_{\mathrm{y}}$ & $\mathrm{y} / \mathrm{H}$ & $\mathrm{Nu}_{\mathrm{y}}$ \\
\hline 1.000 & 4.34 & 0.726 & 34.02 & 0.452 & 36.67 & 0.164 & 50.10 \\
\hline 0.957 & 7.63 & 0.709 & 34.34 & 0.433 & 43.67 & 0.148 & 53.62 \\
\hline 0.942 & 8.79 & 0.692 & 37.06 & 0.414 & 40.25 & 0.132 & 50.96 \\
\hline 0.926 & 15.97 & 0.675 & 34.45 & 0.395 & 40.23 & 0.116 & 54.51 \\
\hline 0.911 & 17.11 & 0.658 & 35.90 & 0.377 & 44.73 & 0.100 & 57.51 \\
\hline 0.896 & 22.92 & 0.641 & 39.51 & 0.358 & 40.72 & 0.084 & 58.52 \\
\hline 0.881 & 25.34 & 0.624 & 35.34 & 0.339 & 43.04 & 0.068 & 56.42 \\
\hline 0.865 & 28.76 & 0.607 & 36.46 & 0.321 & 42.39 & 0.052 & 64.37 \\
\hline 0.850 & 29.41 & 0.590 & 40.70 & 0.302 & 45.38 & 0.041 & 64.63 \\
\hline 0.835 & 28.86 & 0.574 & 37.24 & 0.283 & 44.86 & 0.031 & 68.68 \\
\hline 0.819 & 34.66 & 0.557 & 35.31 & 0.265 & 42.61 & 0.021 & 74.04 \\
\hline 0.804 & 30.49 & 0.540 & 37.50 & 0.246 & 48.11 & 0.010 & 72.62 \\
\hline 0.789 & 32.80 & 0.523 & 38.82 & 0.227 & 44.24 & 0.001 & 56.83 \\
\hline 0.774 & 34.00 & 0.506 & 36.09 & 0.211 & 47.24 & & \\
\hline 0.758 & 32.17 & 0.489 & 39.73 & 0.195 & 47.95 & & \\
\hline 0.743 & 36.59 & 0.470 & 38.98 & 0.179 & 50.22 & & \\
\hline
\end{tabular}

Table G.4 Local Nusselt numbers for high permeability screen with $b=1 \mathrm{~cm}$

\begin{tabular}{|c|c|c|c|c|c|c|c|}
\hline $\mathrm{y} / \mathrm{H}$ & $\mathrm{Nu}_{\mathrm{y}}$ & $\mathrm{y} / \mathrm{H}$ & $\mathrm{Nu}_{\mathrm{y}}$ & $\mathrm{y} / \mathrm{H}$ & $\mathrm{Nu}_{\mathrm{y}}$ & $\mathrm{y} / \mathrm{H}$ & $\mathrm{Nu}_{\mathrm{y}}$ \\
\hline 0.989 & 7.31 & 0.664 & 34.09 & 0.431 & 37.50 & 0.213 & 45.67 \\
\hline 0.977 & 10.87 & 0.655 & 35.62 & 0.424 & 39.30 & 0.204 & 43.87 \\
\hline 0.966 & 14.98 & 0.645 & 34.85 & 0.418 & 41.65 & 0.195 & 46.75 \\
\hline 0.957 & 16.75 & 0.635 & 29.62 & 0.412 & 41.18 & 0.186 & 46.29 \\
\hline 0.947 & 18.55 & 0.619 & 30.25 & 0.404 & 41.42 & 0.177 & 50.13 \\
\hline 0.938 & 21.51 & 0.612 & 34.53 & 0.397 & 42.17 & 0.169 & 52.36 \\
\hline 0.929 & 23.00 & 0.605 & 35.31 & 0.389 & 43.83 & 0.161 & 50.53 \\
\hline 0.919 & 23.03 & 0.598 & 35.14 & 0.382 & 40.03 & 0.153 & 50.89 \\
\hline 0.909 & 30.95 & 0.591 & 38.04 & 0.374 & 42.72 & 0.139 & 53.87 \\
\hline 0.899 & 27.96 & 0.584 & 30.25 & 0.367 & 44.66 & 0.129 & 50.97 \\
\hline 0.889 & 28.13 & 0.577 & 31.81 & 0.359 & 43.64 & 0.120 & 47.98 \\
\hline 0.879 & 26.92 & 0.570 & 35.35 & 0.352 & 44.78 & 0.111 & 51.60 \\
\hline 0.870 & 28.44 & 0.563 & 36.80 & 0.344 & 44.78 & 0.102 & 51.76 \\
\hline 0.858 & 29.27 & 0.556 & 34.46 & 0.337 & 42.63 & 0.092 & 58.42 \\
\hline 0.829 & 26.81 & 0.549 & 39.88 & 0.329 & 44.82 & 0.083 & 54.46 \\
\hline 0.819 & 32.06 & 0.542 & 32.08 & 0.322 & 43.71 & 0.074 & 51.05 \\
\hline
\end{tabular}




\begin{tabular}{|l|l|l|l|l|l|l|l|}
\hline 0.809 & 32.44 & 0.536 & 33.77 & 0.314 & 42.47 & 0.065 & 53.32 \\
\hline 0.799 & 30.54 & 0.529 & 36.77 & 0.307 & 43.75 & 0.056 & 54.49 \\
\hline 0.789 & 30.13 & 0.522 & 36.08 & 0.299 & 43.66 & 0.047 & 63.73 \\
\hline 0.777 & 32.48 & 0.515 & 36.33 & 0.292 & 43.79 & 0.042 & 61.10 \\
\hline 0.764 & 30.45 & 0.508 & 38.69 & 0.285 & 43.76 & 0.037 & 60.70 \\
\hline 0.752 & 33.23 & 0.481 & 39.95 & 0.277 & 44.95 & 0.032 & 59.07 \\
\hline 0.740 & 30.85 & 0.475 & 38.49 & 0.270 & 43.68 & 0.027 & 58.80 \\
\hline 0.731 & 37.35 & 0.469 & 37.19 & 0.262 & 45.17 & 0.023 & 67.26 \\
\hline 0.721 & 34.23 & 0.463 & 38.64 & 0.254 & 44.90 & 0.018 & 61.85 \\
\hline 0.712 & 34.28 & 0.456 & 39.91 & 0.247 & 44.72 & 0.014 & 65.30 \\
\hline 0.703 & 34.54 & 0.450 & 43.15 & 0.239 & 45.71 & 0.009 & 65.52 \\
\hline 0.693 & 32.96 & 0.444 & 41.41 & 0.231 & 46.34 & 0.004 & 62.43 \\
\hline 0.684 & 28.51 & 0.437 & 37.89 & 0.222 & 50.74 & 0.001 & 66.14 \\
\hline
\end{tabular}

Table G.5 Local Nusselt numbers for no screen case

\begin{tabular}{|c|c|c|c|c|c|c|c|}
\hline $\mathrm{y} / \mathrm{H}$ & $\mathrm{Nu}_{\mathrm{y}}$ & $\mathrm{y} / \mathrm{H}$ & $\mathrm{Nu}_{\mathrm{y}}$ & $\mathrm{y} / \mathrm{H}$ & $\mathrm{Nu}_{\mathrm{y}}$ & $\mathrm{y} / \mathrm{H}$ & $\mathrm{Nu}_{\mathrm{y}}$ \\
\hline 0.993 & 11.84 & 0.710 & 37.91 & 0.463 & 42.11 & 0.197 & 54.68 \\
\hline 0.980 & 8.37 & 0.703 & 37.21 & 0.455 & 41.74 & 0.188 & 54.00 \\
\hline 0.967 & 12.41 & 0.695 & 34.15 & 0.447 & 43.38 & 0.179 & 55.25 \\
\hline 0.952 & 17.29 & 0.672 & 39.29 & 0.438 & 43.60 & 0.171 & 60.06 \\
\hline 0.937 & 22.60 & 0.665 & 36.97 & 0.414 & 40.62 & 0.162 & 52.06 \\
\hline 0.924 & 25.30 & 0.657 & 38.82 & 0.405 & 46.80 & 0.154 & 55.81 \\
\hline 0.911 & 30.22 & 0.650 & 38.07 & 0.397 & 43.78 & 0.145 & 56.76 \\
\hline 0.898 & 32.66 & 0.642 & 36.77 & 0.389 & 43.64 & 0.136 & 54.40 \\
\hline 0.885 & 33.17 & 0.635 & 40.13 & 0.381 & 44.96 & 0.128 & 59.80 \\
\hline 0.875 & 33.56 & 0.627 & 36.12 & 0.356 & 43.21 & 0.119 & 58.45 \\
\hline 0.865 & 31.33 & 0.620 & 40.59 & 0.347 & 45.59 & 0.111 & 63.59 \\
\hline 0.855 & 33.83 & 0.604 & 39.02 & 0.339 & 46.66 & 0.102 & 65.04 \\
\hline 0.846 & 36.43 & 0.597 & 37.92 & 0.331 & 44.74 & 0.094 & 61.61 \\
\hline 0.830 & 36.98 & 0.589 & 38.90 & 0.314 & 46.82 & 0.085 & 65.15 \\
\hline 0.817 & 37.98 & 0.582 & 39.88 & 0.306 & 46.76 & 0.076 & 64.36 \\
\hline 0.804 & 38.83 & 0.574 & 37.35 & 0.298 & 49.63 & 0.059 & 64.42 \\
\hline 0.791 & 38.44 & 0.567 & 40.20 & 0.281 & 49.91 & 0.051 & 62.38 \\
\hline 0.778 & 39.55 & 0.559 & 37.16 & 0.273 & 49.56 & 0.042 & 59.73 \\
\hline 0.769 & 35.05 & 0.552 & 40.55 & 0.265 & 46.82 & 0.033 & 65.84 \\
\hline 0.761 & 35.05 & 0.536 & 41.27 & 0.248 & 49.75 & 0.025 & 61.70 \\
\hline 0.753 & 38.29 & 0.521 & 42.25 & 0.240 & 50.60 & 0.016 & 63.21 \\
\hline 0.740 & 38.94 & 0.488 & 40.38 & 0.231 & 50.55 & 0.008 & 67.69 \\
\hline 0.725 & 37.32 & 0.480 & 42.62 & 0.222 & 49.41 & 0.001 & 50.97 \\
\hline 0.717 & 36.48 & 0.472 & 40.66 & 0.205 & 50.95 & & \\
\hline
\end{tabular}


Table G.6 Local Nusselt numbers for low permeability screen with $b=2 \mathrm{~cm}$

\begin{tabular}{|c|c|c|c|c|c|c|c|}
\hline $\mathrm{y} / \mathrm{H}$ & $\mathrm{Nu}_{\mathrm{y}}$ & $\mathrm{y} / \mathrm{H}$ & $\mathrm{Nu}_{\mathrm{y}}$ & $\mathrm{y} / \mathrm{H}$ & $\mathrm{Nu}_{\mathrm{y}}$ & $\mathrm{y} / \mathrm{H}$ & $\mathrm{Nu}_{\mathrm{y}}$ \\
\hline 0.968 & 3.43 & 0.788 & 22.30 & 0.520 & 33.00 & 0.178 & 44.10 \\
\hline 0.958 & 4.02 & 0.780 & 24.49 & 0.510 & 33.80 & 0.168 & 47.23 \\
\hline 0.948 & 6.11 & 0.745 & 26.22 & 0.492 & 34.22 & 0.158 & 46.82 \\
\hline 0.938 & 6.76 & 0.730 & 24.22 & 0.473 & 34.79 & 0.146 & 43.99 \\
\hline 0.928 & 7.12 & 0.714 & 26.15 & 0.454 & 31.51 & 0.136 & 45.90 \\
\hline 0.918 & 7.66 & 0.699 & 25.84 & 0.434 & 35.33 & 0.127 & 47.90 \\
\hline 0.908 & 8.43 & 0.683 & 27.97 & 0.415 & 37.85 & 0.117 & 48.46 \\
\hline 0.899 & 8.92 & 0.667 & 28.24 & 0.396 & 34.33 & 0.108 & 51.61 \\
\hline 0.892 & 10.25 & 0.652 & 26.48 & 0.376 & 36.81 & 0.098 & 53.47 \\
\hline 0.886 & 10.53 & 0.636 & 29.00 & 0.357 & 40.85 & 0.089 & 51.71 \\
\hline 0.880 & 11.08 & 0.627 & 30.15 & 0.339 & 38.44 & 0.079 & 56.27 \\
\hline 0.874 & 11.27 & 0.617 & 29.05 & 0.320 & 38.33 & 0.069 & 56.78 \\
\hline 0.867 & 13.44 & 0.607 & 27.08 & 0.302 & 36.33 & 0.058 & 58.81 \\
\hline 0.861 & 13.11 & 0.597 & 27.36 & 0.283 & 37.48 & 0.048 & 57.56 \\
\hline 0.855 & 14.05 & 0.588 & 28.80 & 0.265 & 40.81 & 0.038 & 62.44 \\
\hline 0.838 & 16.21 & 0.578 & 34.54 & 0.247 & 42.08 & 0.027 & 67.92 \\
\hline 0.830 & 16.81 & 0.568 & 31.82 & 0.228 & 44.47 & 0.017 & 73.15 \\
\hline 0.822 & 17.68 & 0.558 & 31.54 & 0.218 & 43.37 & 0.006 & 56.32 \\
\hline 0.813 & 18.91 & 0.549 & 30.77 & 0.208 & 42.85 & & \\
\hline 0.805 & 19.60 & 0.539 & 30.52 & 0.198 & 41.50 & & \\
\hline 0.797 & 20.88 & 0.529 & 32.90 & 0.188 & 42.18 & & \\
\hline
\end{tabular}




\section{References}

ASHRAE. (2013). ASHRAE Handbook-Fundamentals (S.I.). Atlanta, GA.

Brunger, A., Dubrous, F. M., \& Harrison, S. (1999). Measurement of the solar heat gain coefficient and U value of windows with insect screens. ASHRAE Transactions, 105(2), 1038-1044.

Christie, E. A., \& Hunter, A. J. (1984). Total infrared radiation property measurements of diathermanous films with a reflectometer. Solar Energy, 33(6), 613-618.

Coleman, H. W., \& Steele, W. G. (2009). Data analysis, regression, and reporting of results. Experimentation, validation, and uncertainty analysis for engineers (3rd ed., pp. 217248). Hoboken, N.J.: John Wiley \& Sons.

Dassault Systèmes SolidWorks Corp. (2013). SolidWorks 2013 SP4.0 [computer software]. VélizyVillacoublay, France.

Dassault Systèmes SolidWorks Corp. (2010). SolidWorks Flow Simulation Technical Reference. VélizyVillacoublay, France.

ESRU, University of Strathclyde. (2013). ESP-r (version 11.11) [computer software]. Glasgow, Scotland.

Fatnassi, H., Boulard, T., Poncet, C., \& Chave, M. (2006). Optimisation of greenhouse insect screening with computational fluid dynamics. Biosystems Engineering, 93(3), 301-312.

Finlayson, E. U., Arasteh, D. K., Huizenga, C., Rubin, M. D., \& Reilly, M. S. (2013). WINDOW (version 6.3.74) [computer software]. Berkeley, CA: Lawrence Berkeley National Laboratory, Energy and Environmental Division. 
Goldstein, R. J. (1970). Optical measurement of temperature. Measurement Techniques in Heat Transfer, eds. E.R.G. Eckert and R.J. Goldstein (pp. 177-228). Slough, England: Technivision Services.

Hauf, W., \& Grigull, U. (1970). Optical methods in heat transfer. Advances in Heat Transfer, 6(C), 133366.

ISO 15099:2003 - Thermal performance of windows, doors and shading devices - Detailed calculations. (2003). Geneva: International Standards Organization.

Kline, S. J., \& McClintock, F. A. (1953). Describing uncertainties in single-sample experiments. Mechanical Engineering, 75, 3-8.

Kotey, N. A., Wright, J. L., \& Collins, M. R. (2009). Determining off-normal solar optical properties of insect screens. ASHRAE Transactions, 115(1), 155-164.

Kotey, N. A., Wright, J. L., Barnaby, C. S., \& Collins, M. R. (2009). Solar gain through windows with shading devices: Simulation versus measurement. ASHRAE Transactions, 115(2), 18-30.

Laouadi, A., \& Parekh, A. (2007). Optical models of complex fenestration systems. Lighting Research and Technology, 39(2), 123-145.

Machin, A. D., Naylor, D., Harrison, S. J., \& Oosthuizen, P. H. (1998). Experimental study of free convection at an indoor glazing surface with a venetian blind. HVAC\&R Research, 4(2), 153-166.

Miguel, A. F. (1998). Airflow through porous screens: From theory to practical considerations. Energy and Buildings, 28(1), 63-69.

Naylor, D., \& Duarte, N. (1999). Direct temperature gradient measurement using interferometry. Experimental Heat Transfer, 12(4), 279-294. 
Naylor, D., Foroushani, S. S. M., \& Zalcman, D. (2012, November). Numerical study of free convection in a tall enclosure with a porous wall. Paper presented at the 2012 International Forum on Heat Transfer, Nagasaki, Japan.

Norris, N., \& Collins, M. (2008, August). Modelling the effects of insect screens on natural convection in window cavities. Paper presented at the $3^{\text {rd }}$ Canadian Solar Buildings / $33^{\text {rd }}$ Annual SESCI Conference, Fredereicton, NB.

Ostrach, S. (1953). An analysis of laminar free-convection flow and heat transfer about a flat plate parallel to the direction of the generating body force. National Advisory Comittee for Aeronautics, Technical Report 1111, 63-79.

Phase One. (2008). Capture One Pro (Version 4.5.1) [computer software]. Denmark.

Poulad, M. E., Naylor, D., \& Oosthuizen, P. H. (2011). Measurement of time-averaged turbulent free convection in a tall enclosure using interferometry. Journal of Heat Transfer, 133(4), 042501 1-8.

Roeleveld, D. (2013). Experimental and numerical study of free convection in a vertical channel with opposing buoyancy forces. (Doctoral dissertation). Ryerson University, Toronto.

Slepicka, J. S., \& Cha, S. S. (1995). Stabilized nonlinear regression for interferogram analysis. Applied Optics, 34(23), 5039-5034.

Teitel, M. (2010). Using computational fluid dynamics simulations to determine pressure drops on woven screens. Biosystems Engineering, 105(2), 172-179.

Teitel, M. (2011). On the applicability of the Forchheimer equation in simulating flow through woven screens. Biosystems Engineering, 109(2), 130-139. 
Touloukian, Y. S., Liley, P. E., and Saxena, S. C. (1970). Thermal conductivity: Nonmetallic liquids and gases. Thermophysical Properties of Matter, Vol. 3, Plenum Publishing Corporation, New York.

Touloukian, Y. S., and Makita, T. (1970). Specific heat: Nonmetallic liquids and gases. Thermophysical Properties of Matter, Vol. 6, Plenum Publishing Corporation, New York.

Touloukian, Y. S., Saxena, S. C., and Hestermans, P. (1975). Viscosity. Thermophysical Properties of Matter, Vol. 11, Plenum Publishing Corporation, New York.

Valera, D. L., Molina, F. D., Álvarez, A. J., López, J. A., Terrés-Nicoli, J. M., \& Madueño, A. (2005). Contribution to the characterization of insect-proof screens: experimental measurements in wind tunnel and CFD simulations. Acta Horticulture, 691, 441-448.

Valera, D. L., Álvarez, A. J., \& Molina, F. D. (2006). Aerodynamic analysis of several insect-proof screens used in greenhouses. Spanish Journal of Agricultural Research, 4(4), 273-279.

Wright, J. L., Sullivan, H. F. (1992) VISION3 Glazing system thermal analysis: Reference manual [computer software and manual]. Waterloo, ON: Advanced Glazing Laboratory, Department of Mechanical Engineering, University of Waterloo.

Wright, J. L. (2008). Calculating Center-glass performance indices of glazing systems with shading devices. ASHRAE Transactions, 114(2), 199-209. 